MARCOS FERNANDO GARBER

\title{
ESTRUTURAS FLUTUANTES PARA A EXPLORAÇÃO \\ DE CAMPOS DE PETRÓLEO NO MAR (FPSO): APOIO À DECISÃO NA ESCOLHA DO SISTEMA
}

Dissertação apresentada ao Departamento de Engenharia Naval da Escola Politécnica da Universidade de São Paulo para obtenção do título de Mestre em Engenharia.

São Paulo

2002 
MARCOS FERNANDO GARBER

\section{ESTRUTURAS FLUTUANTES PARA A EXPLORAÇÃO \\ DE CAMPOS DE PETRÓLEO NO MAR (FPSO): APOIO À DECISÃO NA ESCOLHA DO SISTEMA}

Dissertação apresentada à Escola

Politécnica da Universidade de

São Paulo para obtenção do

título de Mestre em Engenharia.

Área de Concentração:

Engenharia Naval e Oceânica

Orientador:

Dr. Oscar Brito Augusto

São Paulo

2002 
FICHA CATALOGRÁFICA

Garber, Marcos Fernando

Estruturas flutuantes para a exploração de campos de petróleo no mar (FPSO): apoio à decisão na escolha do sistema I Marcos Fernando Garber. -- São Paulo, 2002.

$91 \mathrm{p}$.

Dissertação (Mestrado) - Escola Politécnica da Universidade de São Paulo. Departamento de Engenharia Naval e Oceânica.

1.FPSO \{Requisitos\} 2.Métodos de apoio à decisão I.Universidade de São Paulo. Escola Politécnica. Departamento de Engenharia Naval e Oceânica II.t. 


\section{SUMÁRIO}

\section{DEDICATÓRIA}

AGRADECIMENTOS

LISTA DE ABREVIATURAS E SÍMBOLOS

LISTA DE FIGURAS

LISTA DE TABELAS

RESUMO

ABSTRACT

RESUMEN

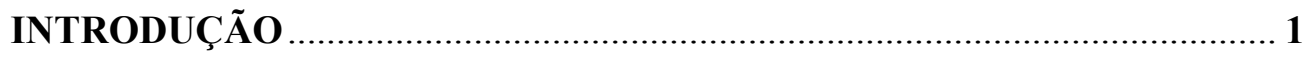

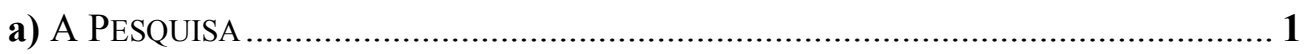

b) O PRoblema da Escolha de UMa InSTALAÇÃo FPSO ..................................... 2

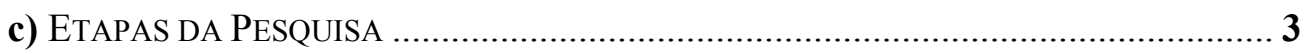

1. PRINCÍPIOS DA ANÁLISE DA DECISÃO.............................................. 4

1.1 MÉTOdOS DE APOIO À DECISÃO ……………………………………………. 4

1.1.1 BREVE NotíCIA HISTÓRICA ……………………................................. 4

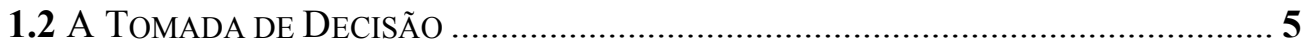

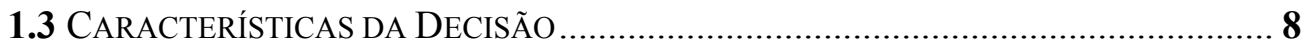

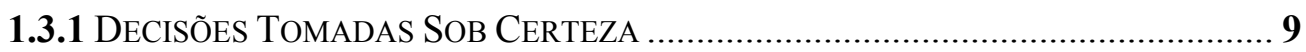

1.3.2 MÉtodo da ANÁlise HiERÁRquiCa - AHP ……………………………..... 10

1.3.3 Outros Métodos MulticritérIo ........................................................... 18

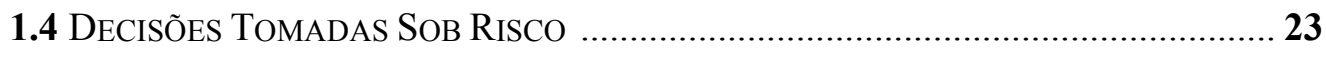

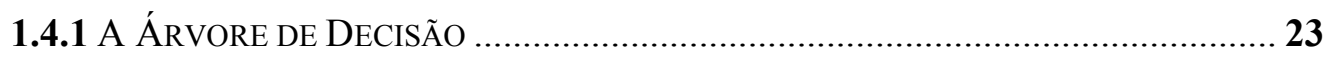

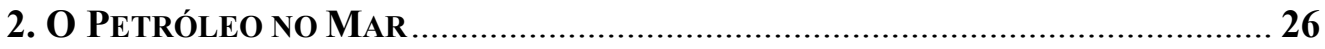

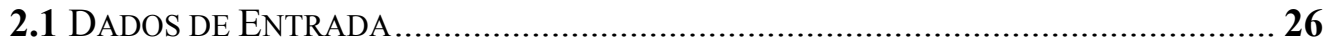

2.2 O Método Clássico da Espiral de Projeto..................................................... 29

2.2.1 Requisitos Básicos PARA O PROJETO de EMBARCAÇÕES ................................. 32

2.2.2 DiMENSÕES PRINCIPAIS ...........................................................................33

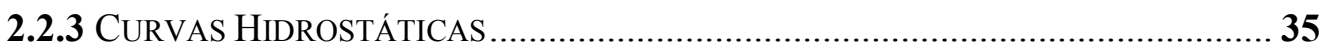

2.2.4 ESTIMATIVA DE PotÊNCIA ........................................................................... 36

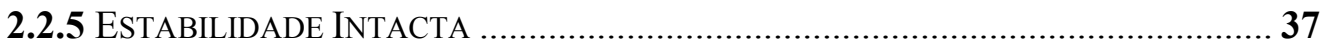




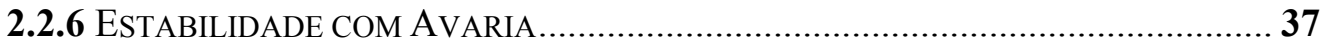

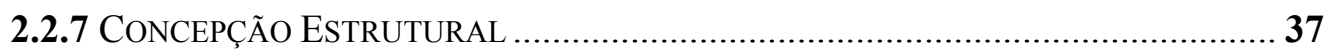

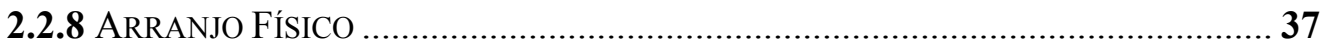

2.2.9. SISTEMAS DE EMERGÊNCIA ....................................................................... 38

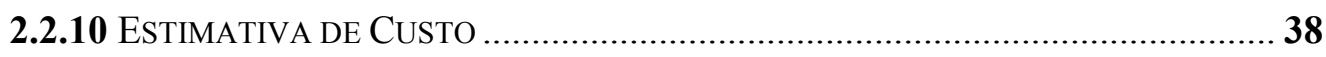

2.3. REQUISITOS BÁSICOS DE UMA INSTALAÇÃO FPSO ............................................. 38

2.3.1 Requisitos COMUNS Às ESTRUTURAS FlutUANTES DE EXPLORAÇÃO

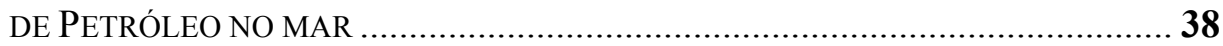

2.3.2 REQUISITOS ESPECÍFICOS PARA INSTALAÇÕES FPSO ......................................40

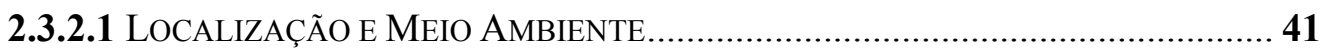

2.3.2.2 FUNÇÃO E VIDA ÚTIL DO CAMPO........................................................... 42

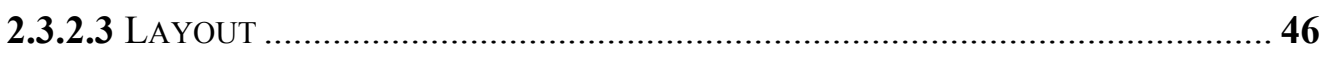

2.3.2.4 DistribuiÇÃO De PeSOS E DiMensões.....................................................51

2.3.2.5 SELEÇÃO DA EMBARCAÇÃO ..................................................................... 52

2.3.2.6 MOVIMENTAÇÃO NA INSTALAÇÃO FPSO...................................................... 54

2.3.2.7 DimENSÃO dA TRIPUlaÇÃO E InSTALAÇÕES do PESSOAL ..............................55

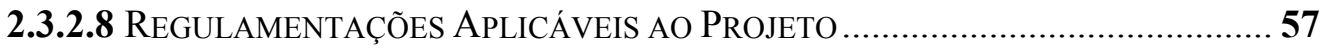

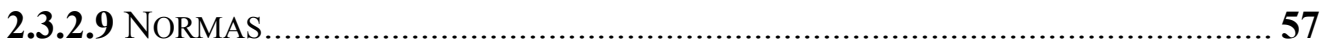

2.3.2.10 SeguranÇa e Saúde com RelaÇão ao Meio Ambiente .......................... 58

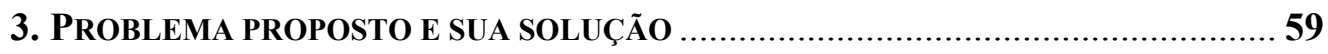

3.1 APLICANDO O DIAGRAMA DA ÁRVORE DE DECISÃO..........................................60

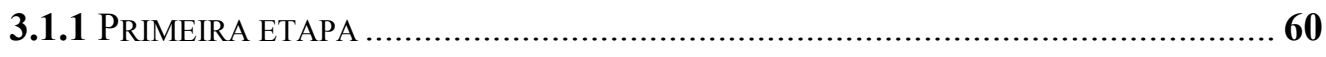

3.1.2 VERIFICAÇÃO DE SENSIBILIDADE DO PROCESSO …........................................63

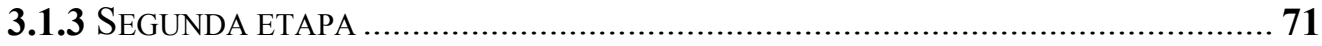

3.2 APLICAÇÃO DO MÉTODO AHP, TERCEIRA ETAPA …........................................ 74

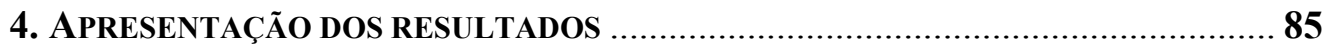

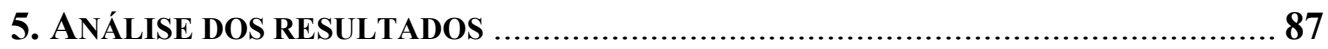

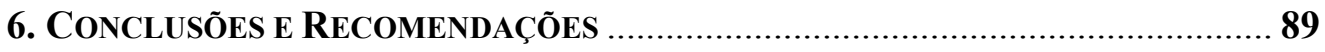

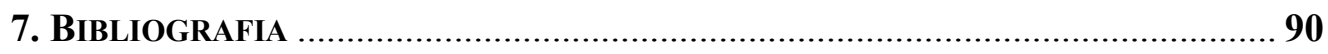




\section{LISTA DE ABREVIATURAS E SÍMBOLOS}

$\lambda_{\max }$ MAIOR AUTOVALOR DA MATRIZ

C.I. COEFICIENTE DE INCONSISTÊNCIA

IR ÍNDICE RANDÔMICO

MCP MATRIZ DE COMPARAÇÃO POR PARES

$\boldsymbol{n}$ NÚMERO DE LINHAS OU DE COLUNAS DA MATRIZ

Mbp Milhões DE BARRIS DE PETRÓLEO 


\section{LISTA DE FIGURAS}

FigURA 1.1: DiAgRAMA DO PROCESSO DE DECISÃO SEGUNDO CLEMEN..................... 6

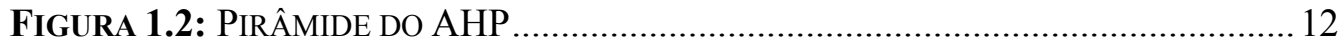

FIGURA 1.3: ESTRUTURAÇÃO DO MÉTODO ELECTRE …............................................220

FIGURA 1.4: ESQUEMA DE ARVORE DE DECISÃO .................................................... 25

FIGURA 2.1: VISTA DE UM CAMPO NO FUNDO DO MAR ..............................................28

FigURA 2.2: ESPIRAL DE ProJeto de EMBARCAÇÃo ...................................................... 31

FIGURA 3.1: ÁRVORE DE DECISÃO PARA CRITÉRIO DE TEMPO DE PRODUÇÃO DE

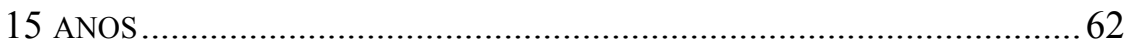

FigurA 3.2: ÁRVORE DE DECISÃO PARA TEMPO DE PRODUÇÃO DE 14 ANOS ..............6 65

FIGURA 3.2: ÁRVORE DE DECISÃO PARA TEMPO DE PRODUÇÃO DE 17ANOS ................68

FIGURA 3.3: ÁRVORE DE DECISÃO PARA TEMPO DE PRODUÇÃO DE 20 ANOS ............. 71

FIGURA 3.4: ÁRVORE DE DECISÃO PARA PERFIL DE EXTRAÇÃO .................................. 73 


\section{LISTA DE TABELAS}

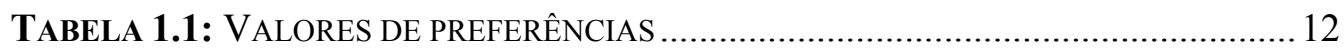

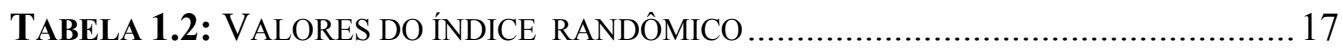

TABELA 2.1: VALORES MÉdios DE COEFICIENTES DE FORMA. FONSECA(1989) ......... 34

TABELA 2.2: COMPARAÇÃO DO POSICIONAMENTO DA SUPERESTRUTURA .................. 48

TABELA 3.1: CRITÉRIO TEMPO DE PRODUÇ̃̃O, VALORES EM MILHÕES DE BARRIS DE PETRÓLEO (MBP)

TABELA 3.2: CRITÉRIO TEMPO DE PRODUÇÃO, VALORES EM MILHÕES DE BARRIS DE

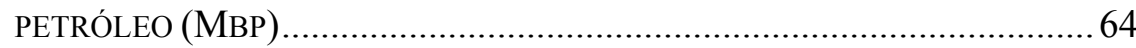

TABELA 3.3: CRITÉRIO TEMPO DE PRODUÇÃO, VALORES EM MILHÕES DE BARRIS DE PETRÓLEO (MBP) 
A MINHA ESPOSA BEATRIZ E A MEU FILHO GABRIEL SEM CUJA AJUDA NOS MOMENTOS CRÍTICOS NUNCA TERIA CONSEGUIDO CHEGAR ATÉ AQUI. 


\section{AGRADECIMENTOS}

Ao Professor Dr. Oscar Brito Augusto, meu orientador, pela paciência, compreensão e guia, tanto no campo acadêmico do qual faz parte do meu paraninfo pessoal, quanto no das relações humanas, durante o período de convivência no Departamento de Engenharia Naval e Oceânica.

Ao Professor Dr. Moyses Szajnbok, sem cujo incentivo, seu conselho e seu balizamento contínuo neste caminho que é a vida profissional jamais poderia atingir o estagio atual da minha vida.

A todos os componentes do Departamento de Engenharia Naval e Oceânica pela cordialidade e hospitalidade com que me receberam.

A ANP pela bolsa de estudo, sem a qual teria sido difícil atingir este objetivo.

Ao Professor Dr Hernani Brinati pelo apoio recebido nos momentos necessários. 


\section{RESUMO}

Freqüentemente os profissionais da construção naval tomam decisões para selecionar os elementos que devem ser especificados na composição de determinado projeto. Além da experiência e do conhecimento necessários para optar por um caminho adequado, a escolha deve atender eficientemente ao problema proposto e às preferências do projetista.

A seleção de componentes do projeto de estruturas flutuantes para exploração de campos de petróleo no mar envolve aspectos objetivos e subjetivos. $\mathrm{O}$ trabalho apresenta e aplica alguns métodos de auxílio à tomada de decisão possibilitando ao projetista aprimorar sua sensibilidade.

O objetivo da pesquisa é apresentar de forma sumária as duas bases para a decisão sobre o projeto, que são os métodos de apoio e os requisitos que as instalações FPSO devem atender, fornecendo como resultado um procedimento que permitirá aos usuários a melhor escolha dos componentes e aumentar a sensibilidade dos projetistas na seleção entre as possíveis opções (fazer totalmente novo ou aproveitar o existente).

O trabalho apresenta uma revisão dos princípios da análise da decisão, informações sobre métodos de apoio à decisão, os dados de entrada do problema proposto, o método de projetos navais, os requisitos básicos para construção de estruturas flutuantes de exploração de petróleo no mar e os requisitos básicos para uma instalação FPSO.

Para a solução do problema se aplicaram os métodos de árvore de decisão, para a parte correspondente às decisões sob risco e o método de análise hierárquica AHP para as decisões tomadas sob certeza. 


\begin{abstract}
Frequently, naval construction engineers take decisions to select the elements which must specified for the composition of a determined project. Besides the necessary experience and the knowledge to choose a proper way, the option must fulfil efficiently the problem requirements and the preferences of the designer.

The choice of components in the design off-shore structures for production in sea oilfields, involves objective and subjective aspects. This work introduces and uses a few methods of decision aids, helping the designer to improve his sensibility.

The objective of this research is to present in a simple way two foundations to decide about the project, which are the aid decision methods and the requirements which the FPSO (Floating Production Storage and Offloading System) must fulfil, supplying a procedure that enables the designer to take the best choice of components and to increase his sensibility referring to the selection among the possible options, wich are to make a completely new FPSO or to use an existing one.

This work offers a revision of the principles of the decision analysis theory, the data input of the problem, the classic naval design method, the basic requirements to build floating structures to off-shore oil extraction, and the basic requirements for a FPSO installation.

To solve the problem the decision tree method, for decision under risk, and the AHP (Analytic Hierarchy Process), for decision under certainty, were applied.
\end{abstract}




\section{RESUMEN}

Frecuentemente los profesionales de la construcción naval toman decisiones para seleccionar los elementos que deben ser especificados en la composición de determinado proyecto. Además de la experiencia y de los conocimientos necesarios para optar por un camino adecuado, la elección debe atender eficientemente al problema propuesto y a las preferencias del proyectista.

La selección de componentes de proyecto de estructuras flotantes para la explotación de campos de petróleo en el mar, envuelve aspectos objetivos y subjetivos. Este trabajo presenta y aplica algunos métodos de auxilio para la tomada de decisión, posibilitando al proyectista mejorar su sensibilidad.

El objetivo de la pesquisa es presentar de forma sumaria las dos bases para la decisión sobre el proyecto, que son: los métodos de apoyo y los requisitos que deben atender las instalaciones FPSO (Floating Production Storage and Offloading System), dando como resultado un procedimiento que permitirá a los usuarios la mejor selección de los componentes y aumentar la sensibilidad de los proyectistas para la elección entre las posibles opciones (hacer totalmente nuevo o aprovechar uno existente).

El trabajo presenta una revisión de los principios de análisis de la decisión, informaciones sobre métodos de apoyo a la decisión, los datos de entrada del problema propuesto, el método tradicional de proyectos navales, los requisitos básicos para la construcción de estructuras flotantes de explotación de petróleo en el mar y los requisitos básicos para una instalación del tipo FPSO.

Para la solución del problema se aplicaron los métodos de árbol de decisión para la parte correspondiente a las decisiones tomadas sobre riesgo y el método de análisis jerárquico AHP para las decisiones tomadas sobre certeza. 


\section{INTRODUÇÃO}

Freqüentemente os profissionais da construção naval tomam decisões para selecionar os elementos que devem ser especificados na composição de determinado projeto. Além da experiência e do conhecimento necessários para optar por um caminho adequado, a escolha deve atender eficientemente ao problema proposto e às preferências do projetista.

A seleção de componentes do projeto de estruturas flutuantes para exploração de campos de petróleo no mar envolve aspectos objetivos e subjetivos. O trabalho apresenta e aplica alguns métodos de auxílio à tomada de decisão possibilitando ao projetista aprimorar sua sensibilidade.

\section{a) A Pesquisa}

A finalidade do trabalho é propor um método para o desenvolvimento de estruturas flutuantes com aplicação de processos de auxílio à decisão.

O foco da pesquisa é descrever como se pode conjugar a utilização de alguns métodos de apoio à decisão com os requisitos usuais para projeto de estruturas flutuantes, em particular de instalações de produção, estoque e descarga de petróleo no mar, conhecidas pela sigla da língua inglesa FPSO - (Floating Production Storage and Offloading System).

O objetivo da pesquisa é apresentar de forma sumária as duas bases para a decisão sobre o projeto, que são os métodos de apoio e os requisitos que as instalações FPSO devem atender, fornecendo como resultado um procedimento que permitirá aos usuários a melhor escolha dos componentes instalados e aumentar a sensibilidade dos projetistas na seleção entre as possíveis opções. 


\section{b) O Problema da Escolha de uma Instalação FPSO}

São apresentadas considerações sobre alguns métodos de apoio à decisão, os métodos de projeto clássicos e os requisitos básicos a serem satisfeitos de modo a definir a instalação que melhor atenderá os requisitos do armador.

A realização de uma instalação do tipo FPSO pode partir de um casco novo ou, como alternativa, utilizar o de um navio petroleiro existente. $\mathrm{O}$ projeto requer a definição dos componentes do sistema, considerando os dados de entrada.

São dados de entrada para a escolha da instalação as informações sobre o campo de exploração, os processos de extração e os sistemas de apoio.

Quanto ao campo, supõe-se conhecidos a quantidade de poços da jazida, a sua forma e disposição, suas vazões e o perfil de produção de poços semelhantes.

Quanto ao processo de extração, devem ser consideradas as instalações semelhantes, em particular a técnica atual da montagem dos conjuntos de "risers", a sua faixa de utilização e o correspondente valor de eficiência do processo, assim como os conjuntos para bombear ou aspirar.

O FPSO tem como componentes o casco com determinada capacidade de armazenagem, o sistema de ancoragem e os equipamentos necessários para os processamentos a bordo.

Os equipamentos têm como principais componentes às bombas, os sistemas de separação do petróleo, da água e do gás, o de tratamento de água e o de injeção de água e gás no campo em exploração.

O sistema de apoio à exploração é constituído dos elementos de interface. Para a interface com o campo, o FPSO usa bóias para conexão com "risers", inclusive os umbilicais de controle. Para a conexão com os navios de alívio, dispõe de dutos e bóias. 


\section{c) Etapas da Pesquisa}

A pesquisa é desenvolvida nas seguintes etapas:

i) no capítulo 1 , será apresentada uma revisão dos princípios da análise da decisão e informações sobre métodos de apoio à decisão;

ii) no capítulo 2 , serão apresentados os dados de entrada do problema, o método de projetos navais, os requisitos básicos para construção de estruturas flutuantes de exploração de petróleo no mar e os requisitos básicos para uma instalação FPSO;

iii) no capítulo 3, será feita a aplicação dos princípios e métodos examinados nos capítulos anteriores;

iv) no capítulo 4 , serão apresentados resultados obtidos na aplicação dos métodos;

v) no capítulo 5 , será feita a análise dos resultados obtidos;

vi) no capítulo 6 , serão apresentadas as conclusões sobre à aplicação dos métodos, os resultados obtidos e as recomendações cabíveis.

O trabalho será finalizado com referências bibliográficas. 


\section{PRINCÍPIOS DA ANÁLISE DA DECISÃO}

O capítulo 1 destina-se a apresentar uma revisão dos princípios da análise da decisão e informações sobre métodos de apoio à decisão.

\subsection{Métodos de Apoio à Decisão}

Segundo Samson (1988) "A humanidade tem tomado decisões fazendo uso do bom senso, heurística ou em forma intuitiva. Somente neste século a teoria da decisão tem surgido como um elemento de auxílio à decisão”.

A análise de decisão ajuda a dar suporte aos nossos processos decisórios e às habilidades intuitivas e cognitivas do decisor. Os modelos aplicados são baseados em abstrações da realidade que focalizam cada estágio de solução do problema, desde a identificação e a formulação, até a solução do mesmo.

Nesta seção será apresentado um breve histórico do desenvolvimento dos métodos de apoio à decisão. Além disto, alguns serão expostos com maior detalhamento, de forma a possibilitar sua aplicação à escolha de uma instalação do tipo FPSO, que será realizada no capítulo 3.

\subsubsection{Breve Notícia Histórica}

As informações mais antigas de contribuições metodológicas e filosóficas da forma em que as conhecemos hoje foram dadas por Daniel Bernoulli (1738) com o paradoxo de São Petesburgo. J. Neyman e E.S. Pearson(1928) iniciam um trabalho pioneiro na Teoria da Decisão, usando a distribuição probabilística conhecida a priori; Ramsay (1931), De Finatti (1937) e Von Neumann e Morgenstren (1947), desenvolveram dois temas importantes da Teoria da Decisão, a Teoria da Utilidade e a da Probabilidade Subjetiva, as quais consideram valores que permitem uma aproximação maior do cálculo em relação ao tipo de perfil de comportamento de quem deve decidir.

A. Wald (1939) introduz na Teoria da Decisão a noção de risco e Savage (1954) incorpora regras mais abrangentes ao desenvolvimento da Teoria da Decisão 
Estatística, que permanecem até hoje como base teórica do processo de auxílio à decisão, R.L.P. Chang e T. Pavlidis (1977) apresentam árvores de decisão difusa.

Segundo Bekman e Costa Neto (1980) a Análise de Decisão ou Teoria da Decisão não é descritiva ou explicativa; pelo contrário, trata-se de uma teoria prescritiva ou normativa.

No seu livro Managerial Decision Analysis (1980) o professor Danny Samson afirma que a Teoria da Decisão pode ser considerada uma filosofia e ao mesmo tempo um processo formal de análise, indicando que este envolve geralmente os seguintes estágios:

- Identificação do problema e, em decorrência deste, a escolha da estruturação do modelo de decisão.

- Avaliação das probabilidades e das magnitudes envolvidas.

- Uso de um critério de decisão para modelar o processo de seleção de alternativas.

- Análise de sensibilidade, para determinar a consistência das soluções.

- Implementação da estratégia preferida ou escolhida hierarquicamente.

Em Making Hard Decisions (1991) Clemen R.T. expõe a forma de análise para os processos de tomadas de decisão, mostrando as ferramentas para auxiliar quem toma as decisões, sistematizando seu pensamento sobre os grandes problemas e melhorando, desta maneira, a qualidade das mesmas.

\subsection{A Tomada de Decisão}

a) Clemen (1991) indica quatro dificuldades para a tomada de uma decisão:

1) complexidade do problema;

2) informações imprecisas ou incertezas;

3) vários objetivos para um único problema; e

4) conclusões diferentes, aplicando a mesma sistemática, devido à mudança de dados.

O processo da tomada de decisão, segundo Clemen (1991), está esquematizado na figura 1.1. 


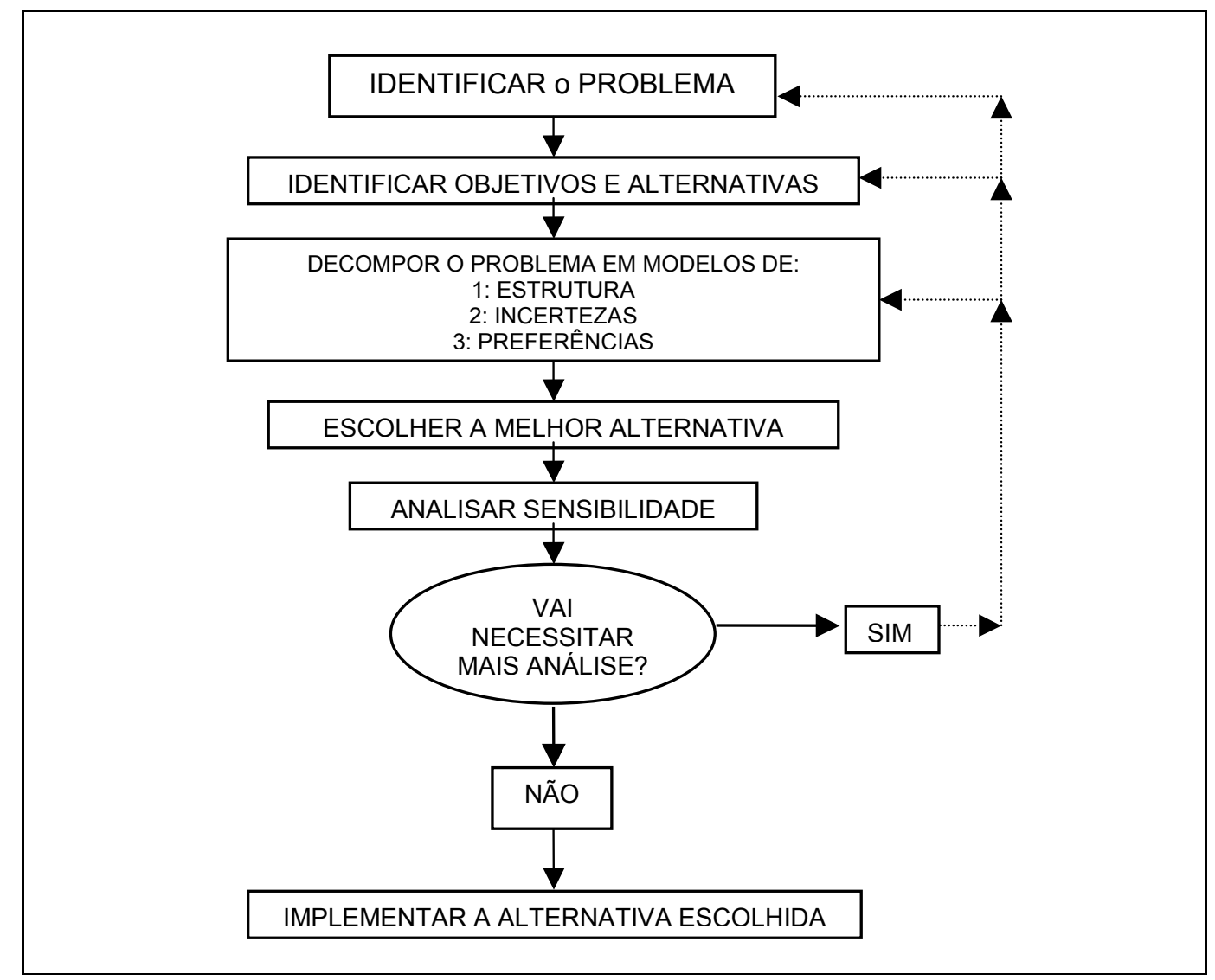

Figura 1.1: Diagrama do processo de decisão segundo Clemen

Alguns comentários devem ser feitos a respeito da figura acima.

Identificar o Problema não é algo difícil, mas o fato de não conseguir fazêlo com precisão, poderá levar-nos a tratá-lo de forma totalmente equivocada.

A segunda etapa do diagrama, Identificar Objetivos e Alternativas, é um processo de criação e introspeção.

A terceira etapa, Decompor o problema em modelos, representa a forma como a modelagem do problema é tratada na maioria das publicações referentes a metodologias de auxílio às decisões. Nesta etapa devemos definir as alternativas candidatas à solução do problema.

O Modelo de estrutura representa o resultado da análise profunda do problema, utilizando ferramentas para o decompor em elementos, fazendo uso de diagramas de relacionamento, matrizes de decisão, diagramas de árvores e intercâmbio de informações, quando o problema envolver um grupo de pessoas. 
O Modelo de incertezas indica, com o uso da estatística e da simulação, as bases para a obtenção das informações que completam os modelos.

O Modelo de preferências é a representação matemática do problema para que o tomador de decisão possa escolher a melhor alternativa, considerando os objetivos e o equilíbrio entre os elementos de conflito, utilizando o fator subjetividade.

$\mathrm{Na}$ quarta etapa, Escolher a melhor alternativa, selecionamos a solução do problema.

A Análise de sensibilidade é o processo de observar a variação que o modelo matemático indicaria se as condições do problema mudassem. Esta avaliação auxilia a definir se uma solução necessita ou não mais análise para ser implementada.

A seguinte etapa, Vai necessitar mais análise? define o caminho a seguir. Se não restar nenhuma dúvida sobre a indicação do processo este será completado. Ao Implementar a alternativa escolhida. Porém, se o parecer do decisor indica que persiste alguma dúvida com referência à indicação do processo de auxílio à decisão, o caminho é o retorno à etapa do processo que for questionada a fim de dirimir qualquer diferença que se apresente.

Além da análise apresentada, Moreira (2000) explicita que existem três elementos comuns a qualquer problema de decisão:

a) estratégias alternativas: um problema só pode ser resolvido se sairmos do estágio de procurar uma solução para o processo de escolher entre várias alternativas de solução. Torna-se necessário possuir uma lista, tão completa quanto possível, de todos os cursos de ação que possam levar à solução do problema;

b) resultados: cada alternativa de solução leva a um ou mais resultados;

c) estados da natureza: são as ocorrências futuras que podem influir sobre as alternativas, fazendo com que elas possam apresentar mais de um resultado. Podem ser apresentadas em forma única ou em partes, sempre respeitando a teoria de Bayes.

Em princípio, todos os problemas de decisão respondem a este tipo de seqüência, sendo importante ter muito bem definido cada um dos passos. 


\subsection{Características da Decisão}

a) Estruturação dos processos decisórios.

A estruturação dos processos de auxílio à decisão é feita de acordo com as características dos dados.

1. Decisão tomada sob certeza: neste caso todos os dados e as opções de solução são conhecidos de forma determinística. Pode-se aplicar métodos que utilizem critério único ou multicritérios. São estruturados em forma de objetivo, critérios e opções. Para definir qual é a melhor opção, as diversas possibilidades são ponderadas mediante diversos critérios obtendo-se atributos ou vantagens que cada uma destas oferece, maximizando ou minimizando os resultados. No caso de critérios subjetivos, se estabelece uma escala de valores para representá-los.

2. Decisão tomada sob risco: neste caso as informações são apresentadas por meio de distribuições de probabilidades dos estados da natureza.

$\mathrm{Na}$ decisão tomada sob risco, o problema pode ser estruturado em forma de matriz de decisão ou de árvore de decisão. No caso da forma matricial, cada coluna representa a probabilidade de existência dos estados da natureza, enquanto que na forma de árvore de decisão, cada ramo é afetado pela probabilidade do resultado da alternativa em exame.

3. Decisão tomada sob incerteza: neste caso a distribuição das probabilidades em que se apresentarão os estados da natureza é desconhecida, mas supomos que podemos listar os resultados possíveis.

$\mathrm{Na}$ decisão tomada sob incerteza, a estruturação pode ser feita como nos casos anteriores, em forma matricial ou de árvore de decisão. No caso de utilização de um único critério, a decisão pode ser tomada por um dentre os seguintes.

i."Maximin": o critério busca entre os resultados mais desfavoráveis de cada alternativa as opções que têm os melhores desempenhos (maior compensação ou lucro). Ou seja, entre as alternativas existentes, em suas piores performances, qual dará o maior lucro (critério pessimista).

ii."Maximax": o critério busca entre os resultados mais favoráveis de cada alternativa, as opções que têm os melhores desempenhos. Considerando os resultados que propiciam o maior lucro, escolhemos a alternativa que atinge $o$ máximo (critério otimista). 
iii."Minimax": o critério busca entre todos os resultados das possíveis alternativas, a opção de menor perda total (critério das oportunidades).

iv.Se a distribuição de probabilidades no espaço amostral é desconhecida, podemos utilizar o critério de Laplace, que define como equiprováveis os eventos do espaço amostral, isto é, todos têm probabilidades iguais.

Nesta pesquisa, as características apresentadas nas decisões são tomadas ou sob certeza, quando se conhecem as alternativas de solução e os critérios, ou sob risco, por serem conhecidas as distribuições probabilísticas dos estados da natureza.

Cada decisão depende dos critérios de avaliação das possíveis opções. Pode ser usado um critério único ou mais de um, como se verá adiante.

b) Características dos dados sobre as FPSO.

Para fins de projetos, são usuais, entre outros, os seguintes critérios:

- custo, pois todo produto tem uma finalidade e um valor para o usuário;

- $\quad$ prazo, todo projeto deve ter um prazo de execução;

- vida útil, é necessário estimar o tempo que teremos para usufruir do produto;

- reciclagem, é importante saber se após seu uso específico teremos a possibilidade ou não do seu emprego em outra alocação, ou de aproveitar os elementos remanescentes;

- Em cada projeto devem ser adotados, dentre os critérios acima, os que melhor exprimem os objetivos pretendidos, inclusive os "ad-hoc", considerando as características específicas do projeto.

\subsubsection{Decisões Tomadas Sob Certeza}

Na decisão tomada sob certeza, o objetivo é identificado, sendo conhecidos os critérios para determinar os atributos de cada alternativa e as opções de solução.

Para solução do problema, podem ser aplicados vários métodos de auxílio à decisão. Neste trabalho, serão examinados, dentre os muitos já existentes, os seguintes métodos multicritério:

i) AHP "Analytic Hierarchy Process"; 
ii) ELECTRE "Eliminasion et Choix Traduisant la Réalité”;

iii) MAUT "Multiattribute Utility Theory";

iv) MACBETH "Measuring Attractiveness by a Categorical Based Evaluation Technique".

Neste trabalho, será usado o AHP, método de análise hierárquica, pois pode ser empregado em forma individual ou coletiva, por um grupo de pessoas. Este método apresenta um índice que põe em evidência as incoerências e permite a correção e o ajuste dos juízos emitidos para melhorar a precisão destes.

Na seção 1.3.3 serão apresentados, como ilustração, os métodos ELECTRE, MAUT e MACBETH. Nota-se que o método ELECTRE necessita da intervenção de um grupo. O MAUT e o MACBETH, por sua vez, são de difícil aplicação para o emprego de critérios subjetivos.

\subsubsection{Método da Análise Hierárquica - AHP}

O Método de Análise Hierárquica é conhecido pela sua sigla em inglês AHP “Analytic Hierarchy Process". Para seu autor, Saaty (1980), o processo da tomada de decisão depende da avaliação específica das alternativas propostas, resultando na seleção daquela que melhor atenda a um conjunto de critérios. O mais importante na análise de decisão é a seleção e escolha dos fatores relevantes. No AHP estes fatores são organizados em uma hierarquia, começando com o objetivo, seguindo pelos critérios e sub-critérios e finalizando no nível das alternativas ou soluções oferecidas.

O Método de Análise Hierárquica é um sistema para análise e síntese de problemas complexos que permite justificar as decisões e avaliações complicadas, tornando possível examinar os elementos de um problema de forma isolada. Cada elemento é comparado com outro, sempre segundo um dos critérios.

O processo de decisão exposto é o mais simplificado, pois as comparações são feitas aos pares. Auxilia também a organizar e sintetizar as conclusões de melhor para pior ou vice-versa. Tem a vantagem de incorporar conceitos qualitativos e quantitativos para depois combiná-los. Permite que a experiência da pessoa ou do avaliador seja aplicada com o máximo de aproximação do que deverá ser a resposta "ótima". Este método fornece o modelo matemático para compatibilizar os elementos 
objetivos com as decisões e preferências individuais. Opera desenvolvendo prioridades por alternativa e os critérios sob os quais as estas são julgadas.

Os conceitos incorporados neste método são os seguintes:

- estruturação de sistemas complexos em hierarquias: algumas teorias psicológicas propõem que o cérebro humano tem um limite de sete itens quer na sua capacidade de memória de curto prazo quer na capacidade de discriminação; para lidar com situações mais complexas e superar esta limitação o cérebro estrutura as entidades em agrupamentos lógicos ou hierárquicos;

- comparação relativa de pares de conceitos: as comparações relativas são muito mais fáceis que julgamentos absolutos. Por exemplo: é difícil decidir, entre 14 ou mais critérios considerados simultaneamente, qual tem maior peso na decisão e depois fazer o mesmo com os restantes; sempre é mais fácil comparar de dois em dois;

- comparações redundantes: são feitas com o objetivo de reduzir erros provenientes de uma comparação menos coerente e produzir um índice de consistência dessas comparações.

O método é realizado em quatro etapas;

1.- estruturação do problema: selecionando o objetivo, os critérios que servirão de base e as opções oferecidas como solução possível;

2.- obtenção da informação sobre as comparações de cada par de fatores de decisão subdivididos em: objetivos, critérios e alternativas;

3.- definição dos valores relativos aos pesos dos fatores de decisão, em cada nível, e;

4.- consolidação dos valores atribuídos aos fatores, para cada alternativa;

A conclusão que indica a decisão a tomar é dada pela classificação das alternativas ordenadas em forma hierárquica.

Neste método se estabelece uma hierarquia de valores e, numa matriz de comparação, se ordenam as opções pela sua importância. Para isto usamos uma escala proposta pelo idealizador do método, Thomas Lorie Saaty (Tabela 1.1). 


\begin{tabular}{|cc|}
\hline Pareceres de preferências & Valores numéricos \\
\hline Absoluta & 9 \\
\hline & 8 \\
\hline Muito forte & 7 \\
\hline & 6 \\
\hline Forte & 5 \\
\hline & 4 \\
\hline Moderada (pouco melhor) & 3 \\
\hline & 2 \\
\hline Igual (equivalente) & 1 \\
\hline
\end{tabular}

Tabela 1.1: Valores de preferências

Os valores pares são utilizados para fornecer uma maior aproximação ao parecer do avaliador.

Cada dupla é comparada por um determinado critério; então serão feitas tantas matrizes quantos critérios sejam usados na escolha.

A estruturação do problema pode ser esquematizada da seguinte forma.

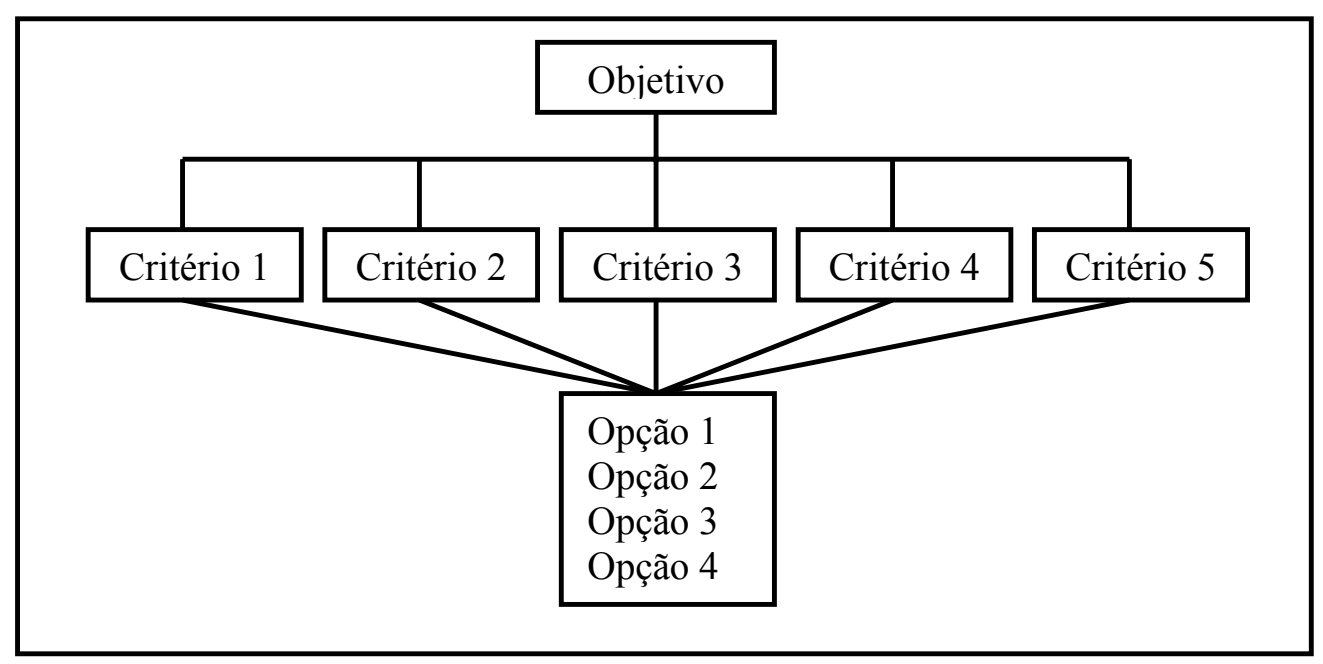

Figura 1.2: Pirâmide do AHP

Há uma atividade muito importante a ser executada entre cada etapa, que é a verificação da consistência dos dados que foram utilizados no julgamento. Esta consistência é basicamente a indicação do desvio que apresenta o cálculo dos resultados em relação a um valor ideal para a mesma quantidade de critérios adotados na avaliação. 
Saaty (1980) estabelece escalas de valores para comparação e guia, como referência à consistência dos julgamentos e Morita (1998) faz uma revisão destes valores. Com esta ferramenta, podemos ter um elemento que permite medir o desvio através do coeficiente de inconsistência.

A prioridade relativa que é calculada para cada elemento deve, segundo Saaty (1994), ser um valor entre 0 e 1 . Para cada grupo de fatores, a soma total dos pesos deve resultar em um valor unitário.

Quando se trabalha com valores determinísticos, o estabelecimento de uma hierarquia pela comparação dos atributos de cada opção de solução é feita maximizando ou minimizando os valores, após o processo de normalização.

Por exemplo, trabalhando com preços de compra de produtos, serão tantos preços quantas opções forem oferecidas como solução do problema. Neste caso, quanto maior o preço de compra, pior a hierarquia, sendo então necessário o conceito de minimização de custos. Usando o critério da vida útil do bem, quanto maior este parâmetro, melhor, sendo então necessário o conceito de maximização da vida útil.

Quando se trabalha com critérios subjetivos, onde são necessárias as ponderações de um avaliador, teremos que recorrer à tabela 1.1 de valores. Neste caso, será estabelecida uma matriz quadrada, que exporá o parecer do avaliador. Cada elemento da linha é comparado com o elemento da coluna correspondente. Este procedimento é feito tanto para a comparação das alternativas dentro de cada critério quanto para determinar a hierarquia dos próprios critérios.

Dada a matriz A, onde $\mathrm{a}_{i j}$ representa o valor de linha $i$ e coluna $j$, se o valor for 1 significa que, na comparação, do elemento da linha $i$ é igual ao elemento da coluna $j$. Se o valor for 5 significa que o elemento da linha $i$ é fortemente melhor que o elemento da coluna $j$, e assim por diante. A diagonal, que representa a comparação do elemento colocado na linha com o mesmo colocado na coluna, tem o valor unitário, que representa a igualdade. A matriz A tem uma particularidade: cada elemento $\mathrm{a}_{i j}$ é o inverso do elemento $\mathrm{a}_{j i}$ da mesma matriz. Por exemplo, se $i$ é muito fortemente preferida a $j, a_{i j}$ será igual a 7 e $a_{j i}$ terá o valor de 1/7. Isto significa que os elementos obedecem à seguinte relação.

$$
\mathrm{a}_{i j}=1 / \mathrm{a}_{j i}
$$


O passo seguinte é a normalização dos valores das colunas, que consiste na divisão de cada elemento pelo somatório dos elementos da coluna. Desta forma, se obterá um valor adimensional expressado por um número decimal para cada elemento da coluna, sendo que o somatório destes é a unidade. A seguir, se calcula a média dos valores de cada linha, dispondo-as num vetor coluna.

Isto é crucial na aplicação do método, pois permite analisar os elementos quantitativos dimensionais junto com os pareceres subjetivos do avaliador.

Quando se faz este procedimento para comparar as alternativas de acordo com um critério, obtemos a matriz hierárquica das alternativas para esse critério. Por outro lado, quando se aplica esta metodologia para atribuir pesos aos critérios, resulta a matriz da hierarquia dos critérios.

Por último, construímos uma matriz consolidada, pela justaposição das matrizes hierárquicas das alternativas para cada critério, na ordem em que os critérios estarão alinhados na matriz hierárquica dos critérios, correspondendo cada coluna da primeira a cada linha desta última.

Para finalizar, multiplicamos as duas matrizes obtendo, como resultado, uma matriz de uma coluna e tantas linhas quantas opções foram analisadas e cada valor representa a hierarquia de cada uma destas. Para verificar se o cálculo está corretamente executado, a somatória dos elementos deve ser igual à unidade.

O AHP utiliza o método do autovetor para determinar as prioridades relativas. Inicia-se com uma matriz de comparação de pares de elementos.

Sendo A uma matriz quadrada de $n$ linhas e $n$ colunas.

$$
\mathrm{A}=\left|\begin{array}{ccccc}
a_{11} & a_{12} & a_{13} & \ldots . & a_{1 n} \\
a_{21} & a_{22} & a_{23} & \ldots . & a_{2 n} \\
\ldots . & \ldots \ldots & \ldots . & \ldots \\
\ldots . & \ldots . . & \ldots . & \ldots . \\
a_{n 1} & a_{n 2} & a_{n 3} & \ldots & a_{n n}
\end{array}\right|
$$

E o vetor de prioridades relativas P fica definido pela solução da equação:

$$
\text { A. } \mathrm{P}=\lambda_{\text {max. }} \mathrm{P}
$$


Onde: A é a matriz quadrada de $n$ linhas e $n$ colunas, sendo $\lambda$ max. o maior autovalor de A, e P é o autovetor associado.

Será mostrado que é válido o uso do autovetor como vetor de prioridades da matriz de comparação de a pares.

Se $A=\left(a_{i j}\right)$ é consistente e se $P=\left(p_{j}\right)$, então o elemento $a_{i j}$ pode ser escrito como uma relação entre os pesos do vetor $\mathrm{P}$.

$$
\mathrm{a}_{\mathrm{ij}}=\mathrm{p}_{\mathrm{i}} / \mathrm{p}_{\mathrm{j}}
$$

$$
\mathrm{A}=\left|\begin{array}{cccc}
\mathrm{p}_{1} / \mathrm{p}_{1} & \mathrm{p}_{1} / \mathrm{p}_{2} & \mathrm{p}_{1} / \mathrm{p}_{3} \ldots \mathrm{p}_{1} / \mathrm{p}_{\mathrm{n}} \\
\mathrm{p}_{2} / \mathrm{p}_{1} & \mathrm{p}_{2} / \mathrm{p}_{2} & \mathrm{p}_{2} / \mathrm{p}_{3} \ldots . & \mathrm{p}_{2} / \mathrm{p}_{\mathrm{n}} \\
\ldots \ldots . . & \ldots \ldots . . & \ldots \ldots . & \ldots \ldots . \\
\ldots \ldots . . & \ldots \ldots . . & \ldots \ldots \ldots & \ldots \ldots . . \\
\mathrm{p}_{\mathrm{n}} / \mathrm{p}_{1} & \mathrm{p}_{\mathrm{n}} / \mathrm{p}_{2} & \mathrm{p}_{\mathrm{n}} / \mathrm{p}_{3} \ldots & \mathrm{p}_{\mathrm{n}} / \mathrm{p}_{\mathrm{n}}
\end{array}\right|
$$

Multiplicando A por P, considerando os elementos da matriz e do autovetor.

$$
\Sigma \mathrm{a}_{\mathrm{ij}} \cdot \mathrm{p}_{\mathrm{j}}=\Sigma\left(\mathrm{p}_{\mathrm{i}} / \mathrm{p}_{\mathrm{j}}\right) \cdot \mathrm{p}_{\mathrm{j}}=n \cdot \mathrm{P}
$$
Resulta
A. $\mathrm{P}=n \cdot \mathrm{P}$

A matriz é uma matriz quadrada A de ordem $n$ que se define como MCP, matriz de comparação por pares, se respeitar as seguintes condições.

$$
\text { Se } a_{i j}=p_{i} / p_{j} \text {, então } a_{j i}=p_{j} / p_{i}=1 / a_{i j} ; \text { e } a_{i i}=p_{i} / p_{i}=1
$$

Dado que todo $\mathrm{p}_{\mathrm{j}}>0$, então $\mathrm{a}_{\mathrm{ij}}>0$

Assim a matriz A do tipo MCP é quadrada, positiva e recíproca.

Saaty (1980) demonstra que se A é uma matriz do tipo de comparação por pares MCP então $\lambda_{\text {max. }} \geq n$ e que A é uma matriz consistente do tipo de comparação

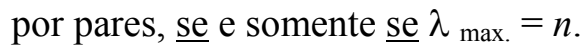

Como no caso consistente $\lambda_{\text {max. }}=n$, então: $\mathrm{A} . \mathrm{P}=\lambda_{\text {max. }} \mathrm{P}$

Se a matriz de comparações não estiver longe da inconsistência então $\lambda$ max. também não estará longe de $n$, e não existe descontinuidade. 
Segundo Saaty (1980) o autovetor máximo $\lambda$ max. é continuamente dependente dos elementos da matriz de comparações, foram testados quatro métodos de aproximação e concluiu-se que o método de médias geométricas fornecia os melhores resultados. Neste trabalho, este método de aproximação é o mais acessível e aplicável.

$\mathrm{O}$ autovetor direito $\mathrm{P}$ da matriz se calcula de forma aproximada pela fórmula:

$$
p_{j}=\sum_{j=1}^{n} \frac{a_{i j}}{n} s_{j}
$$

sendo então $\quad S_{j}=\frac{1}{\sum_{i=1}^{n} a_{i j}}$

onde as variáveis $(\mathrm{i}$ e $\mathrm{j}=1,2 \ldots ., \mathrm{n})$

Se $\mathbf{S}$ é o vetor com os elementos de $S_{1}$ a $S_{n}$ pode-se escrever, que

$$
\mathrm{P}=\mathrm{A} . \mathrm{S} / n=(\mathrm{A} . \mathrm{S}) / n
$$

Considerando as condições de consistência o resultado é:

$$
\text { A. }(\text { A } . S)=n \cdot \text { A. S }
$$

Portanto substituindo na equação $1.2\left(\mathrm{~A} . \mathrm{P}=\lambda_{\max } \mathrm{P}\right)$

$$
\mathrm{A} . \mathrm{P}=\mathrm{A} .(\mathrm{A} . \mathrm{S}) / n=n .(\mathrm{A} . \mathrm{S}) / n=\mathrm{A} . \mathrm{S}
$$

E para o caso consistente onde: $\left(\mathrm{A} . \mathrm{P}=\lambda_{\max } \mathrm{P}\right)$

$$
\lambda_{\text {max. }} \mathrm{P}=n \mathrm{P}=n . \mathrm{A} . \mathrm{S} / n=\mathrm{A} . \mathrm{S}
$$

Pode-se afirmar que: $\quad$ A.P $=\lambda_{\max }$ P

Fica demonstrado que ao se tratar de uma matriz consistente o método de aproximação está correto. De não existir descontinuidades no entorno de 
$\lambda_{\text {max. }}=n, \mathrm{o}$ autovetor $\mathrm{P}$ calculado desta forma (equações a.1.3 e a.1.5) também é válido.

Matematicamente, pode ser provado que sendo $\lambda_{\text {max. }}=n$ a existência da função somente se dá de um lado, mas isto no invalida a conclusão, pois não existem descontinuidades entre os valores dos componentes da matriz em questão e o $\lambda$ max.

Quanto mais próximo $\lambda$ max. estiver de $n$ mais consistentes são as comparações, devido a isto é que a diferença $\left[\lambda_{\text {max. }}-n\right]$ pode ser utilizada para medir a consistência da matriz.

Saaty (1980) define um indicador de inconsistência que pode ser chamado de coeficiente de inconsistência C.I.

$$
\text { C.I. }=\frac{\lambda \max -n}{n-1}
$$

Na tabela seguinte proposta inicialmente por Saaty (1980) e corrigida por Morita (1998), este índice é chamado de índice randômico (IR) de matrizes de comparações paritárias que depende do tamanho da MCP.

John DeSchutter apud Saaty (1990) propôs uma fórmula para calcular o índice randômico:

$$
\mathrm{IR}=1,98(\mathrm{n}-2) / \mathrm{n}=1,98\{1-(\mathrm{n}-1) /[\mathrm{n}(\mathrm{n}-1) / 2]\}
$$

\begin{tabular}{|c|c|c|c|c|c|c|c|c|c|c|c|c|c|}
\hline$n$ & 3 & 4 & 5 & 6 & 7 & 8 & 9 & 10 & 11 & 12 & 13 & 14 & 15 \\
\hline IR & 0,52 & 0,89 & 1,11 & 1,25 & 1,35 & 1,40 & 1,45 & 1,49 & 1,51 & 1,54 & 1,56 & 1,57 & 1,58 \\
\hline
\end{tabular}

Tabela 1.2: Valores do índice randômico

Chama-se de razão de consistência, R.C., a comparação do coeficiente de inconsistência C.I. calculado pela equação (1.12) com o índice das matrizes randômicas IR.

$$
\text { R.C. }=\text { C.I./I.R. }
$$

Este é maior quanto mais inconsistente é a matriz de comparações, e permite que o decisor volte a analisar suas comparações melhorando com a prática sua 
sensibilidade, permitindo que esta inconsistência se situe dentro do $10 \%$ de diferença, fazendo com que a decisão seja bem aproximada da ideal.

Este trabalho se centra na interatividade do projetista com os resultados obtidos, já que ao ser detectada uma razão de consistência maior que o valor estipulado como referência, ele poderá modificar e aperfeiçoar seu julgamento, verificando o resultado numérico na planilha elaborada para este fim.

\subsubsection{Outros Métodos Multicritério}

Com a facilidade introduzida nos estudos pelos sistemas informáticos, os métodos de auxílio à decisão multicritério, além do AHP, se multiplicaram nos últimos 20 anos. Como por exemplo:

a) ELECTRE, com várias versões (I,II,II,IV etc.)

b) MAUT, (Multiple Atribute Theory)

c) MACBETH, (Measuring Attractiveness by a Categorical Based Evaluation Technique).

d) PROMETHEE (Preference Ranking Organization Method for Enrichment Evaluations),

e) SMART, (Simple Multi Attribute Ranking Technic)

f) TODIM (Tomada de Decisão Interativa Multicritério),

g) TOPSIS (Technique for Order Preference by Similarity to Ideal Solution). Como ilustração serão apresentados os três primeiros :

a) A família de métodos ELECTRE (Eliminasion et Choix Traduisant la Réalité), concebidos por Roy (1996), baseados em relações de superação, são utilizados para decidir sobre a determinação de uma solução, que sem ser ótima, se considere satisfatória e ao mesmo tempo obter uma hierarquização das diversas ações alternativas sob análise. Permite representar numericamente os juízos das pessoas que decidem sobre as ações mais atrativas, embora utilizando uma escala cardinal (com graduações quantitativas, numéricas) similar ao AHP, a determinação da escala final é calculada por programação linear.

A escala de valores é definida de acordo ao tipo de critério a ser aplicado, de forma que temos uma matriz de decisão onde são colocados os pesos. Os referidos 
aos elementos financeiros baseiam-se no cálculo do valor presente e os que se referem a outros elementos são considerados numa escala de 0 a 100 pontos.

Serão obtidas então matrizes de decisão com valores positivos e negativos.

A estruturação do método é apresentada na Figura 1.3. Nela pode-se observar que o processo de avaliação de cada alternativa para a obtenção dos atributos das mesmas é puramente objetivo e não permite a intervenção do decisor. A intervenção subjetiva deste somente será exercida sobre os critérios e sua ponderação.

Assumindo que existe um critério definido, g, e um grupo de opções ou alternativas A, a modelagem tradicional de preferência parte do principio que podem ser estabelecidas as relações $\mathbf{P}, \mathbf{I}, \mathbf{J}$, para duas alternativas, $(\mathrm{a}, \mathrm{b}) \in \mathrm{A}$ sendo:

a $\mathbf{P}$ b (a é preferido a b) $\mathbf{g}(\mathrm{a})>\mathbf{g}(\mathrm{b})$

a I b (a é indiferente a b) $\mathbf{g}(\mathrm{a})=\mathbf{g}(\mathrm{b})$

a $\mathbf{J}$ b (a não pode ser comparado com b)

Em contraste com esta forma tradicional de apresentar a comparação de valores, ELECTRE, introduz o conceito de um ponto de indiferença, q e define com ele as comparações:

a $\mathbf{P}$ b (a é preferido a b) $\mathbf{g}(\mathrm{a})>\mathbf{g}(\mathrm{b})+\mathbf{q}$

a I b (a é indiferente a b) $[\mathbf{g}(\mathrm{b})-\mathbf{g}(\mathrm{a})]<\mathbf{q}$

a $\mathbf{J}$ b (a não pode ser comparado com b)

O ponto de indiferença é especificado pelo decisor, mas há um ponto onde o conceito deste muda de indiferente para estritamente preferido. Para isto, o ELECTRE introduz outro conceito que é o de fracamente preferido, esta zona de hesitação para o decisor, corresponde a outra relação binária do tipo mostrado acima 
$\mathbf{P}$ e I , somente que o conceito agora incorporado é p , obtemos então as seguintes comparações onde $\mathbf{Q}$ indica preferências fracas:

a $\mathbf{P}$ b (a é fortemente preferido a b) $\mathbf{g}(\mathrm{a})-\mathbf{g}(\mathrm{b})>\mathbf{p}$

a $\mathbf{Q}$ b (a é fracamente preferido a b) $\mathbf{q}<\mathbf{g}(\mathrm{b})-\mathbf{g}(\mathrm{a})]<\mathbf{p}$

a I b (a é indiferente a b) $[\mathbf{g}(\mathrm{b})-\mathbf{g}(\mathrm{a})]<\mathbf{q}$

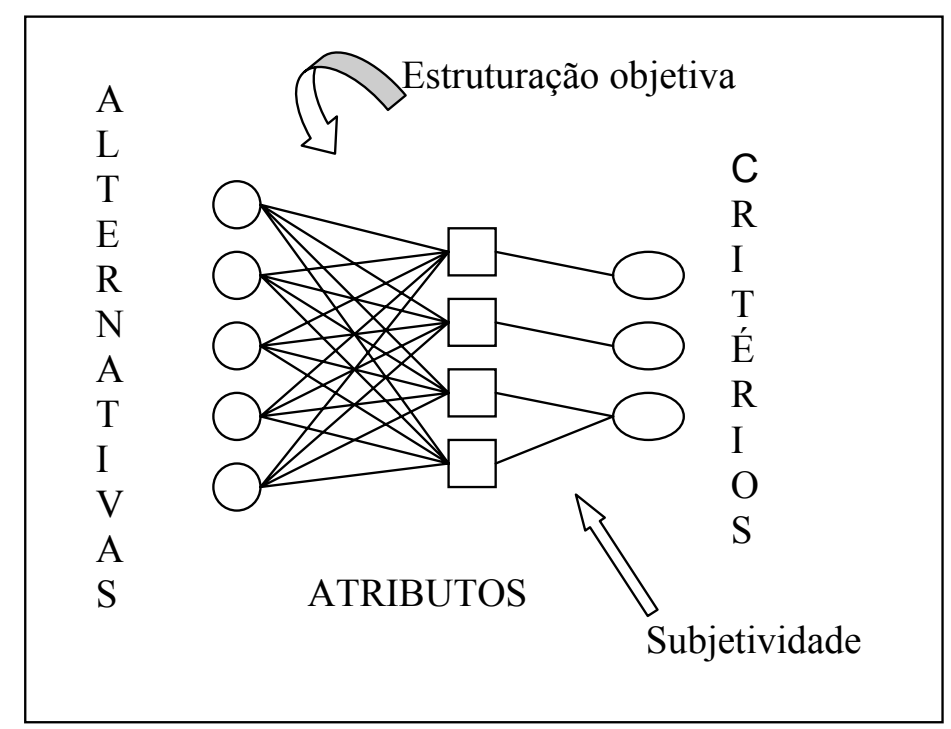

Figura 1.3: Estruturação do método ELECTRE

Este método não considera a possibilidade de existência de um elemento de indicação do desvio, que é motivo principal da escolha, pois permite a melhora contínua da sensibilidade do projetista, objeto deste trabalho.

b) No método aplicado na teoria da utilidade de múltiplos atributos (MAUT), a decisão é feita por meio de uma função de utilidade marginal que possui cada critério, como explicam Keeney e Raiffa (1976). O método representa a aplicação do conceito de utilidade à decisão multicritério. Esta função permite expressar os valores de comparação dos critérios numa escala comum de 0 a 1.

Este método, utilizado para análises quantitativas, apresenta certas dificuldades na sua aplicação a problemas onde existe a combinação de critérios qualitativos e quantitativos. O valor total de cada alternativa indica a escala de preferências. 
Quando a função utilidade está estruturada, este método permite a solução complexa de problemas de decisão utilizando múltiplos critérios e muitas alternativas, que oferecem valores em padrões diferentes e que devem ser comparados.

Para identificar a alternativa preferida, multiplicam-se os valores das funções utilidades correspondentes as alternativas normalizadas pelo peso dos critérios correspondentes, e se procede ao somatório dos resultados obtidos para todos os critérios. A alternativa escolhida é a de maior valor.

A função utilidade é empregada quando a informação quantitativa é conhecida, o que dá ao decisor uma estimativa comprovável. Cada critério utilizado na decisão tem uma função utilidade criada para si, o que facilita a comparação, pois são medidas adimensionais.

Este método não possui um elemento de indicação do desvio que permita o aperfeiçoamento do decisor.

c) O método MACBETH permite a construção de uma estrutura flexível e de fácil compreensão porque incentiva à reflexão sobre uma determinada situação que se está analisando. Isto é feito através do raciocínio natural e sistemático oferecido pela metodologia, a qual incorpora todas as variáveis que podem influenciar a decisão e o que isto significará no futuro, não se limitando apenas em considerar os aspectos qualitativos do mesmo.

Os sistemas reais são compostos por situações complexas, onde há múltiplas informações e inúmeras saídas, amostras coletadas e desvios para serem testados, ou seja, uma gama de variáveis que são elementos que integram e intervêm num processo decisório. A compreensão e interpretação destes sistemas, bem como dos pontos de vistas fundamentais de cada decisor, são usualmente discrepantes. Esta discrepância faz com que cada decisor interveniente no processo veja a necessidade de aplicação de uma ação distinta e, devido a isso, considere que o problema a ser resolvido é diferente daquele para o qual foi consultado. Percebe-se que é necessário, para um bom desempenho do processo, um consenso entre os decisores sobre os pontos de vista e os critérios a serem aplicados. 
Todos os pontos de vista são expostos aos outros decisores e, através de um consenso, estes deverão determinar quais são os fundamentais. Após a identificação, cada ponto de vista fundamental deve ser operacionalizado.

Isto é realizado através de um coordenador. Este determina os possíveis níveis de impactos $\left(\mathrm{N}_{\mathrm{i}}\right)$ para cada ponto de vista fundamental. Após determinar os possíveis níveis de impacto para cada ponto de vista fundamental, segue a construção de uma escala de valores cardinais.

A metodologia do MACBETH faz a seguinte pergunta aos decisores: "Dados os níveis de impactos $\mathrm{i}_{\mathrm{j}}(\mathrm{a})$ e $\mathrm{i}_{\mathrm{j}}(\mathrm{b})$ de dois elementos $\underline{\mathrm{a}}$ e $\underline{\mathrm{b}}$ de $\mathrm{A}$ segundo um critério fundamental $\mathrm{CF}$, sendo a julgada mais atrativa que $\underline{b}$, qual é a diferença de atratividade entre $\underline{a}$ e $\underline{b}$ ?". Pode definir-se como: "muito fraca", "fraca", "moderada", "forte", "muito forte" ou "extrema".

Para facilitar este diálogo entre o coordenador e o decisor, é introduzida uma escala do tipo semântica, formada por seis categorias de diferenças de atratividade, de dimensão não necessariamente igual. Estas seis categorias de diferenças de atratividade são representadas por:

$\mathrm{C}_{1}$ - diferença de atratividade muito fraca;

$\mathrm{C}_{2}$ - diferença de atratividade fraca;

$\mathrm{C}_{3}$ - diferença de atratividade moderada;

$\mathrm{C}_{4}$ - diferença de atratividade forte;

$\mathrm{C}_{5}$ - diferença de atratividade muito forte;

$\mathrm{C}_{6}$ - diferença de atratividade extrema.

Assim, para $(\mathrm{a}, \mathrm{b}) \in \mathrm{A}$, onde a é mais atrativo do que $\mathrm{b}(\mathrm{a} \mathbf{P}$ b), o decisor é solicitado a declarar um juízo qualitativo absoluto sobre a diferença de atratividade existente entre a e b, atribuindo ao par $(\mathrm{a}, \mathrm{b})$ uma e só uma das categorias semânticas propostas acima.

Como exposto acima, poderá observar-se que é necessária a intervenção de um grupo de pessoas na aplicação da metodologia, o que faz que seja este um motivo da não utilização da mesma na aplicação deste trabalho.

Além disto, não possui um coeficiente indicador do desvio que permita sua aplicação para melhorar a sensibilidade do decisor. 


\subsection{Decisões Tomadas Sob Risco}

A decisão tomada sob risco pode ser estruturada em forma de árvore de decisão.

O método da árvore de decisão apresenta a vantagem de facilitar a aplicação de uma distribuição probabilística, afetando a uma ou mais distribuições posteriores.

\subsubsection{A Árvore de Decisão}

Para Bekman,O.R. e Costa Neto, P.L. (1980) "a coleção de eventos para a decisão definem uma distribuição de probabilidade, significando que um e somente um desses eventos irá ocorrer, com probabilidades $\mathrm{P}\left(\mathrm{A}_{1}\right), \mathrm{P}\left(\mathrm{A}_{2}\right), \ldots \mathrm{P}\left(\mathrm{A}_{\mathrm{n}}\right)$, cuja soma é unitária". Por exemplo, estimamos os dados da capacidade de produção do campo em barris de petróleo e a produtividade obtida em situações semelhantes por outros sistemas FPSO, medidas em barris de petróleo extraídos por dia, sendo que estes podem ser: a) conhecidos ou b) desconhecidos.

Se a distribuição de probabilidade é conhecida, poderão ser utilizadas árvores de decisão ou de probabilidade. São estruturas de raciocínio onde se identifica o valor que será obtido de cada alternativa proposta e as probabilidades em que se divide o estado da natureza especificamente, o seja, qual é a probabilidade de achar cada valor de cada alternativa, na forma em que foi dividido o espaço amostral do problema

Esta representação esquemática, que permite estruturar o raciocínio, pode ser aplicada para qualquer problema de decisão, pois permite a identificação clara das alternativas de solução, das variáveis, das probabilidades em que se apresenta dividido o âmbito do problema e do ganho final esperado, de acordo com o tipo de cenário. Sua aplicação à resolução de problemas simples, que permitem a identificação de critério único para sua solução, é a mais freqüente, pois a visualização do problema se torna mais difícil quanto maior a complexidade deste. É um processo, uma ferramenta, que serve para representar em forma esquemática uma situação de escolha.

A representação é a seguinte: 
a) cada ramo representa uma alternativa à solução do problema e parte do vértice da esquerda, indicado por um quadrado, que representa o ponto no qual o decisor tem o controle da escolha;

b) na outra extremidade do ramo se encontra um nó indicado por um círculo, que representa um ponto de evento onde a chance ou a forma em que se encontram divididos os estados da natureza determina um resultado, seguido de outros ramos e em cada extremidade destes o valor que se espera conseguir nesse campo do estado, levando-se em conta o histórico passado.

São dois tipos de eventos, uns de decisão e outros de chances ou probabilidades, organizados de forma a representar a ordem em que eles podem ocorrer, sensatamente ordenados e ressaltando o valor inicial, que será ingressado como informação e o valor esperado, que será obtido como resultado do processo decisório.

Por exemplo, em um problema onde as soluções são três $\left(\mathrm{A}_{1}, \mathrm{~A}_{2}, \mathrm{~A}_{3}\right)$, teremos três ramos partindo da origem. Se o estado da natureza estiver composto por duas situações $\left(\mathrm{S}_{1}, \mathrm{~S}_{2}\right)$, com as probabilidades ou proporções respectivas $\left(\mathrm{P}_{1}, \mathrm{P}_{2}\right)$, cada ramo alternativa será seguido de dois ramos com a indicação das probabilidades em que estas acontecem e, nos extremos destes, os valores previstos para cada situação.

A solução do problema é baseada no valor médio dos valores previstos, que se consegue multiplicando cada valor pela probabilidade de acontecer cada situação, e tomando o somatório dos resultados.

O cálculo de cada valor médio esperado é:

Valor médio esperado da $\mathrm{A}_{1}=\left[\right.$ Valor $\mathrm{A}_{1}$ de $\left.\mathrm{S}_{1}\right] \times\left[\mathrm{P}_{1}\right]+\left[\right.$ Valor de $\mathrm{A}_{1}$ para $\left.\mathrm{S}_{2}\right] \times\left[\mathrm{P}_{2}\right]$ Valor médio esperado da $\mathrm{A}_{2}=\left[\right.$ Valor $\mathrm{A}_{2}$ de $\left.\mathrm{S}_{1}\right] \times\left[\mathrm{P}_{1}\right]+\left[\right.$ Valor de $\mathrm{A}_{2}$ para $\left.\mathrm{S}_{2}\right] \times\left[\mathrm{P}_{2}\right]$ Valor médio esperado da $A_{3}=\left[\right.$ Valor $A_{3}$ de $\left.S_{1}\right] \times\left[P_{1}\right]+\left[\right.$ Valor de $A_{3}$ para $\left.S_{2}\right] \times\left[P_{2}\right]$ 


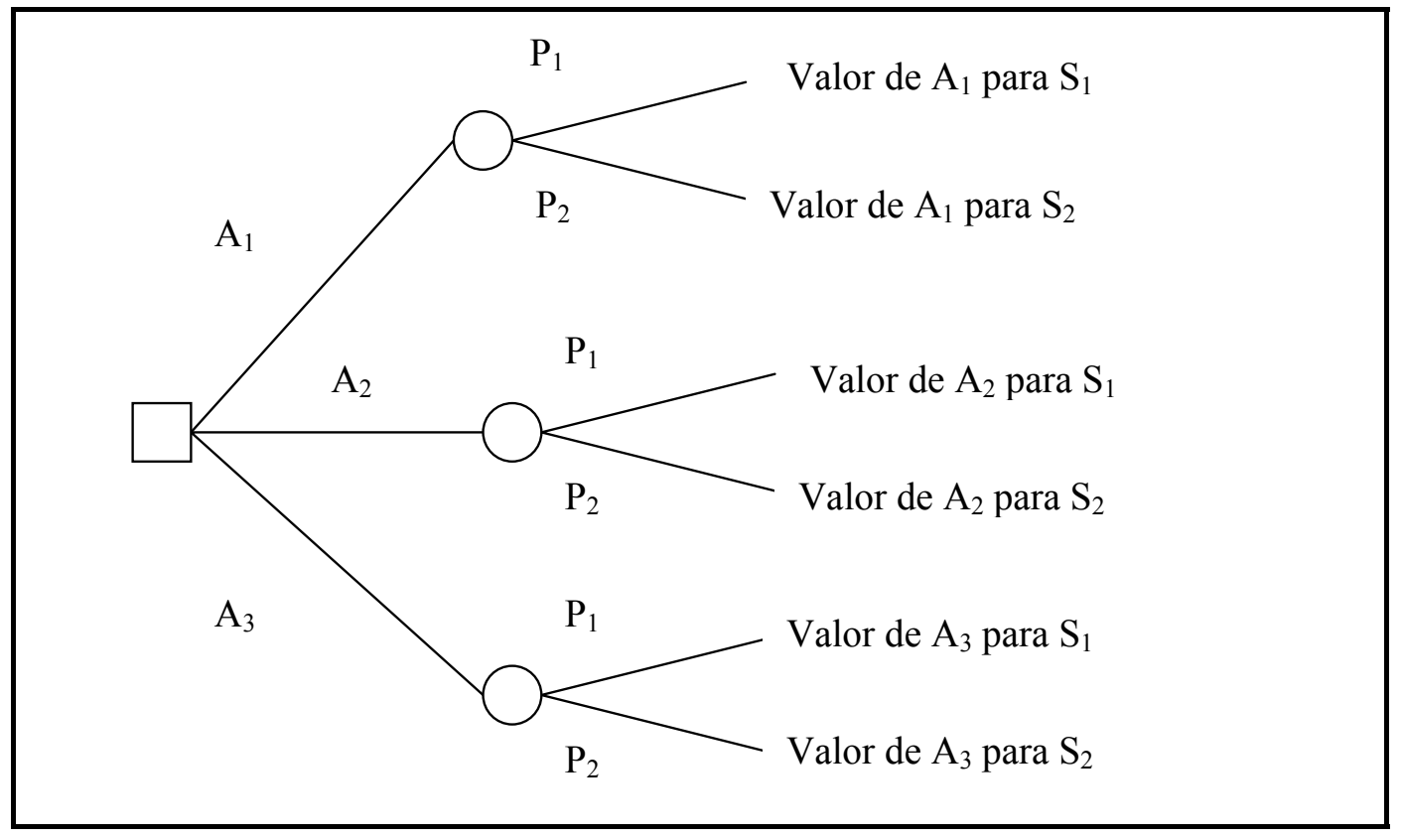

Figura 1.4: Esquema de árvore de decisão

Poderemos calcular, baseados em informações históricas reais, os dados para dimensionar o produto de forma a obter o maior rendimento possível dentro das características de trabalho definidas do mesmo. 


\section{O PETRÓLEO NO MAR}

Um campo de petróleo no mar é geralmente composto de diversos reservatórios que formam um conjunto, estruturados em camadas, ou distribuídos lado a lado. O que define um campo de exploração de petróleo é a quantidade, tamanho e localização geográfica dos seus reservatórios, assim como o tipo de óleo a ser extraído e as condições ambientais.

Reservatório é uma formação porosa e permeável, localizada no subsolo, contendo uma acumulação natural de hidrocarbonetos extraíveis (óleo e/ou gás), o qual é limitado por formações rochosas ou aqüíferas (barreiras de água) que definem seu isolamento hidráulico dos outros reservatórios.

\subsection{Dados de Entrada}

Podemos identificar três componentes das características dos reservatórios que influenciam sua forma de exploração: o volume de hidrocarbonetos contidos; o número e o tipo de poços; a lâmina de água no local.

a) A determinação do volume de um reservatório se faz através de sondagens e explorações em cada local, definido pelos milhões de barris de petróleo contidos. É utilizada a expressão Milhões de Barris de Óleo Equivalentes, que envolve também os componentes gasosos. Quando um campo está em operação, se considera o volume já extraído e o restante é conhecido como reserva do campo.

b) O número e tipo de poços se obtém com base nas características do reservatório e nos tipos de óleo e gás. É importante observar que se determina o número ideal de poços para cada campo aplicando um método que escolhe o maior valor esperado de produção, pois poços de mais ou de menos darão menor produção, e podem tornar a exploração pouco rentável.

c) A lâmina de água (LDA) é a espessura da camada de água medida da superfície livre até o fundo do mar e, junto com a profundidade, define as condições de temperatura dos hidrocarbonetos no interior dos reservatórios. Serve para indicar o tipo de exploração mais indicada. Uma exploração de um determinado reservatório pode ser inviável economicamente com uma certa profundidade e 
rentável com uma LDA menor. A profundidade tem uma importância direta nos custos de exploração. É a partir desta dimensão que se define se será utilizado um sistema fixo ou um sistema de flutuação fixa ou complacente. Nesse sentido, podemos considerar o uso das faixas seguintes:

i) Ultra-rasas: são aquelas LDA's de profundidades menores a $10 \mathrm{~m}$. Esta faixa se caracteriza por ser inacessível a sistemas móveis convencionais. Os sistemas móveis para esta faixa mais conhecidos são as "Jack-ups", as primeiras plataformas "offshore" (1932). Estas sondas de perfuração, instaladas em balsas, eram auto-elevatórias. As colunas se movimentam fazendo o convés elevar-se, permitindo perfurar e completar a produção dos poços. Dependendo das condições de onda, por se tratar de lugares onde são comuns as altas correntes e as ondas podem quebrar, a esbeltez das colunas minimiza o efeito. $\mathrm{O}$ único problema é que as ondas podem atingir o ponto de quebrar no fundo, lançando partículas fluídas a velocidades acima de um valor limite.

ii) Rasas: são LDA's entre 10 e 100 metros de profundidade $(10 \mathrm{~m} \leq \mathrm{LDA} \leq 100 \mathrm{~m})$. Podem ser ainda utilizadas as "Jack-ups" e também podemos ter a ocorrência de altas correntezas, com a vantagem de que as ondas não quebram sobre o casco da plataforma. O uso de sistemas flutuantes é as vezes uma tarefa complicada, pois a tendência é a de aumentar a rigidez horizontal do sistema de ancoragem apresentando picos de tensões na tração das amarras devido à não linearidade na interação entre o casco, o fluído e o sistema de ancoragem. Para sua exploração, é necessário um estudo que divide a faixa para utilização de "Jack-ups" convertidas para produção e para o uso de semi-submersíveis (no extremo superior da profundidade) considerando que estas são mais adequadas para os efeitos das ondas. O problema é que, com lâminas de água de 25 metros ou menos, há o perigo de choques do casco com o fundo do mar, devido aos movimentos de primeira ordem na freqüência das ondas.

iii) Médias: são LDA's entre $100 \mathrm{~m}$ e $400 \mathrm{~m}(100 \mathrm{~m}<\mathrm{LDA} \leq 400 \mathrm{~m})$. Até os $400 \mathrm{~m}$ de profundidade é possível utilizar GBS (Gravity Base Structures) tipos de estruturas fixas apoiadas no fundo do mar e que se caracterizam por serem construídas em concreto armado, fruto de uma tecnologia avançada. São muito usadas nos países da Europa, principalmente na Noruega e possuem geralmente 
tanques de armazenamento de óleo na sua base. São necessárias outras condições, pois deve haver locações em águas calmas e profundas para sua construção (por exemplo, nos Fjords noruegueses). Outras estruturas são as Torres Complacentes, também classificadas como fixas (por se apoiarem no fundo do mar), mas podem oscilar numa faixa limitada à resistência e fadiga dos materiais dos quais estão construídas.

iv) Profundas: são LDA's entre 400m e 1500m (400m $<$ LDA $\leq 1500 \mathrm{~m})$. Esta faixa é a mais difícil de definir por se tratar de uma limitação tecnológica momentânea, devido ao tipo de ancoragem e à tecnologia dos "risers" e “flowlines" flexíveis, isto no caso do Brasil concentra a utilização de FPSO's e semi-submersíveis quando se trata de "completação" submarina (ou molhada) e de TLP's de haver a necessidade da "completação" seca.

v) Ultraprofundas: são láminas de água acima de 1500 metros (LDA $>1500 \mathrm{~m})$.

Quanto às condições ambientais e aos fenômenos que influenciam diretamente na exploração de petróleo no mar, definimos os seguintes:

a) Correntes - São movimentos de massas de água no mar, provocados pela rotação da Terra, pelos ventos e pelos gradientes de temperatura. Uma característica importante das correntes é a velocidade de deslocamento em relação ao elemento que recebe sua influência. Para servirem como elemento de especificação de projetos, são informadas em relação a um referencial fixo à Terra.

b) Ventos - São os movimentos de massas de ar, provocados por gradientes de temperatura e pressão, entre outros, e, assim como as correntes, se caracterizam pela velocidade de deslocamento, sendo medida com referencia a um elemento fixo à Terra.

c) Ondas - São formadas pelas perturbações e movimentos na superfície da água, caracterizadas pela sua altura ou amplitude e pela sua freqüência ou período. Também podem ser regulares ou irregulares.

A figura 2.1 apresenta um esquema típico de distribuição de poços no fundo do mar. 


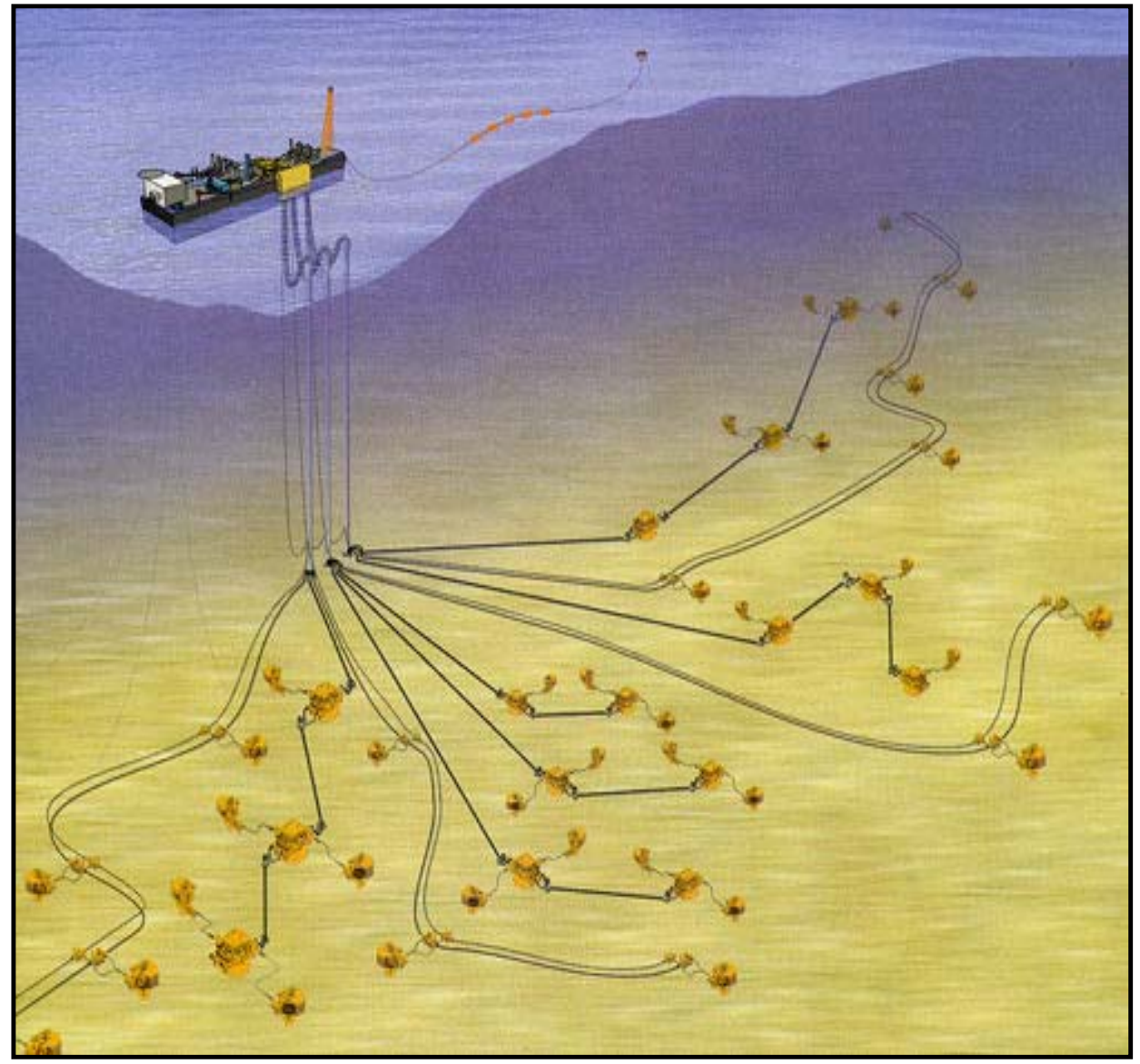

Figura 2.1: Vista de um campo no fundo do mar

\subsection{O Método Clássico da Espiral de Projeto}

O projeto naval envolve várias disciplinas para se ter certeza de atender aos requisitos solicitados.

A seguir está exposto o método de projeto em uso na engenharia naval e oceânica, em suas aplicações a embarcações e a outras estruturas flutuantes, como as instalações FPSO.

O método clássico para o projeto de um sistema naval e oceânico é a espiral de projeto. O conceito foi sugerido pela primeira vez por J. Harvey Evans (1954) para projetar de forma coerente um navio, na sua época, sendo dotado de uma estrutura seqüencial e interativa, caracterizada pela tendência ao produto final e ao aprofundamento do nível de informações, assim como do detalhamento. O procedimento utilizado por engenheiros e arquitetos navais para traduzir os requerimentos do projeto do navio num critério específico de projeto é descrito como 
uma espiral. Por tratar-se de uma estrutura flutuante, a instalação FPSO se considera um dos projetos que podem ser estruturados por meio desta metodologia.

A espiral inicia-se com os requisitos do projeto, normalmente solicitados pelo armador; no caso de companhias de petróleo, por estas ou pela empresa operadora do sistema. Ela é percorrida dirigindo-se sempre para o centro de convergência.

A espiral de projeto é um modelo de cálculo racional que segue uma seqüência, seu esquema indica o estágio em que se encontra. As linhas radiais indicam itens de projeto. Este método tradicional de projeto de navios é representado por um processo de séries interativas de desenvolvimento de engenharia e atividades de projeto para atingir a solução na parte central da espiral.

O término do processo indica que todos os elementos encontram-se ajustados, atendendo todas as restrições técnicas.

Inicia-se com o projeto conceitual, após a análise interativa e de um ou vários giros, ou reiterações, pode-se passar para o projeto básico, que é o documento utilizado para as negociações e contratos. A quantidade de giros necessários depende da profundidade e qualidade da informação e da capacidade de análise e síntese do profissional ou da equipe atuante. Após a avaliação, por parte do armador, do projeto básico, se procede ao projeto de contrato, que toma como base o projeto anterior e elabora uma série de planos e especificações em detalhe suficiente para que permita ao estaleiro construtor formalizar o contrato de construção. O projeto de detalhamento é o documento que serve de base para a execução do produto naval requerido.

Esta forma de distribuição é feita porque não se tem a certeza de atingir todos os requisitos estabelecidos em qualquer uma das etapas.

A autorização para prosseguir é normalmente definida na forma contratual para poder continuar avançando no projeto.

O projeto conceitual começa da formulação dos requisitos para a construção do navio ou da instalação, podendo ser ou não inteiramente executado pelo armador, já que nem sempre este dispõe de corpo técnico habilitado.

O projeto básico ou preliminar é desenvolvido comparando e relacionando uma série de variáveis que devem ser utilizadas para estabelecer os parâmetros mais importantes. 
O projeto de contrato define as especificações de maquinário, equipamentos, acessórios, materiais e aspectos construtivos que permitem avaliar o alcance do projeto, dando uma base para a colocação de custos.

O projeto de detalhamento ou de construção serve de guia para a fabricação do navio e requer normalmente a aprovação de autoridades competentes como as Sociedades Classificadoras.

As etapas em que é organizado o método, como mostra a figura 2.2, são as seguintes:

1. Requisitos ou especificações do armador.

2. Proporções, dimensões principais.

3. Curvas Hidrostáticas. Bonjean.

4. Estimativa de Potência.

5. Estabilidade Intacta.

6. Estabilidade com avaria.

7. Estrutura.

8. Arranjo Físico (máquinas, equipamentos, hotelaria).

9. Sistemas de emergência: incêndio, evacuação, resgate.

10. Estimativa de Custo. 


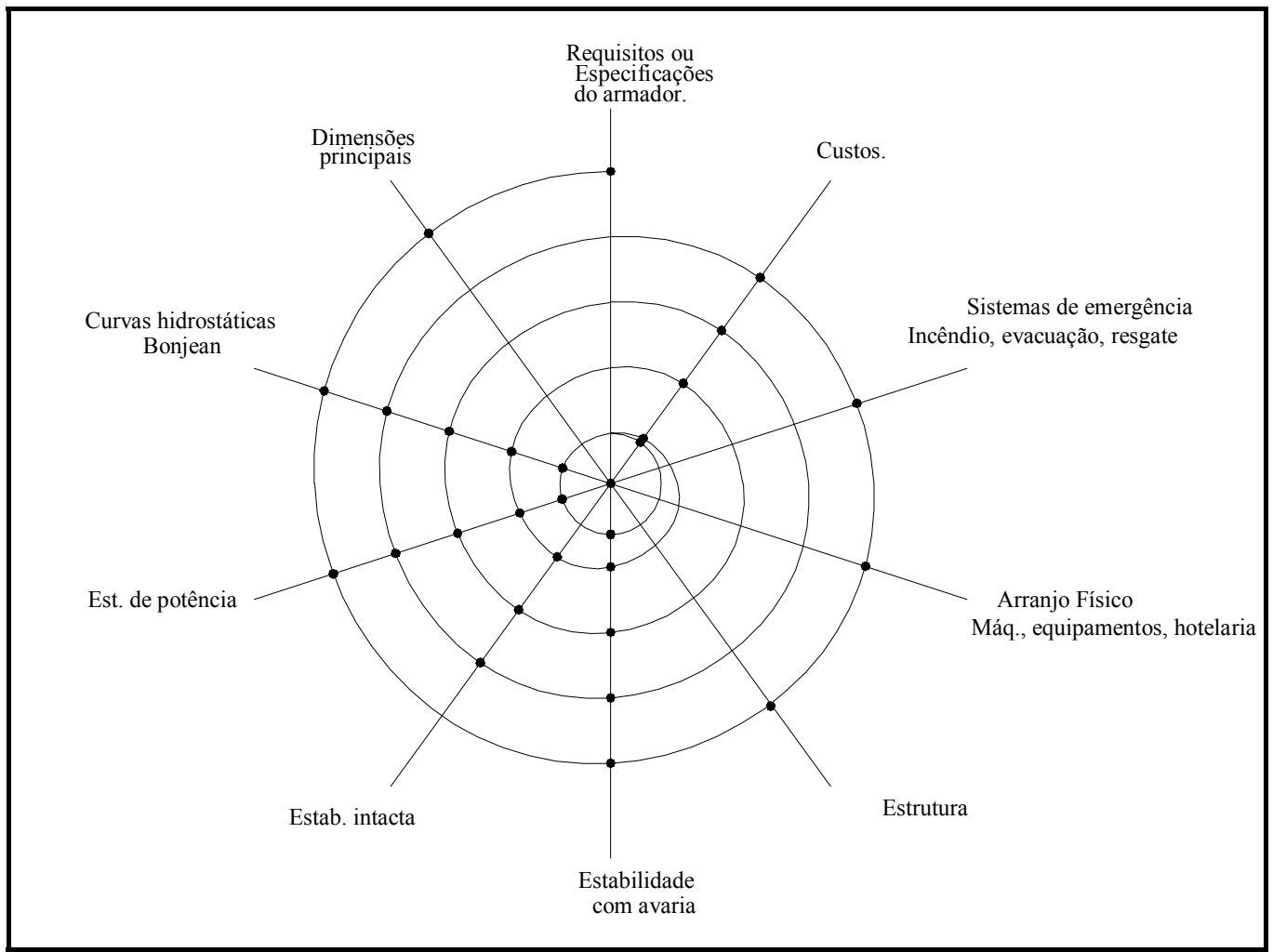

Figura 2.2: Espiral de Projeto de Embarcação

$\mathrm{Na}$ fase de concepção de projeto, deve-se dispor do maior número possível de informações de navios semelhantes com a finalidade de utiliza-los como orientação para as possíveis soluções. Navios semelhantes não significa que sejam geometricamente iguais, mas que possuam as características do navio a ser estudado.

Devem-se identificar navios que possam cumprir os requerimentos do projeto e verificar dados dos mesmos, utilizando-os como roteiro básico do projeto.

\subsubsection{Requisitos Básicos para o projeto de embarcações.}

No projeto de embarcações tem que ser considerados além dos elementos comuns citados anteriormente, outros que são identificados como específicos.

Começando pelos requisitos ou especificações do armador, que em geral consistem numa descrição da missão que deverão cumprir as embarcações. É importante caracterizar o tipo de missão, pois de tratar-se de navios, como elementos de transporte em geral, terão que satisfazer o requisito de velocidade de deslocamento, requisito este que não é importante para a missão da instalação FPSO. 
Esta característica terá influência no dimensionamento e projeto do casco e do sistema de propulsão, sendo este último de pouca importância na instalação FPSO.

Segundo o critério das dimensões principais, as embarcações podem ser classificadas em quatro grandes grupos:

a) embarcações transportadoras de peso morto "dead weigth"

b) embarcações transportadoras de volume

c) embarcações com restrições dimensionais (por exemplo tipo Panamax etc.) onde a rota impões restrições de calado e outras.

d) navios especiais

\subsubsection{Dimensões Principais}

a) As embarcações transportadoras de peso morto têm particularidades que permitem traçar suas dimensões principais a partir das seguintes equações empíricas:

i. Fórmula inglesa:

$\mathrm{W}_{\mathrm{D}}=0,353\left(\mathrm{C}_{\mathrm{b}} \times \mathrm{L} \times \mathrm{B} \times \mathrm{P}+\mathrm{A}\right)$

Sendo :

$\mathrm{W}_{\mathrm{D}}$, a tonelagem bruta;

L, o comprimento do convés medido entre as faces interiores do forro em metros;

B, a boca moldada em metros;

$\mathrm{P}$, o pontal, medido no plano diametral, desde a superfície interior do forro do convés de arqueação, até a face superior do forro interior do fundo do porão em metros (excetua-se o duplo fundo);

A, o volume das superestruturas, em metros cúbicos;

$\mathrm{C}_{\mathrm{b}}$, coeficiente de bloco;

$\mathrm{O}$ coeficiente de bloco é a relação entre volume deslocado $\mathrm{V}$ e o volume do paralelepípedo que tem por arestas respectivamente $\mathrm{L}_{\mathrm{pp}}$ : comprimento entre PP; $\mathrm{B}_{\mathrm{M}}$ : boca máxima da parte imersa; e $\mathrm{C}$ : calado médio.

$$
\mathrm{C}_{\mathrm{b}}=\mathrm{V} /(\mathrm{L} \times \mathrm{B} \times \mathrm{C})
$$

Coeficiente prismático, coeficiente cilíndrico ou coeficiente longitudinal é o coeficiente da relação entre o volume deslocado e o volume de um 
sólido que tenha um comprimento igual ao comprimento do navio na flutuação e uma seção transversal igual à da parte imersa da seção mestra.

$$
\mathrm{C}_{\mathrm{p}}=\mathrm{V} /(\mathrm{A} \times \mathrm{L})
$$

Coeficiente da seção a meia nau, é a relação entre a área da parte imersa da seção a meia nau e a área do retângulo circunscrito.

$$
\mathrm{C}_{\mathrm{MN}}=\mathrm{A} /(\mathrm{B} \times \mathrm{C})
$$

Estes coeficientes são normalmente determinados e seguem um padrão.

\begin{tabular}{|c|c|c|c|}
\hline Navio & $\mathrm{C}_{\mathrm{b}}$ & $\mathrm{C}_{\mathrm{MN}}$ & $\mathrm{C}_{\mathrm{p}}$ \\
\hline Navios Tanques & 0,76 & 0,97 & 0,77 \\
\hline Cargueiros Grandes & 0,78 & 0,99 & 0,78 \\
\hline
\end{tabular}

Tabela 2.1: Valores médios de coeficientes de forma Fonseca(1989)

ii. Fórmula portuguesa:

$\mathrm{W}_{\mathrm{D}}=0,18 \times \mathrm{L} \times[1 / 2 \times(\mathrm{B}+\mathrm{M})]^{2}+\mathrm{A} \times(1 / 2,83)$

Sendo:

$\mathrm{W}_{\mathrm{D}}$, a tonelagem bruta;

L, o comprimento do convés medido entre as faces interiores do forro em metros;

$\mathrm{B}$, a boca máxima em metros;

M o perímetro do a seção mestra, limitado pela interseção da face superior do convés com o forro exterior em metros; (pode ser obtido pela corrente da camisa de colisão);

A, o volume das superestruturas, em metros cúbicos.

b) As embarcações transportadoras de volume têm uma equação específica:

$$
\mathrm{V}_{\mathrm{h}}=\mathrm{C}_{\mathrm{bD}}=\frac{(V r-V u)}{(1-s)}+\mathrm{V}_{\mathrm{m}}
$$

Sendo:

$\mathrm{C}_{\mathrm{bD}}$ coeficiente de bloco moldado no pontal.

$\mathrm{V}_{\mathrm{h}}$ volume total, em $\mathrm{m}^{3}$ do navio sob o convés superior entre perpendiculares;

$\mathrm{V}_{\mathrm{r}}$ capacidade total de carga requerida $\mathrm{em}^{3}$;

$\mathrm{V}_{\mathrm{u}}$ capacidade de carga sobre o convés em $\mathrm{m}^{3}$; 
S dedução devido à estrutura, nos espaços de carga expressada como proporção do volume moldado nesses espaços.

$\mathrm{C}_{\mathrm{m}}$ volume requerido para operação do navio, maquinaria, equipamentos, tanques de combustível etc.

c) Embarcações com restrições dimensionais, são aquelas que devido ao tipo de missão que é solicitada pelo armador, vem suas dimensões de boca e calado limitados. Por exemplo, o caso dos navios que devem circular através do canal de Panamá que tem uma restrição de boca máxima de 32,2 metros e um calado máximo de 13 metros. Estes são denominados "Panamax"; embarcações especiais, são consideradas as demais embarcações como, rebocadores, iates, veleiros, chatas, etc.

Segundo Leite (2000),no caso da instalação FPSO o conceito geométrico foi otimizado, surgindo como diferencial o formato RamForm, trata-se de um projeto de casco onde a boca máxima do mesmo coincide com a popa, embora a experiência ainda não é suficiente para obter conclusões a respeito. $\mathrm{O}$ elemento de controle que pode apresentar alguma influência é a manutenção do leme, dependendo da posição da "turret".

Para instalações FPSO construídas com casco novo a relação comprimento/ boca é menor que para navios tanque.

$$
\begin{aligned}
& \text { Relação para navios tanque: } \frac{L}{B}>6 \\
& \text { Relação para FPSO : } \frac{L}{B} \geq 5
\end{aligned}
$$

Esta relação é devido a que os navios tanques necessitam ser esbeltos para melhorar sua performance na navegação, enquanto que o FPSO por se tratar de uma instalação com objetivo específico de processar e armazenar o produto da extração, tem de dar maior importância à estabilidade e ao posicionamento no mar.

\subsubsection{Curvas Hidrostáticas}

Para traçar as curvas principais, no projeto preliminar, é possível a utilização de uma metodologia de múltiplos critérios como exposto no trabalho de Andrade (2001), que agiliza a definição das curvas hidrostáticas e permite atingir um projeto 
ótimo. Estas curvas podem ser utilizadas como referência para comparação em cascos reaproveitados.

\subsubsection{Estimativa de Potência}

Nos navios em geral a estimativa de potência tem como finalidade atender a missão de transporte.

Sendo:

$\mathrm{W}_{1}$ Peso da estrutura do casco, acessórios, equipamentos, suplementos, e água potável.

$\mathrm{W}_{2}$ Peso da instalação propulsora.

$\mathrm{W}_{3}$ Peso do combustível para propulsão.

$\mathrm{W}_{4}$ Peso independente do navio, que nos mercantes corresponde a carga, lastro e margem e nos navios de guerra corresponde a margem, lastro, armamento, munição etc.

A potência pode ser expressa em termos de velocidade e deslocamento, da seguinte forma:

$$
\mathrm{W}_{1}=\mathrm{k}_{1} \times \Delta \quad \text { onde } \mathrm{k}_{1} \text { é um valor menor que a unidade, ou valor }
$$
médio entre navios do mesmo tipo.

$\mathrm{W}_{2}=\mathrm{L} \times \mathrm{SHP}$ onde $\mathrm{\iota}$ é o peso específico da máquina em termos de potência.

Por sua vez a potência pode ser expressa em termos de velocidade e deslocamento, da seguinte forma:

$$
K_{2}=\frac{S H P}{\Delta^{2 / 3} \cdot V^{3}}
$$

Onde $\mathrm{K}_{2}$ é denominado Coeficiente do Almirantado sendo estimado a partir de navios semelhantes.

Nas instalações FPSO a necessidade de geração de energia é bem maior para atender as demandas de processamento. De ser estudada uma instalação FPSO com posicionamento dinâmico as necessidades são maiores que as de posicionamento por meio de sistemas de ancoragem. 


\subsubsection{Estabilidade Intacta}

Os cálculos de estabilidade intacta são de aplicação idêntica tanto para navios tanques quanto para FPSO, e consistem numa relação de posicionamento entre o metacentro e o centro de gravidade do navio.

\subsubsection{Estabilidade com Avaria}

Consiste na verificação de comportamento do navio no caso de um acidente que possa descontrolar todo o sistema de flutuação do mesmo, é de idêntica aplicação para embarcações em geral e para as instalações do tipo FPSO. O processo faz uma simulação das avarias que podem provocar variações na estabilidade do navio, alagando os diversos compartimentos deste, que são divididos segundo a distribuição de estanqueidade definida pelo projetista.

\subsubsection{Concepção Estrutural}

A concepção estrutural de um navio, sobretudo de um navio tanque, não difere da concepção de uma instalação FPSO, esta pode ser feita aproveitando o casco de um navio transportador de petróleo já existente ou com um casco novo.

A resistência estrutural longitudinal deve ter uma importância maior, devido ao grande comprimento da embarcação, sendo que a distribuição de carga em seu interior é considerada uniforme, pelo tipo e a forma de esta. Também o navio fica em posição de alquebramento na maior parte do tempo. Como as condições de ondas oblíquas se fazem presentes em determinadas situações é necessária uma boa resistência à torção.

\subsubsection{Arranjo Físico}

Nesta etapa do projeto são analisadas as distribuições de peso dos equipamentos necessários para as diversas atividades a serem realizadas pelas pessoas a bordo da embarcação, como sistemas de processamento, ar condicionado e 
hotelaria em geral. A diferença entre uma embarcação de transporte e uma instalação FPSO, consiste em que o arranjo físico do convés é sumamente importante para atingir o objetivo principal da missão.

\subsubsection{Sistemas de Emergência}

Estes sistemas dependem do tipo de missão, o dimensionamento do equipamento contra incêndio, assim como dos sistemas de evacuação e resgate, devem ser desenvolvidos partindo dos princípios de supervivência e aplicados conforme cada caso.

\subsubsection{Estimativa de Custo}

Consiste na somatória dos custos que integrarão a embarcação considerando todos os elementos que a compõem.

\subsection{Requisitos Básicos de uma Instalação FPSO}

Em princípio pode-se considerar que uma instalação FPSO é uma planta de produção e armazenamento de petróleo e gás flutuante, que tem forma de navio.

\subsubsection{Requisitos Comuns às Estruturas Flutuantes de Exploração de Petróleo no mar}

Como neste trabalho tratamos de produtos navais e oceânicos utilizados para a produção de petróleo no mar, é importante salientar que para o desenvolvimento e análise da produção de petróleo no mar são utilizadas as espirais de projeto, logicamente que a complexidade das mesmas é muito maior que de tratar-se de um navio, também a complexidade aumentará se a produção em questão se encontra em águas rasas, profundas ou ultraprofundas.

Segundo Leite, A.J.P. em "Concepções para produção de óleo e gás offshore”(2000). “A função de toda e qualquer estrutura oceânica para produção de 
petróleo no mar é: servir de suporte à planta de processo, aos equipamentos de perfuração ou de produção quando for o caso, e aos condutores (risers) de produção e extração". Neste estudo a atenção estará focada no caso de pré-seleção de uma instalação tipo FPSO.

Os tipos de FPSO existentes de acordo com seu sistema de posicionamento no local, são basicamente três:

1. SMS "Spread Mooring System" possui várias linhas de ancoragem, em catenária simples ou utilizando flutuadores in-line "spring buoys" ou pesos "clamp weights" intermediários, ancorados ao fundo do mar através de âncoras de arrasto ou estacas. Outra extremidade das linhas é conectada ao navio em pontos localizados no seu perímetro, portanto mantendo o aproamento praticamente fixo.

2. SPM "Single Point Mooring", a diferencia do SMS, o SPM permite que o aproamento da embarcação varie conforme a direção da resultante dos agentes ambientais, possui um ponto de pivotamento ancorado no fundo do mar que permite a embarcação girar livremente no plano horizontal.

Há três tipos de SPM:

a) CALM "Catenary Anchor Leg Mooring" consiste em uma bóia de grande porte ancorada ao fundo do mar por linhas em catenária. A embarcação é conectada através de cabos denominados "soft-calm" ou através de braços rígidos e articulados "yoke", neste caso "Calm-yoke".

b) SALM "Single Anchor Leg Mooring", sistema composto de uma estrutura flutuante de ancoragem para FPSO, fixada a sua vez ao fundo do mar por uma conexão articulada.

c) TURRET MOORING, a embarcação é conectada rigidamente (o único grau de liberdade é o movimento horizontal) a uma estrutura cilíndrica (turret) a qual está ancorada ao fundo do mar através de catenárias.

3) Posicionamento Dinâmico, sigla em inglês DP e "TAS" Sistemas Assistidos por Impulsores convencionais e laterais ou azimutais, que agem em forma automática, mantendo a posição e aproamento desejados, os hélices convencionais são utilizados apenas para auxiliar o sistema de ancoragem. 
Ainda segundo Leite, os requisitos básicos para o projeto baseado nas opções de aplicação para um determinado campo definido, como tipo de risers, jaquetas em LDA's profundas, e as condições dos agentes ambientais do local (correntes, ventos, ondas etc.) são os seguintes.

- Peso da planta de processo e das facilidades necessárias.

- Área total para planta e facilidades, incluindo informações sobre se a área deve ser coberta ou não.

- Carga proveniente de "risers".

- Bóia de conexão ou "turret", com descrição dos tipos de risers.

- Tipo, dimensão e pesos dos equipamentos de completação, árvores de natal molhadas (ANM) ou secas (ANS).

- Capacidade de armazenamento do óleo e gás produzidos.

- Sistema de ancoragem.

- Consumíveis.

- Acomodações.

\subsubsection{Requisitos Específicos para Instalações FPSO}

As sociedades classificadoras cobrem uma variedade de instalações flutuantes incluindo plataformas de perfuração, plataformas do tipo semi-subs, TLPs e SPARs, e inevitavelmente fazem referência às normas de classificação de navios.

Segundo o UKOOA FPSO Design Guidance Notes for UKCS Service os elementos que influenciam a seleção e projeto de uma instalação FPSO são os dez seguintes:

1) Localização e meio ambiente.

2) Função e vida útil do campo.

3) Layout.

4) Distribuição de pesos e dimensões.

5) Seleção da embarcação.

6) Movimentação na instalação FPSO. 
7) Dimensão da tripulação e instalações do pessoal.

8) Regulamentações aplicáveis no projeto.

9) Normas.

10) Segurança e saúde com relação ao meio ambiente

\subsubsection{Localização e Meio Ambiente}

A localização e o meio ambiente influenciam os seguintes elementos do projeto:

- Estabelecimento das restrições de projeto para os sistemas de ancoragem da "turret" que permitem minimizar as cargas do sistema de ancoragem da instalação FPSO dependendo da localização e das condições climáticas do local.

- Escolha de tamanho e forma de casco apropriado e com boas características de mobilidade.

- Convés.

- Projeto dos elementos de produção para minimizar as paradas.

- Medida do casco para proporcionar uma armazenagem adequada minimizando problemas entre tempos de carga dos navios aliviadores.

- Projeto da estrutura do casco considerando esforços e fadiga.

- Projetos e processos das instalações marinhas.

Outro requisito que orienta a definição da vida útil da instalação FPSO é a especificação da durabilidade desta sem ter que fazer revisões e inspeções em doca seca pelo período de produção do campo. Existe um potencial de falha nas instalações marinhas de "risers" e ancoragem, a ser levado em conta, com as conseqüências normais de desconexão e conexão em caso de problemas ambientais, com a perda de produção e o possível derramamento de óleo. Por outro lado em caso de acontecer problemas de consertos estruturais resulta muito onerosa a reforma dos cascos para permitir atingir a extensão da vida útil requerida já que os custos de reparações "in situ" são de tal porte que incentivam à necessidade de construção de novas instalações em substituição daquelas que precisam de reparações maiores. 


\subsubsection{Função e Vida Útil do Campo}

A função e a vida útil do campo influenciam os seguintes elementos do projeto:

A função de uma instalação FPSO é determinada pelo tipo e quantidade de fluidos que deve processar e transferir, assim como pelas condições necessárias de armazenagem da sua produção de petróleo. O tamanho do reservatório em termos de reservas e produtividade tem grande influência tanto no dimensionamento da planta de processamento quanto ao tempo de permanência da instalação no campo. O sistema de transferência do produto também terá que ser considerado na determinação da necessidade de armazenagem.

Quando uma embarcação existente seja comparada com uma nova, o propósito de construir uma nova deve ser considerado como uma aplicação específica. É importante observar que a vida útil da instalação existente é limitada pela sua vida útil remanescente em função do tempo de utilização e da vida útil de projeto.

Uma instalação FPSO convenientemente projetada para desenvolver um campo deve considerar: a) os elementos que influem no tamanho do casco e, b) o dimensionamento da planta de produção e dos equipamentos, que são fundamentais para os armadores, operadores e projetistas.

Os principais elementos que influem para determinar o tamanho do casco da instalação FPSO são:

i) Armazenagem de óleo cru.

Deverá projetar-se o casco considerando os valores do pico de produção e se a capacidade é suficiente para cobrir o ciclo dos navios aliviadores entre cada transferência.

O ciclo compreende:

- Tempo de carga no campo.

- Tempo de navegação desde e para o porto (incluindo atrasos por mau tempo).

- Tempo de descarga no porto.

- Tempo de conexão e desconexão ao FPSO. 
- Previsão de demoras nas conexões com a instalação FPSO devido a mau tempo.

Outra prática que influi no projeto do volume de armazenagem, se o navio aliviador forma parte de um "pool” com dimensões comuns, é que a capacidade na FPSO deve ser do mesmo tamanho para permitir que os navios aliviadores regulem o ciclo.

Para campos de grande capacidade, é economicamente mais correta a utilização de navios aliviadores adicionais, e conseguir desta forma maior freqüência na descarga durante os picos de produção, do que optar pelo aumento da capacidade de armazenagem. Quando o campo se encontrar no final da sua vida e a produção decline poderá diminuir-se a quantidade de navios aliviadores, considerando a possibilidade de compartilhar o serviço destes com outros campos de produção.

Se fosse utilizado um casco de navio aproveitado de um petroleiro, as possibilidades de coincidir com a dimensão do casco ideal projetado são remotas, e de resultar este com uma capacidade menor, a solução poderia ser a utilização de uma maior freqüência nos navios aliviadores e, de resultar uma capacidade de armazenagem maior daquela especificada no projeto, provocará um incremento no custo devido ao aumento do dimensionamento nos sistemas de ancoragem.

No caso de utilizar um sistema de dutos para a transferência da produção ou de possuir um navio FSO, o dimensionamento do casco poderá ser reduzido tendo somente que ser observado o espaço mínimo necessário para o processamento dos produtos extraídos assim como as condições de navegabilidade.

\section{ii) Espaço no convés}

Para pequenos e médios campos de produção as dimensões dos cascos provêem automaticamente o espaço necessário no convés para a instalação dos equipamentos de processamento. Para grandes campos onde os equipamentos de produção se complicam pela injeção de água e gás, o casco pode não ser grande o suficiente e possuir um convés com espaço limitado para instalar tudo num mesmo nível, fazendo necessária a construção de novas estruturas. Nas novas instalações 
poderá ser preferível o aumento do casco antes do que ter de construir estruturas acima do convés.

iii) Viabilidade de conversão de navios tanques.

As dimensões dos cascos de navios tanques para conversão em FPSOs, dependem da viabilidade e existência de unidades apropriadas. Os critérios técnicos são:

- Condições estruturais (com ênfase no projeto à fadiga).

- Dimensões razoáveis que permitam a minimização dos custos de ancoragem (sobre tudo em condições ambientais adversas).

- Armazenagem adequada e capacidade de lastro suficiente, alem do layout dos tanques para minimizar o derramamento.

- Espaço no convés adequado e capacidade de carga.

iv) Desempenho no mar.

O desempenho no mar é função do tamanho e da forma do navio, e sua performance influi nos seguintes elementos:

- Segurança da tripulação e operacionalidade.

- Alta produção na extração.

- Operacionalidade dos helicópteros.

- Movimentação dos terminais dos "risers" dentro das limitações.

De analisar cascos pequenos ou de formas inovadoras é necessário uma análise profunda de cada caso.

Para o item b) dimensionamento da planta e dos equipamentos de produção.

Os elementos chaves para o dimensionamento das cargas no convés devido aos equipamentos e ao processamento são:

- A quantidade de sistemas a instalar

- Características do reservatório.

- Escolha das rotas de transferência.

- Linhas de processamento simples ou duplas.

- Possibilidade de reaproveitamento em outro campo. 
Com referência à quantidade de sistemas a instalar, eles dependerão da:

i) a quantidade de petróleo a separar da água e do gás;

ii) processamento de gás (desidratação e compressão) e possível transferência;

iii) tratamento da água extraída manuseio e re-injeção;

iv) tratamento da água do mar e injeção;

v) transferência de petróleo cru por meio de aliviadores ou dutos;

vi) geradores principais, número e tamanho das unidades.

As informações sobre as características do reservatório têm máxima influência na especificação dos equipamentos para processamento, é necessária muita confiabilidade nas informações de:

i) perfil de produção para petróleo, gás e água extraída;

ii) estimativa do tempo de produção do campo;

iii) possibilidade de ampliação da extração em campos visinhos;

iv) pressão do reservatório e dimensionamento da quantidade e forma da re-injeção de gás e água;

v) proporção de gás e petróleo e condições de impulsão pelo gás;

vi) propriedades dos fluidos a extrair como: conteúdo de ceras, viscosidade e peso específico;

vii) temperaturas de chegada ao FPSO;

No caso de necessitar de injeção de água, as unidades de tratamento desta, assim com as de retirada do ar, deverão ser dimensionadas em forma coerente.

Um conhecimento profundo e confiável das informações sobre o reservatório é necessário para:

- minimizar as mudanças tardias no projeto e seu impacto para o programa de construção e orçamento;

- reduzir os riscos de solicitações dos equipamentos em níveis maiores daqueles para os que foram projetados. 
É possível a utilização de instalações do tipo FPSO em reservatórios com informações pouco confiáveis ou por um período curto de tempo para obter melhores informações e otimizar as condições de exploração futuras do mesmo.

A escolha do sistema de transferência dos fluidos influirá no tamanho da planta, não somente nas quantidades do fluído, como no caso de escolher que a transferência se faça através de dutos ou aliviadores, senão também no nível de separação requerido pelo petróleo especificado para cada rota. No caso de petróleos pesados, viscosos ou parafínicos, quando a temperatura de chegada do fluído é baixa, será necessário o aquecimento deste, o que imporá a necessidade de equipamentos de aquecimento, com geradores de gás e outros elementos.

Linhas de processamento simples ou duplas? O armador da instalação FPSO deverá decidir se esta requer de uma linha simples ou dupla para o processo e sobre a compressão de gás. $\mathrm{O}$ armador deverá avaliar se é mais conveniente correr o risco de utilizar uma única linha de processamento e no caso de uma parada perder de fornecer o produto ou investir um pouco mais dotando à planta de uma linha dupla de processamento, decisão esta que duplicará a segurança da operação.

No caso da escolha de uma linha única de processamento, será necessária a confecção de uma lista de equipamentos e partes sobressalentes para serem substituídos em caso de falhas e assim poder executar um melhor gerenciamento do sistema.

Quando a instalação FPSO for alocada para um campo com período curto de tempo, por exemplo, quatro ou cinco anos, enquanto se define e constrói a instalação definitiva ou perante a possibilidade de reaproveitamento em outro campo, em ambos casos a percepção das oportunidades de marketing serão as informações que poderão propiciar a instalação de dispositivos e peças especiais no sistema.

\subsubsection{Layout}

O layout da instalação FPSO dependerá das seguintes condições: se for nova, propositadamente construída; se for construída com reaproveitamento de casco; ou de ser uma unidade existente reformada. 
Com uma nova, propositadamente construída, o projetista terá duas decisões importantes a fazer que influirão em toda a distribuição, a escolha de posicionamento da superestrutura, e a escolha da posição da bóia de conexão "turret". No caso de uma existente o posicionamento da superestrutura já está definido ficando somente a escolha do posicionamento da "turret".

A principal consideração é com referência à segurança do pessoal e a redução de exposição a problemas previsíveis numa instalação de armazenagem e processamento de petróleo e gás. Qualquer configuração que for escolhida com estes princípios irá minimizar a chance de acontecer problemas e levar estes longe da superestrutura onde mora o pessoal. Considerará também os refúgios temporários e os principais pontos de evacuação.

a) A escolha da posição da Turret” ou bóia de conexão pode ter várias possibilidades:

i) a proa

A colocação a proa da bóia de conexão permitirá à instalação FPSO um posicionamento livre da necessidade de propulsão. São retiradas do casco as solicitações e esforços da parte central e não são necessários reforços estruturais na região longitudinal. Isto é sumamente importante no caso de reforma de navios tanque.

As limitações de oscilações de parte da embarcação, pitch, roll, e movimentos verticais. O esforço estrutural produzido por esta causa.

ii) À frente da parte central, permite rotações de até 270 graus e o sistema pode posicionar-se em calmaria.

b) Superestrutura

Nos petroleiros convertidos em FPSO é comum a conservação do lugar da superestrutura, e aposentos.

Para "turrets" a proa, a colocação da superestrutura é feita na popa para conseguir o máximo afastamento dos possíveis acidentes que podem acontecer na conexão principal e nos equipamentos de produção.

Para "turrets" situadas na parte central do navio a superestrutura é colocada a proa, o mais afastada possível. A possibilidade de movimentação do pessoal de bordo assim como a operacionalidade do helicóptero devem ser checados num 
estagio anterior ao de projeto final, pois nesta posição do navio se fazem sentir energicamente os efeito do heave e do pitch.

\begin{tabular}{|c|c|c|}
\hline Posição & Vantagens & Desvantagens \\
\hline A proa & $\begin{array}{l}\text { - A superestrutura e o } \\
\text { heliporto encontram-se a } \\
\text { barlavento dos problemas } \\
\text { maiores que possam se } \\
\text { apresentar com incêndio ou } \\
\text { fumaça numa emergência. }\end{array}$ & $\begin{array}{l}\text { - Grande movimento vertical na } \\
\text { proa pode afetar o conforto da } \\
\text { tripulação e as operações do } \\
\text { helicóptero. } \\
\text { - O movimento de ancoragem } \\
\text { natural da instalação FPSO é } \\
\text { difícil de conseguir sem a } \\
\text { aplicação de um sistema de alta } \\
\text { pressão no "swivel" próximo da } \\
\text { superestrutura. } \\
\text { Uma "turret" colocada a meia nau } \\
\text { consegue a separação entre } \\
\text { superestrutura e o "swivel" de alta } \\
\text { pressão, mais requer potência de } \\
\text { empuxo substancial para a } \\
\text { orientação preferencial do FPSO. }\end{array}$ \\
\hline A meia nau & $\begin{array}{l}\text { - Reduz o movimento vertical } \\
\text { (comparado à proa) para } \\
\text { maior conforto da tripulação } \\
\text { e das operações do } \\
\text { helicóptero. } \\
\text { - Orientação natural da } \\
\text { instalação FPSO pode ser } \\
\text { atingida sem empuxo. } \\
\text { - Ampla separação entre a } \\
\text { superestrutura e o "swivel" } \\
\text { de alta pressão. }\end{array}$ & \\
\hline
\end{tabular}

Tabela 2.2: Comparação do posicionamento da superestrutura. 
b) Deck para helicóptero

O deck para helicóptero é na maioria dos projetos, posicionado acima da superestrutura, por razões de segurança e logísticas, eventualmente pode ser colocado a proa ou a popa da instalação FPSO. Deve se tomar em conta as correntes de ar em volta da instalação FPSO, turbulências específicas, componentes verticais da velocidade do vento, térmicas de ar quente e chamas soltas provenientes dos queimadores. A parte superior do deck para helicóptero deve estar afastada do topo da superestrutura permitindo um espaço, que assegure um fluxo de ar livre e desimpedido, de ser necessário pode ser estudado em um túnel de vento.

c) Rota de Fuga e Evacuação

Nos estudos e desenvolvimento do layout dos sistemas principais de produção a localização das rotas de fuga dessas áreas em direção à superestrutura e aos refúgios temporários é de maior importância.

No caso de FPSO com grandes plantas de produção a parte livre do convés é consideravelmente menor que aqueles cuja capacidade de produção é reduzida.

É importante que a tripulação tenha livre acesso às rotas de escape nos primeiros momentos do acidente para assegurar umas saídas rápidas das áreas congestionadas ou densamente utilizadas na produção.

Um ou mais túneis de escape podem ser previstos para prover uma passagem livre desde os postos de trabalho até a superestrutura. Estes túneis devem ser dimensionados para resistir e proteger o pessoal dos efeitos majores de explosões ou incêndios, também deve permitir o acesso livre e desimpedido aos bombeiros e ao resgate.

O posicionamento dos túneis também deve ser tal que estes percorram o convés principal ao longo da planta de produção, como mínimo. Devem ser feitos estudos da segurança não somente de resistência destes e também podem ser projetados para ficarem totalmente isolados e até pressurizados, ou podem possuir uma parte livre ao mar aberto.

Deve ser assegurada a passagem livre de obstruções tanto dentro como fora destes túneis, este princípio deve manter-se para as áreas fechadas como o casco, casa de máquinas, tanques e superestrutura. 
Também é importante analisar as rotas de escape secundárias a serem utilizadas quando as principais estão impedidas de serem utilizadas.

d) Evacuação

O sistema de evacuação principal deve ser via helicóptero, sujeito a viabilidade e proximidade de utilização deste meio, sujeito às condições do clima.

Quando se escolha além do helicóptero outro meio para ser utilizado como botes salva-vidas ou rampas de escape este devem ficar próximos dos refúgios temporários.

Pontos secundários de evacuação devem ser previstos tanto nos túneis quanto nos refúgios temporários, aumentando as possibilidades da fuga.

e) Queimadores, Exaustores e Tubulações de ventilação.

- Queimadores

A posição das estruturas dos queimadores que eliminam os gases remanescentes do processo, é influenciada substancialmente pela localização da superestrutura, um depende do outro em forma direta. Uma vez decidida a posição da estrutura dos queimadores livres, deve ser analisada com cuidado a localização dos aquecedores do processo e do escape de gases pertinentes a estes, para que atinjam uma pressão compatível com a do sistema de combustão dos gases excedentes.

Devem ser seguidas normas de exposição humana às radiações para projetar todo o sistema, incluindo estruturas vizinhas.

A ocorrência potencial de "flaming rain" ou "chuva de fogo" devido ao queimado de substâncias líquidas, e seu despejo em áreas de produção também deve ser levado em conta no momento da definição do layout.

\section{- Exaustores}

A exaustão ou saída dos gases decorrentes do processo de geração principal de energia ou das turbinas de compressão é dominante no projeto do convés. Além do que a localização das turbinas deve manter-se afastada da circulação e não resulta uma decisão muito simples. As turbinas que provém a potência elétrica principal devem localizar-se o mais afastadas possível dos pontos de risco. 
No caso de reformas e aproveitamento de navios existentes pode manter-se a casa de máquinas principal, sempre considerando a interação que terão os condutos de escapes de gases com as áreas de trabalho adjacentes.

- Tubulações de ventilação

As tubulações de ventilação dos tanques têm pontos de descarga atmosféricos que devem considerar em sua distribuição, a elevação com referência ao convés principal.

Um túnel de vento pode ser utilizado para verificação da incidência destes gases no convés, assim como de todos os efeitos anteriores que podem incidir na segurança da instalação.

\subsubsection{Distribuição de Pesos e Dimensões}

a) Distribuição de pesos

O peso da instalação FPSO esta regida pelo peso do óleo armazenado e pelo peso do casco, os equipamentos de produção representam uma pequena porcentagem do total, geralmente $5 \%$ a $7 \%$, ao contrario que outros tipos de estruturas flutuantes de produção e processamento de petróleo o peso próprio da planta não é crítico do ponto de vista da estabilidade da embarcação. O controle do peso dos equipamentos de produção é importante no projeto da estrutura de produção propriamente dita e nos reforços a serem instalados no convés durante a fabricação da instalação FPSO.

Deve ser mantido um controle dos pesos e do posicionamento destes em referência aos centros de gravidade e metacentro, já que estes podem ser utilizados em forma positiva na distribuição de pesos.

O primeiro objetivo no projeto é determinar o centro de gravidade sem carga, e metacentro, com os tanques vazios e sem fluídos na planta de processamento, para ser confirmado após a construção da instalação FPSO com ensaios de inclinação etc.

É muito importante introduzir e ajustar o programa de monitoramento e gerenciamento de pesos desde os primeiros momentos do projeto, incorporando estas informações nas especificações estruturais e outras. 
b) Controle do espaço

A dimensão da área do convés tem facilitado a sua utilização tendo como critérios a segurança e o custo, isto pode levar ao projetista a pensar que não existem limitações, mais para os casos complexos de alto índice de extração, os problemas que se apresentam, por exemplo, na localização de painéis elétricos as vezes relegados ao casco, impedem o acesso para manutenção, provocando atrasos na produção. Por outro lado poderá ser colocado equipamento crítico em lugares onde pode ser mais vulnerável às solicitações marítimas.

O espaço do convés pode vir a ser aumentado pelo projetista utilizando tanto da ampliação do casco, quanto de um convés duplo, dependendo da análise custo/eficiência.

O controle do espaço deve ser considerado no projeto antes do projeto final do casco por motivos de segurança e operacionalidade.

\subsubsection{Seleção da Embarcação}

a) Fatores de seleção

A seleção da embarcação é governada pelas especificações do campo de extração e também depende do seu potencial de uso. As escolhas estão pautadas em:

- Fatores técnicos, (dimensões dos equipamentos, cargas devido ao meio ambiente).

- Considerações comerciais.

- Vida útil do campo.

- Manutenção, reparação e inspeções "in-situ” (especialmente para campos de vida útil extensa)

- Disponibilidade e adequação das embarcações para conversão.

As embarcações poderão ser analisadas em três categorias:

i) Nova embarcação.

ii) Adaptação e conversão de navio tanque de uso comercial.

iii) Conversão de tanque em construção.

Tratando-se de uma nova embarcação, esta oferece a oportunidade de um projeto à medida das necessidades do campo e oferece as seguintes vantagens: 
- Otimização das dimensões permitindo menores custos do casco e do sistema de ancoragem.

- Otimização da performance hidrodinâmica.(navegabilidade, operações no mar)

- Sistemas estruturais projetados para os requisitos de serviço e duração da vida útil.

- Novos sistemas estruturais projetados para minimizar custos.

- Otimização do custo benefício no ciclo de vida útil.

Novos projetos e construções são necessários quando as conversões são inviáveis, por exemplo, insuficiente capacidade de armazenagem ou espaço para plantas de processamento de grande porte ou também, quando a reforma seja antieconómica, para adequação a um campo de grande produção ou condições severas de meio ambiente.

No caso de adaptação de um navio tanque comercial em uso, torna-se uma solução para os problemas de programação de tempo, e são usualmente mais indicados para campos de dimensões meias e pequenas, assim como de vida útil de curto e meio prazo. Isto não significa que não possam existir aqueles grandes navios que possam ser utilizados nos casos extremos de capacidade, resistência e vida útil.

Os critérios básicos para seleção de embarcações adequadas são:

- Sistemas e estrutura apropriada para atingir a durabilidade necessária e a vida útil do campo.

- Viabilidade para executar um programa de extensão da vida útil.

- Dimensões razoáveis para minimizar custos dos sistemas de ancoragem.

- Capacidade e disposição da armazenagem adequada e do lastro, minimizando as possibilidades de derramamento.

- Espaço adequado no convés.

c) A conversão de tanque em construção diminui o prazo de execução do projeto, procurando utilizar este no momento em que o casco está no processo de construção. Os outros benefícios são: contar com um casco novo, e a possibilidade de adequação para o serviço específico da instalação FPSO. 
Os critérios de seleção deste tipo de embarcação são similares aos dos tanques de uso comercial, com a vantagem de se contar com um casco novo sem uso.

\subsubsection{Movimentação na Instalação FPSO}

a) Comportamento humano

A instalação FPSO está em movimento constante, ainda em condições do mar mais calmo. É muito importante considerar uma solução para este tipo de problema que pode acontecer não somente em condições severas de navegação senão em condições climáticas favoráveis.

Um tripulante arriba a instalação FPSO por meio de um helicóptero e não tem tempo para aclimatar-se ao movimento, sendo que se espera que sua disposição seja boa o suficiente para tomar decisões e desenvolver suas rotinas de trabalho. Embora o tripulante não seja susceptível ao balanço da embarcação, deverá manter-se atento quando é empurrado sobre os equipamentos. Quando a movimentação da instalação FPSO se torne mais pronunciada a necessidade de preservar a estabilidade será maior, pois é importante que os tripulantes prestem atenção a sua auto-proteção.

O comportamento humano em resposta a este tipo de problemas deve ser considerado nas características requeridas de movimentação próprias de cada projeto, e consideradas nos inícios destes.

Embora exista um período de aclimatação para a tripulação no momento do arribo destes ao local de trabalho o contrário se observa no instante do regresso a terra firme.

b) Efeitos nos equipamentos.

Todos os equipamentos embarcados são submetidos aos esforços provocados pelas acelerações provenientes dos movimentos de heave, pitch e roll, assim com os decorrentes das quebras de ondas.

Todos os equipamentos de rotação como centrífugas, bombas, e compressores induzem vibrações que devem ser consideradas no projeto, para minimizar as possibilidades de derramamento de óleo. 
No caso de equipamentos pressurizados, como os aquecedores e vasos de pressão, estes devem ser verificados para evitar os possíveis derramamentos de óleo.

Especialmente em embarcações de grande porte deve ser considerada a utilização de sistemas de controle de nível, evitando a concentração de líquidos em posições extremas.

d) Operações dos helicópteros

A operação dos helicópteros será afetada pelos movimentos da embarcação, no que se refere a: pitch, roll, movimento vertical e velocidade do vento.

e) Ensaio do tanque

Todos os ensaios possíveis, com modelos do tanque devem ser feitos a fim de prever as cargas decorrentes dos movimentos, isto se torna especialmente importante para formas novas de casco, onde não existam dados anteriores, e podem ser agregados aos valores obtidos para as cargas provenientes dos equipamentos com “turrets", "risers" e outros necessários à exploração do campo.

\subsubsection{Dimensão da Tripulação e Instalações do Pessoal}

a) Base para o dimensionamento da tripulação:

O objetivo é dimensionar a tripulação considerando a quantidade mínima possível de tripulantes que conserve a capacidade de operar e dar o melhor nível de manutenção, suporte as condições do meio ambiente e conserve sua integridade.

O dimensionamento da tripulação depende dos seguintes critérios.

i) O planejamento da produção é iniciado no mesmo momento do projeto, neste sentido os elementos considerados para o layout e as diversas operações de produção e manutenção darão coerência ao dimensionamento da tripulação.

ii) $\mathrm{O}$ acompanhamento constante assim como o planejamento para as operações do dia a dia, fora das operações mais importantes deve considerar:

- manutenção de curto e longo prazo;

- programas de inspeção da integridade da instalação FPSO;

- duração e freqüência da paradas planejadas; 
- extensão do tempo de suporte dado por especialistas técnicos e engenheiros;

- necessidade de suporte em trabalhos subaquáticos;

- suporte de engenharia do reservatório;

- possibilidade de paradas não planejadas e suas soluções;

Todos estes fatores influirão no dimensionamento da tripulação, alem das atividades marinhas associadas à instalação FPSO e o serviço de transferência às operações dos navios aliviadores.

iii) Provisão para a instalação de FPSO, trabalhos comissionados, reparos principais.

Há uma tendência a dimensionar a superestrutura considerando as operações regulares, pensando que, ao manter as acomodações da tripulação no nível mínimo, resultará em diminuição de custos para o projeto. Tal aproximação pode não resultar desta forma considerando os outros fatores como a provisão das instalações assim como das possibilidades de reparações maiores no futuro.

Muitas instalações FPSO podem atingir o nível desejado da dotação para a missão para qual foram projetadas, mas é importante notar que antes de iniciar o processamento do petróleo, do gás e da água extraída, e de que todas as operações submarinas se encontrem operando, não poderemos ter certeza da operação completa.

Os maiores problemas aparecerão no momento do início da instalação e nem sempre será possível aumentar a capacidade das instalações da tripulação, nem de instalar um hotel flutuante que possa prover acomodações para o pessoal comissionado.

iv) Acomodações

As instalações para os tripulantes podem ser:

- os refúgios temporário junto aos equipamentos de luta contra incêndio;

- sala de controle e respostas às emergências;

- sala de controle, sala de radio, oficinas e salas de reuniões;

- refeitórios, salas de laser e cabinas privadas;

- lavandarias e depósitos;

- sala de geração de energia elétrica e acumuladores; 
- enfermaria e ambulatório médico;

- instalações de recepção de helicóptero;

O armador deverá definir em tempo se as habitações da tripulação serão individuais ou duplas e a possibilidade de adaptá-las temporariamente para três pessoas assim como se deverá dividir o espaço para tripulantes masculinos e femininos.

Normalmente os móveis deverão ser fixados em cada posição por causa dos movimentos próprios da navegação.

\subsubsection{Regulamentações Aplicáveis ao Projeto}

É importante notar que todos as normas e regulamentações estão baseadas nas boas práticas da engenharia.

Existem numerosas atas e instrumentos institucionais que se aplicam às instalações FPSO. A principal legislação é a "Offshore Petroleum Production and Pipelines Act", que trata sobre efeitos ao meio ambiente, Reg. 1999 (SI1999/360). A ata da Marinha Mercante de 1979 e de 1996 de prevenção da poluição de petróleo no mar, (SI1996/2154) aplicações dos requerimentos da MARPOL 73/78.

\subsubsection{Normas}

a) Normas e códigos internacionais.

Algumas normas e códigos devem ser aplicados ao projeto das instalações FPSO:

Recomendações da API RP1FPS, para planejar, projetar e construir FPSO contém o escopo mais amplo, ela contempla o projeto da embarcação e o sistema completo de produção incluindo as seções subaquáticas.

Normas ISO/WD 19904 Offshore Structures - Floating Systems and NORSOK Standard N004 Design of Steel Structures, ambas focadas nos aspectos do projeto de estruturas flutuantes.

b) Normas das sociedades classificadoras.

American Bureau of Shipping: (ABS) Construção e Classificação de Instalação Flutuante e Localizada, Julho (1999). 
Det Norske Veritas (DNV) Offshore 2000 Regras de Classificação de Unidades Flutuantes de Produção e Armazenagem. OSS-102, Janeiro 2001.

O projeto deverá respeitar os códigos internacionais de construção, sendo que as regras das sociedades classificadoras focalizam em forma detalhada os sistemas de produção e serviços, devido ao seu conhecimento na classificação de navios.

As vantagens da classificação se percebem nos seguros, e no marketing das instalações construídas.

\subsubsection{Segurança e Saúde com Relação ao Meio Ambiente}

As considerações mais importantes neste tipo de projeto de longo ou de pequeno alcance são:

- A segurança e o bem-estar de todos os envolvidos na construção, instalação e operação do projeto.

Causar o mínimo impacto no meio ambiente vizinho à instalação durante sua vida útil e após sua retirada. 


\section{O PROBLEMA PROPOSTO E SUA SOLUÇÃO}

O problema proposto é a construção de uma instalação flutuante de produção e armazenamento de petróleo do tipo FPSO.

Dado um campo de extração de petróleo e gás é necessária a construção de uma instalação tipo FPSO, que permita processar e armazenar uma quantia de 180.000 (bpd) barris de petróleo por dia, equivalente a 24 horas de funcionamento de 25 poços (18 produtores, 5 injetores de água e 2 injetores de gás), considerando a necessidade de um sistema de alívio da reserva via tandem na popa do FPSO, que permite transferir a produção a um navio tipo aliviador "shuttle".

Neste caso a jazida está avaliada em 1 bilhão de barris de petróleo e o prazo máximo para extração, considerando os 180.000 bpd especificados, é de 15 anos.

As soluções ao problema podem ser:

a) Alternativa 1: instalação nova construída especialmente com capacidade de armazenamento de 1.9 milhões de barris e equipamento de processamento de 180.000 barris de petróleo por dia (bpd), com revisão prevista em dique seco para 20 anos, e prazo de construção de 3 anos.

b) Alternativa 2: navio usado com aproveitamento do seu casco e outros elementos existentes, com vida útil remanescente de 15 anos, condicionado e reformado no prazo de 18 meses, com uma capacidade de armazenamento de 1,9 milhões de barris e planta de processamento de $180.000 \mathrm{bpd}$.

c) Alternativa 3: navio usado, com aproveitamento do casco e outras partes, reformado e condicionado no prazo de 24 meses, com uma capacidade de armazenamento 1,9 milhões de barris e equipamento de processamento de 180.000 bpd, com vida útil remanescente de 8 anos.

Para resolver o problema este será dividido em três etapas, na primeira e na segunda por tratar-se de uma decisão tomada sob risco será aplicado o método da árvore de decisão como exposto no item 1.4 e na terceira por tratar-se de uma decisão sob certeza será aplicado o método AHP como exposto no item 1.3.2.

Na primeira etapa, para comparação e análise dos dados de cada opção, será considerada: a distribuição dos prazos de entrega das instalações e sua capacidade de produção. 
$\mathrm{Na}$ segunda etapa, tomando em conta o investimento e a distribuição probabilística da produtividade, baseados num perfil de produção conhecidos, serão analisados e comparados os retornos de cada opção. Em ambas etapas será aplicado o critério de maximização de valores esperados.

$\mathrm{Na}$ terceira etapa serão utilizados os critérios de projeto, tanto determinísticos quanto os subjetivos decorrentes da comparação entre as opções.

Os critérios a serem utilizados em comparação com os requisitos do armador para seleção são os seguintes:

a) Hierarquização de valores determinísticos como: custo, dimensões principais, capacidade de armazenamento, vida útil e prazo de entrega.

b) Valores subjetivos como: comparação do estado das estruturas, comparação das curvas hidrostáticas, comparação das superfícies para distribuição de equipamentos e superestrutura, reciclagem ou realocação.

\subsection{Aplicação do Diagrama de Árvore de Decisão}

Como foi explicado no item 1.4 para iniciar a análise com referência ao objetivo do prazo, monta-se uma árvore de decisão com a vida útil prevista de cada navio e o prazo em que este poderá entrar em funcionamento. Considerando o valor de produção como negativo (entre parêntesis), no período em que a instalação não se encontra no local e como positivo, a partir do momento em que a instalação se conecta ao restante do sistema de extração.

Cada alternativa é considerada afetada pelo estado da natureza correspondente, e o espaço amostral se divide entre o período no qual se prevê que a instalação estará sendo construída e o período após sua localização na zona de extração, sendo afetado pelo prazo de uso entre inspeções obrigatórias e reformas em dique seco.

\subsubsection{Primeira etapa}

Alternativa 1: prazo de fabricação, 3 anos. 
Vida útil prevista para o campo: 15 anos. Vida útil prevista para a instalação FPSO 20 anos. (o excedente será considerado favorável para a amortização da instalação FPSO mas não pode ser considerado na avaliação própria para o campo.)

Antes da instalação: 180.000 bpd x 3 anos x 360 dias/ano $=(194.400 .000)$ bp

Após a conexão : 180.000 bpd x 15 anos x 360 dias/ano $=972.000 .000$ bp

Alternativa 2:

Vida útil prevista para a instalação FPSO: 15 anos, vida útil prevista para o campo 15 anos.

Antes da conexão : 180.000 bpd x 1,5 anos x 360 dias/ano $=(97.200 .000)$ bp

Após a conexão: 180.000 bpd x 15 anos x 360 dias/ano $=972.000 .000$ bp

Alternativa 3

Vida útil prevista para a instalação FPSO: 8 anos, é o valor a ser considerado por ser menor que o previsto para o campo.

Antes da conexão : 180.000 bpd x 2 anos x 360 dias/ano $=(129.600 .000) b p$

Após a conexão: 180.000 bpd x 8 anos x 360 dias/ano $=518.400 .000$ bp

Após a conexão tempo improdutivo:

180.000 bpd $\times 7$ anos $\times 360$ dias/ano $=(453.600 .000) b p$

\begin{tabular}{|c|c|c|}
\hline & Tempo improdutivo & Tempo produtivo \\
\hline Alternativa 1 & $(194,40)$ & 972,0 \\
\hline Alternativa 2 & $(97.2)$ & 972,0 \\
\hline Alternativa 3 & $(583,20)$ & 518,40 \\
\hline
\end{tabular}

Tabela 3.1: Critério tempo de produção, valores em milhões barris de petróleo (Mbp).

O estado da natureza tomando em conta o tempo de trabalho entre revisões em dique seco será:

Alternativa 1: prazo de fabricação da instalação 3 anos, máximo período produtivo previsto 15 anos, proporção entre os prazos:

a) até o início da extração; $[3 / 18]=\mathrm{P}_{1}=0,166$

b) após o início e até o final da vida do equipamento; [15/18] $=\mathrm{P}_{2}=0,834$ 
Alternativa 2: prazo de fabricação da instalação 1,5 anos , período entre revisões em dique seco previsto, 15 anos, proporção entre os prazos:

a) até o início da extração; $[1,5 / 16,5]=\mathrm{P}_{3}=0,09$

b) após o início da extração e até o final do equipamento; $[15 / 16,5]=\mathrm{P}_{4}=$ 0,91

Alternativa 3: prazo de adaptação da instalação 2 anos, período entre revisões em dique seco previsto 8 anos, vida útil do reservatório 15 anos (do ponto de vista da utilidade proporcionada pela instalação faltarão 7 anos para esgotar o reservatório, este tempo deverá ser considerado improdutivo), proporção entre os prazos:

a) até o início da extração 2 anos e após o término da vida útil da FPSO 7 anos total 9 anos inativo; $[9 / 17]=\mathrm{P}_{5}=0,53$

b) após o início da extração e até o final do equipamento; $[8 / 17]=\mathrm{P}_{6}=0,47$

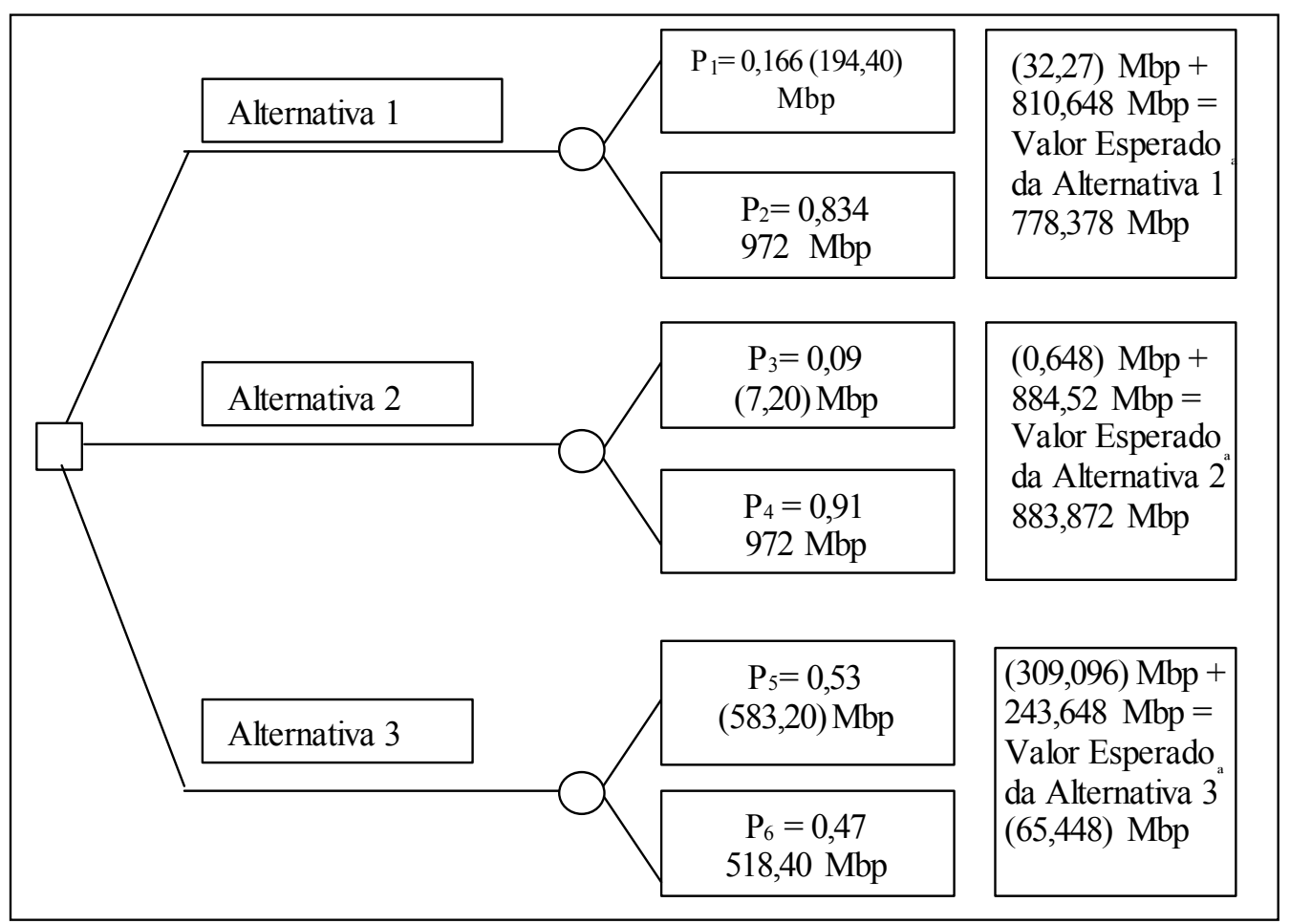

Figura 3.1: Árvore de decisão para critério de tempo de produção de 15 anos. 
Utilizando o critério de maximização, a alternativa indicada é a que possui o maior valor esperado, neste caso a Alternativa 2 que corresponde à instalação FPSO construída aproveitando um navio tanque existente.

\subsubsection{Verificação de sensibilidade do processo.}

O passo seguinte é verificar a sensibilidade do processo de auxílio à decisão, para isto podemos utilizar como comparação os resultados obtidos mudando os dados do problema.

Se for mudada a capacidade prevista da jazida, de 1 bilhão de barris para 900 milhões de barris, o prazo de extração considerando um processamento de 180.000 bpd será reduzido para aproximadamente 14 anos.

Repetindo o mesmo processo anterior com os novos dados:

Alternativa 1: prazo de fabricação 3 anos.

a) Antes da instalação: 180.000 bpd x 3anos x 360dias/ano=(194.400.000) bp

Vida útil prevista para o campo: 14 anos. Vida útil prevista para a instalação FPSO 20 anos.

b) Após a conexão : 180.000 x 14 anos x 360 dias/ano $=907.200 .000$ bp

Alternativa 2: Prazo de fabricação 1,5 anos.

Vida útil prevista para a instalação FPSO: 15 anos. Vida útil prevista para o campo: 14 anos.

Antes da conexão : 180.000 bpd x 1,5 anos x 360 dias/ano $=(97.200 .000)$ bp

Após a conexão: 180.000 bpd x 14 anos x 360 dias/ano $=907.200 .000$ bp

Alternativa 3: Prazo de fabricação 2 anos.

Vida útil prevista para a instalação FPSO: 8 anos, é o valor a ser considerado por ser menor que o previsto para o campo.

Antes da conexão : 180.000 bpd x 2 anos x 360 dias/ano $=(129.600 .000) b p$

Após a conexão: 180.000 bpd x 8 x $360=518.400 .000$ bp

Faltarão 6 anos para esgotar o reservatório, este tempo o volume deverá ser considerado improdutivo e somado ao de antes da conexão; 
180.000 bpd x 6 anos x 360 dias/ano $=(388.800 .000)$ bp

Volume do tempo improdutivo da alternativa 2 :

$(129.600 .000) b p+(388.800 .000) b p=(518.400 .000) b p$

\begin{tabular}{|c|c|c|}
\hline & Tempo improdutivo & Tempo produtivo \\
\hline Alternativa 1 & $(194,40)$ & 907,20 \\
\hline Alternativa 2 & $(97,20)$ & 907,20 \\
\hline Alternativa 3 & $(518,40)$ & 518,40 \\
\hline
\end{tabular}

Tabela 3.2: Critério tempo de produção, valores em milhões de barris de petróleo (Mbp).

O estado da natureza tomando em conta o tempo de trabalho entre revisões em dique seco será:

Alternativa 1: prazo de fabricação da instalação 3 anos, máximo período produtivo previsto 14 anos, proporção entre os prazos.

a) Até o início da extração; [3/17] $=\mathrm{P}_{1}=0,18$

b) Após o início e até o final da vida do equipamento; [14/17] $=\mathrm{P}_{2}=0,72$

Alternativa 2: prazo de fabricação da instalação 1,5 anos , período entre revisões em dique seco previsto, 15 anos. Vida útil do campo 14 anos, proporção entre os prazos.

a) Tempo improdutivo para extração; $[1,5 / 15,5]=\mathrm{P}_{3}=0,10$

b) Após o início da extração e até o final do equipamento;

$[14 / 1458,5]=\mathrm{P}_{4}=0,90$

Alternativa 3: prazo de adaptação da instalação 2 anos, período entre revisões em dique seco previsto 8 anos, vida útil do reservatório 14 anos (do ponto de vista da utilidade proporcionada pela instalação faltarão 6 anos para esgotar o reservatório, este tempo deverá ser considerado improdutivo), proporção entre os prazos.

a) Até o início da extração 2 anos e após o término da vida útil da FPSO 6 anos total 8 anos improdutivo; $[8 / 16]=\mathrm{P}_{5}=0,5$

b) Após o início da extração e até o final do equipamento; $[8 / 16]=\mathrm{P}_{6}=0,5$ 


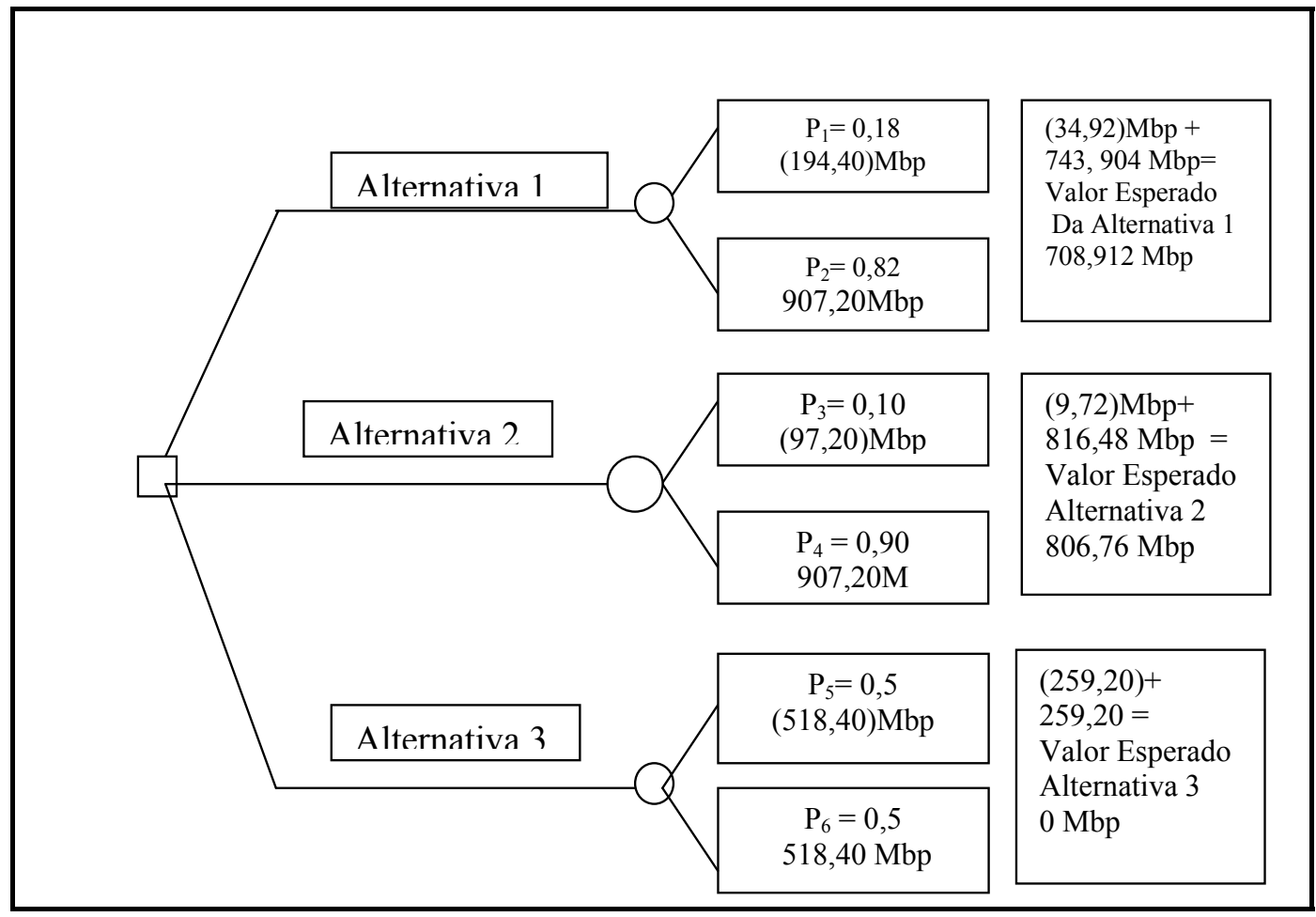

Figura 3.2: Árvore de decisão para tempo de produção de 14anos.

Utilizando o critério de maximização, a alternativa indicada é a que possui o maior valor esperado, neste caso a Alternativa 2 que corresponde à instalação FPSO construída a partir de um navio tanque usado com uma vida remanescente de 15 anos.

Se for mudada a capacidade prevista da jazida, de 1 bilhão de barris para 1,1 bilhão de barris, o prazo de extração considerando um processamento de 180.000 bpd será ampliado para 17 anos.

Repetindo o mesmo processo anterior com os novos dados:

Alternativa 1: prazo de fabricação 3 anos.

a) Antes da instalação: $180.000 \mathrm{bpd}$ x 3anos x 360dias/ano $=(194.400 .000) \mathrm{bp}$ Vida útil prevista para o campo: 17 anos. Vida útil prevista para a instalação FPSO 20 anos.

b) Após a conexão : 180.000 x 17 anos x 360 dias/ano = 1.101.600.000 bp 
Alternativa 2: Prazo de fabricação 1,5 anos.

Vida útil prevista para a instalação FPSO: 15 anos. Vida útil prevista para o campo 17 anos.

a) Antes da conexão: 180.000 bpd x 1,5 anos x 360 dias/ano=(97.200.000) bp

b) Após a conexão: 180.000 bpd x $15 \operatorname{anos}$ x 360 dias/ano $=972.000 .000$ bp

Faltarão 2 anos para esgotar o reservatório, este tempo o volume deverá ser considerado improdutivo e somado ao de antes da conexão;

180.000 bpd x 2 anos x 360 dias/ano $=(129.600 .000)$ bp

Volume do tempo improdutivo da alternativa 2 :

$(97.200 .000) b p+(129.600 .000) b p=(226.800 .000) b p$

Alternativa 3: Prazo de fabricação 2 anos.

Vida útil prevista para a instalação FPSO: 8 anos, é o valor a ser considerado por ser menor que o previsto para o campo.

a) Antes da conexão:

$180.000 \mathrm{bpd} \times 2$ anos $\times 360$ dias/ano $=(129.600 .000) \mathrm{bp}$

b) Após a conexão: 180.000 bpd x 8 x $360=518.400 .000$ bp

Faltarão 9 anos para esgotar o reservatório, este tempo o volume deverá ser considerado improdutivo e somado ao de antes da conexão;

180.000 bpd x 9 anos x 360 dias/ano $=(583.200 .000) \mathrm{bp}$

Volume do tempo improdutivo da alternativa 2 :

$(129.600 .000) b p+(583.200 .000) b p=(712.800 .000) b p$

\begin{tabular}{|c|c|c|}
\hline & Tempo improdutivo & Tempo produtivo \\
\hline Alternativa 1 & $(194,40)$ & $1.101,6$ \\
\hline Alternativa 2 & $(226.80)$ & 972,0 \\
\hline Alternativa 3 & $(712,80)$ & 518,40 \\
\hline
\end{tabular}

Tabela 3.2 Critério tempo de produção, valores em milhões barris de petróleo (Mbp). 
O estado da natureza tomando em conta o tempo de trabalho entre revisões em dique seco será:

Alternativa 1: prazo de fabricação da instalação 3 anos, máximo período produtivo previsto 17 anos, proporção entre os prazos

a) Até o início da extração; [3/20] $=\mathrm{P}_{1}=0,15$

b) Após o início e até o final da vida do equipamento; [17/20] $=\mathrm{P}_{2}=0,85$

Alternativa 2: prazo de fabricação da instalação 1,5 anos , período entre revisões em dique seco previsto, 15 anos, (do ponto de vista da utilidade proporcionada pela instalação faltarão 2 anos para esgotar o reservatório, este tempo deverá ser considerado improdutivo), proporção entre os prazos.

a) Tempo improdutivo para extração; $[3,5 / 18,5]=\mathrm{P}_{3}=0,19$

b) Após o início da extração e até o final do equipamento; $[15 / 18,5]=\mathrm{P}_{4}=0,81$

Alternativa 3: prazo de adaptação da instalação 2 anos, período entre revisões em dique seco previsto 8 anos, vida útil do reservatório 15 anos (do ponto de vista da utilidade proporcionada pela instalação faltarão 9 anos para esgotar o reservatório, este tempo deverá ser considerado improdutivo), proporção entre os prazos:

a) Até o início da extração 2 anos e após o término da vida útil da FPSO 9 anos total 11 anos improdutivo; [11/19] $=\mathrm{P}_{5}=0,58$

b) Após o início da extração e até o final do equipamento; $[8 / 19]=\mathrm{P}_{6}=0,42$ 


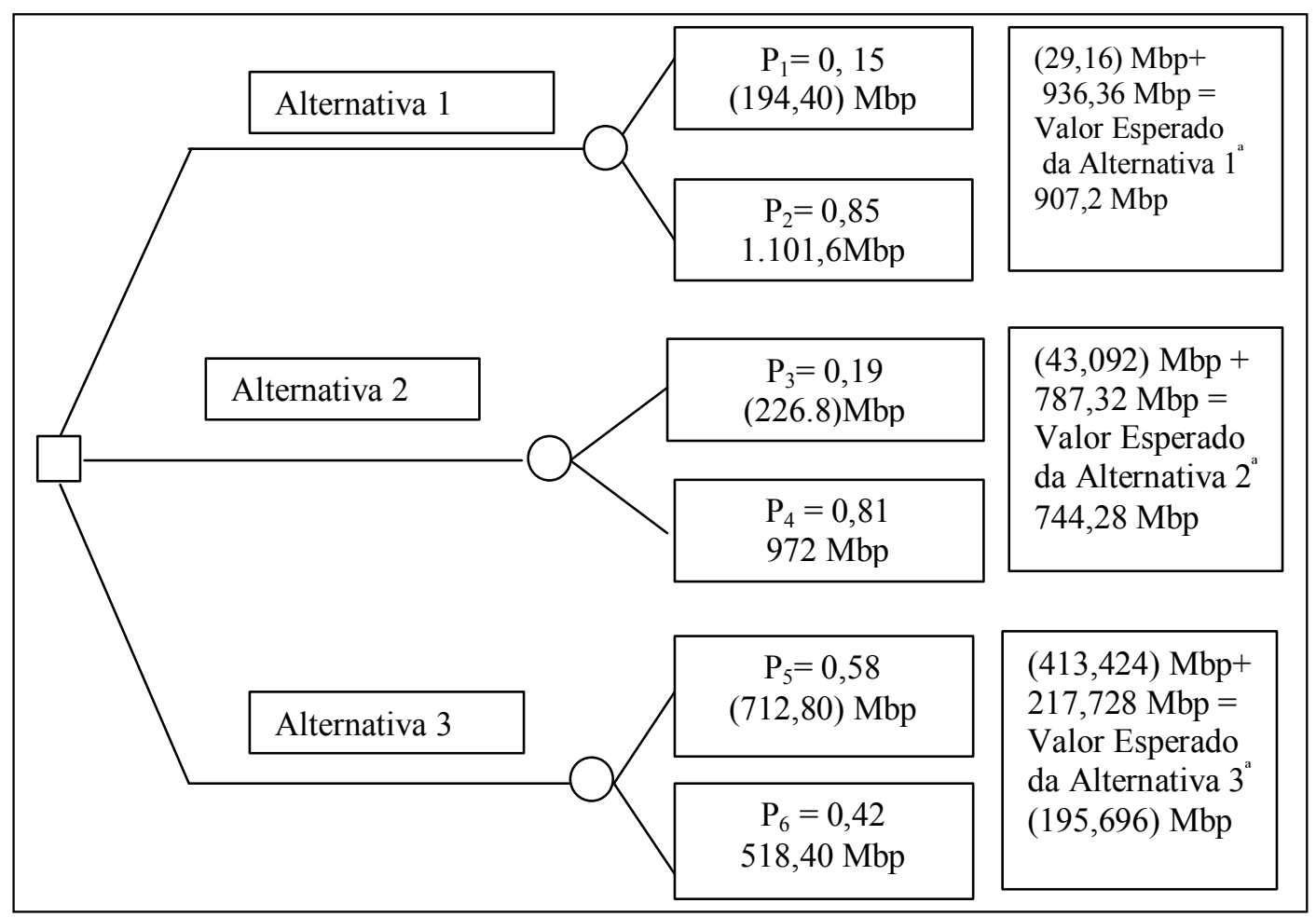

Figura 3.2: Árvore de decisão para tempo de produção de 17anos.

Utilizando o critério de maximização, a alternativa indicada é a que possui o maior valor esperado, neste caso a Alternativa 1 que corresponde à instalação FPSO totalmente nova.

Se for mudada a capacidade prevista da jazida, de 1 bilhão de barris para 1,3 bilhões, o prazo de extração considerando um processamento de 180.000 bpd será ampliado para 20 anos.

Repetindo o mesmo processo anterior com os novos dados:

Alternativa 1: prazo de fabricação 3 anos.

a) Antes da instalação: $180.000 \mathrm{bpd}$ x 3 anos x 360dias/ano = $(194.400 .000) \mathrm{bp}$ Vida útil prevista para o campo: 20 anos. Vida útil prevista para a instalação FPSO 20 anos.

b)Após a conexão : 180.000 x 20 anos x 360 dias/ano $=1.296 .000 .000$ bp 
Alternativa 2: Prazo de fabricação 1,5 anos.

Vida útil prevista para a instalação FPSO: 15 anos. Vida útil prevista para o campo 20 anos.

a) Antes da conexão: $180.000 \mathrm{bpd} \times 1,5$ anos x 360dias/ano $=(97.200 .000) \mathrm{bp}$

b) Após a conexão: 180.000 bpd x 15 anos x 360 dias/ano $=972.000 .000$ bp

Faltarão 5 anos para esgotar o reservatório, este tempo o volume deverá ser considerado improdutivo e somado ao de antes da conexão;

$180.000 \mathrm{bpd} \times 5$ anos $\times 360$ dias/ano $=(324.000 .000) \mathrm{bp}$

Volume do tempo improdutivo da alternativa 2 :

(97.200.000) bp $+(324.000 .000) b p=(421.200 .000) b p$

Alternativa 3: Prazo de fabricação 2 anos.

Vida útil prevista para a instalação FPSO: 8 anos, é o valor a ser considerado por ser menor que o previsto para o campo.

a) Antes da conexão : 180.000bpd x 2anos x 360dias/ano $=(129.600 .000) \mathrm{bp}$.

b) Após a conexão: 180.000 bpd x 8anos x 360 dias/ano = 518.400.000 bp

Faltarão 12 anos para esgotar o reservatório, este tempo o volume deverá ser considerado improdutivo e somado ao de antes da conexão;

$180.000 \mathrm{bpd} \times 12$ anos $\times 360$ dias/ano $=(777.600 .000) \mathrm{bp}$

Volume do tempo improdutivo da alternativa 2 :

$(129.600 .000) b p+(777.600 .000) b p=(907.200 .000) b p$

\begin{tabular}{|c|c|c|}
\hline & Tempo improdutivo & Tempo produtivo \\
\hline Alternativa 1 & $(194,40)$ & 1.296 \\
\hline Alternativa 2 & $(421,2)$ & 972,0 \\
\hline Alternativa 3 & $(907,2)$ & 518,40 \\
\hline
\end{tabular}

Tabela 3.3: Critério tempo de produção, valores em milhões de barris de petróleo (Mbp). 
O estado da natureza tomando em conta o tempo de trabalho entre revisões em dique seco será:

Alternativa 1: prazo de fabricação da instalação 3 anos, máximo período produtivo previsto 20 anos, proporção entre os prazos:

a) Até o início da extração; $[3 / 23]=\mathrm{P}_{1}=0,13$

b) Após o início e até o final da vida do equipamento; [20/23] $=\mathrm{P}_{2}=0,87$

Alternativa 2: prazo de fabricação da instalação 1,5 anos , período entre revisões em dique seco previsto, 15 anos, (do ponto de vista da utilidade proporcionada pela instalação faltarão 5 anos para esgotar o reservatório, este tempo deverá ser considerado improdutivo), proporção entre os prazos:

a) Até o início da extração; $[6,5 / 21,5]=\mathrm{P}_{3}=0,30$

b) Após o início da extração e até o final do equipamento;

$$
[15 / 21,5]=\mathrm{P}_{4}=0,70
$$

Alternativa 3: prazo de adaptação da instalação 2 anos, período entre revisões em dique seco previsto 8 anos, vida útil do reservatório 15 anos (do ponto de vista da utilidade proporcionada pela instalação faltarão 7 anos para esgotar o reservatório, este tempo deverá ser considerado improdutivo), proporção entre os prazos:

a) Até o início da extração 2 anos e após o término da vida útil da FPSO 12 anos total 14 anos inativo; $[14 / 22]=\mathrm{P}_{5}=0,63$

b) Após o início da extração e até o final do equipamento; $[8 / 22]=\mathrm{P}_{6}=0,37$ 


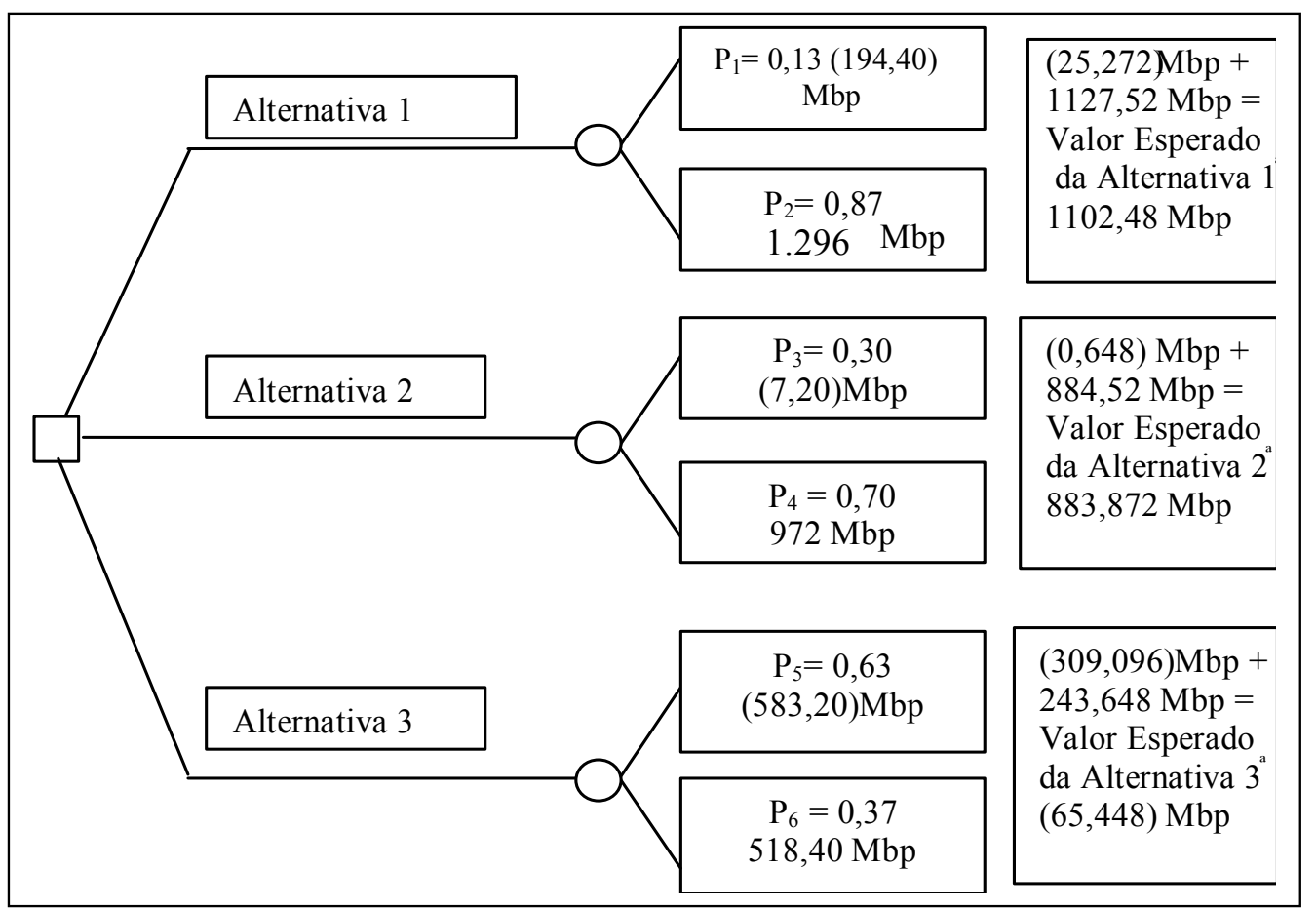

Figura 3.3: Árvore de decisão para tempo de produção de 20 anos.

Considerando estes novos dados o resultado é outro, a alternativa mais indicada considerando a maximização do valor esperado é a alternativa 1, sendo que neste caso a vida útil prevista para a instalação FPSO coincide com a vida útil prevista para o reservatório.

Confirmando a sensibilidade do processo de auxílio à decisão que indica precisamente que a alternativa escolhida como solução do problema onde a vida útil do campo é 15 anos é a alternativa 2 proposta, consistente em uma instalação FPSO produzida a partir de um navio petroleiro usado.

Uma vez que o objetivo de prazo está definido é indica um caminho a seguir pode-se então aprofundar na seleção da solução, passando para Segunda etapa do processo proposto.

\subsubsection{Segunda etapa}

Analisando qual é a alternativa de construção, se o totalmente novo, aquele com o casco a ser reutilizado e que tem pouco uso ou o terceiro com o casco 
proveniente de um petroleiro usado e com preço menor, mas com investimentos maiores para sua atualização, utilizando desta vez os dados de sistemas similares conhecidos.

Para identificar uma decisão neste caso deve-se considerar o estado da natureza, ou como historicamente está composto, por um perfil de produção, conhecido a priori, como exposto na árvore de decisão a seguir.

A probabilidade de ter uma produção com Boa eficiência, $(97 \%$ da capacidade nominal de processamento), é de $30 \%$, a probabilidade de ter uma produção com Média eficiência, ( $87 \%$ da capacidade nominal de processamento), é de $40 \%$, e a probabilidade de ter uma produção com Baixa eficiência, $(75 \%$ da capacidade nominal de processamento), é de 30\%. De modo que se pode calcular em primeira instância o Valor Esperado de cada Alternativa.

Analisando as alternativas tomando a produção em cada período, afetada pela proporção de tempo em que essa produção foi atingida, se obtém um perfil de produtividade esperada desta FPSO.

Para o cálculo da utilidade média de cada navio podem-se considerar: o tempo em que cada navio poderá permanecer trabalhando, tomando o retorno como se fosse um arrendamento, considerando sua capacidade final de trabalho, o tamanho da jazida em barris de petróleo e a influência que tem no seu trabalho o ambiente marinho, sendo possível recorrer às informações históricas correspondentes ao local. Por último, na incorporação deste valor na árvore de decisão, devem ter-se em conta três coeficientes de produtividade: otimista, médio e pessimista, com as distribuições probabilísticas de acontecer cada uma destes perfis de produção.

Tendo em conta a velocidade de retirada do fluído e avaliando a capacidade instalada na FPSO correspondente, se obterá um prazo de extração. Considerando estatisticamente a eficiência da operação, obtém-se um perfil do valor a analisar. Alem disto, é necessário, para o estudo, ponderar coeficientes como os descritos acima.

Utilizando como referência o barril de petróleo para todos os valores. Independente do seu preço atual, embora se reconheça que pode ser fruto de uma flutuação de mercado. 
$\mathrm{Na}$ estruturação probabilística em forma de árvore de decisão são colocadas em seqüência lógica as alternativas, neste problema serão considerados três níveis de aproveitamento e as porcentagens de existência destes, nos estados da natureza propostos, influenciados por um coeficiente de eficiência de extração para cada caso.

Analisando a utilidade média de cada navio, se obtém um resultado que indica uma hierarquia de conveniências, sem perder de vista que, para a aplicação do método, se toma em conta o retorno diário decorrente do investimento. Desta forma, poderá ser estabelecida uma estratégia, ou um plano combinando as opções ou alternativas, para cada situação que se apresentará, e onde poderemos obter sempre o máximo valor esperado.

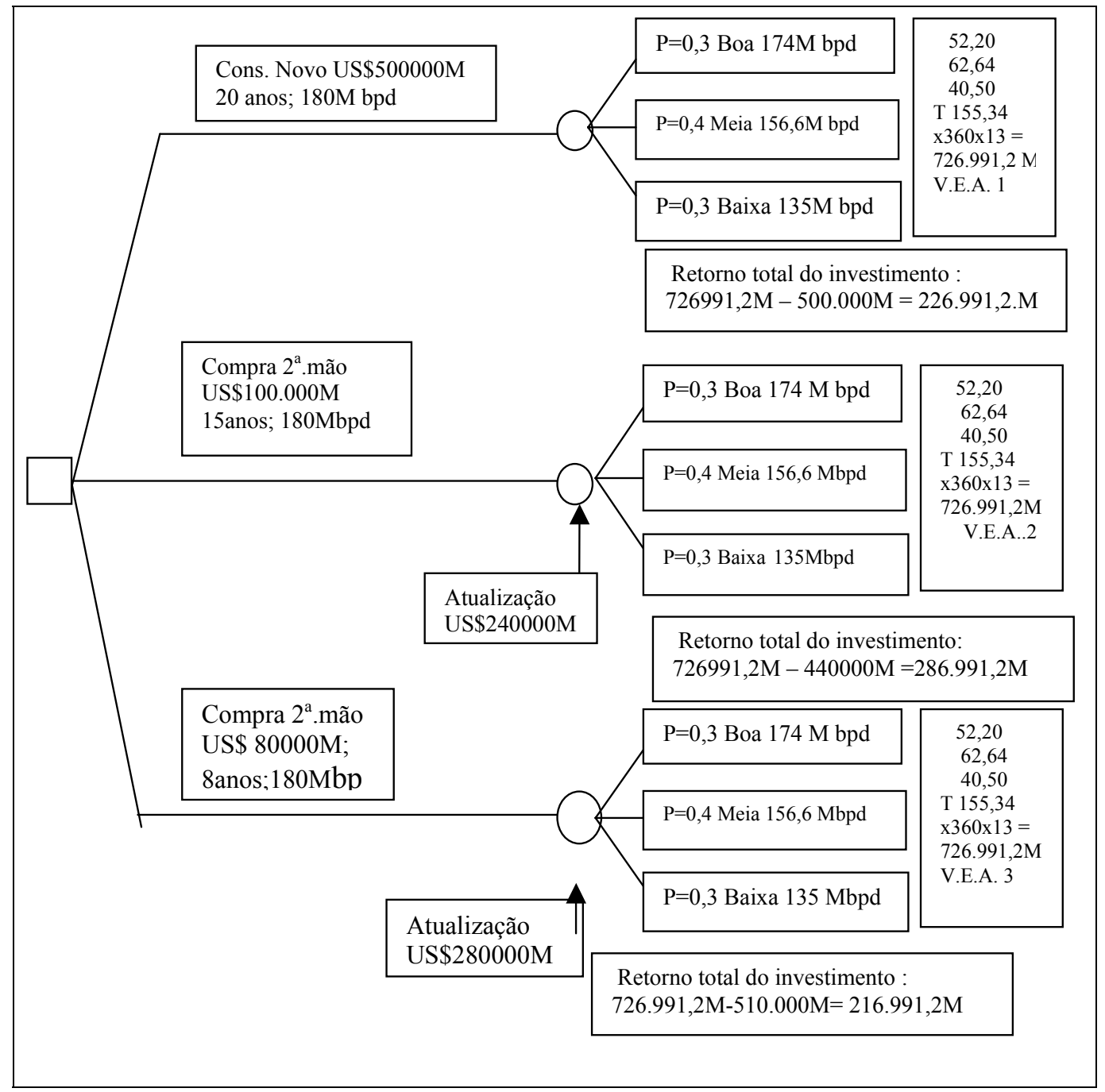

Figura 3.4: Árvore de decisão com perfil de extração. 
Utilizando para a análise o critério de máximo retorno, descontado do investimento, o máximo valor esperado é o decorrente da opção de construção, com aproveitamento do casco de um petroleiro que tem 15 anos de vida útil remanescente.

Confirmada a opção de solução do problema que foi analisada tomando em conta dois critérios, um de tempo e outro de utilidade, se pode continuar com a terceira etapa.

\subsection{Aplicação do método AHP}

O problema, a partir desta etapa, se centra na escolha do petroleiro para adaptação, já que existem vários que podem ser adquiridos, dentro da mesma categoria, será utilizada a metodologia para auxílio à decisão exposta no item 1.3.2 a qual facilita a seleção dando confiabilidade ao projetista sem perder de vista que a subjetividade deste e ou do perito avaliador serão levadas em conta.

Para estruturar o problema, segundo Saaty (1980) se deve estabelecer o objetivo, neste caso, o objetivo do problema é a seleção de um navio que melhor se adapte para ser transformado em FPSO.

Seguidamente é necessário definir os critérios e sub-critérios que guiarão a avaliação. Este segundo passo é utilizado para a obtenção dos pareceres ou julgamentos entre os fatores de decisão. A metodologia básica consiste em caso de comparações onde intervem um critério subjetivo, atribuir valores às comparações entre elementos (sempre dois a dois), para isto é utilizada a escala mostrada na Tabela 1.1: Valores de preferências, montando uma matriz de comparação por pares.

No caso de um critério ser determinístico, podem simplesmente ser utilizados os critérios de maximização ou minimização, segundo o conceito, para estabelecer as hierarquias.

Por último devemos listar as opções ou alternativas propostas, com todas as informações pertinentes. 


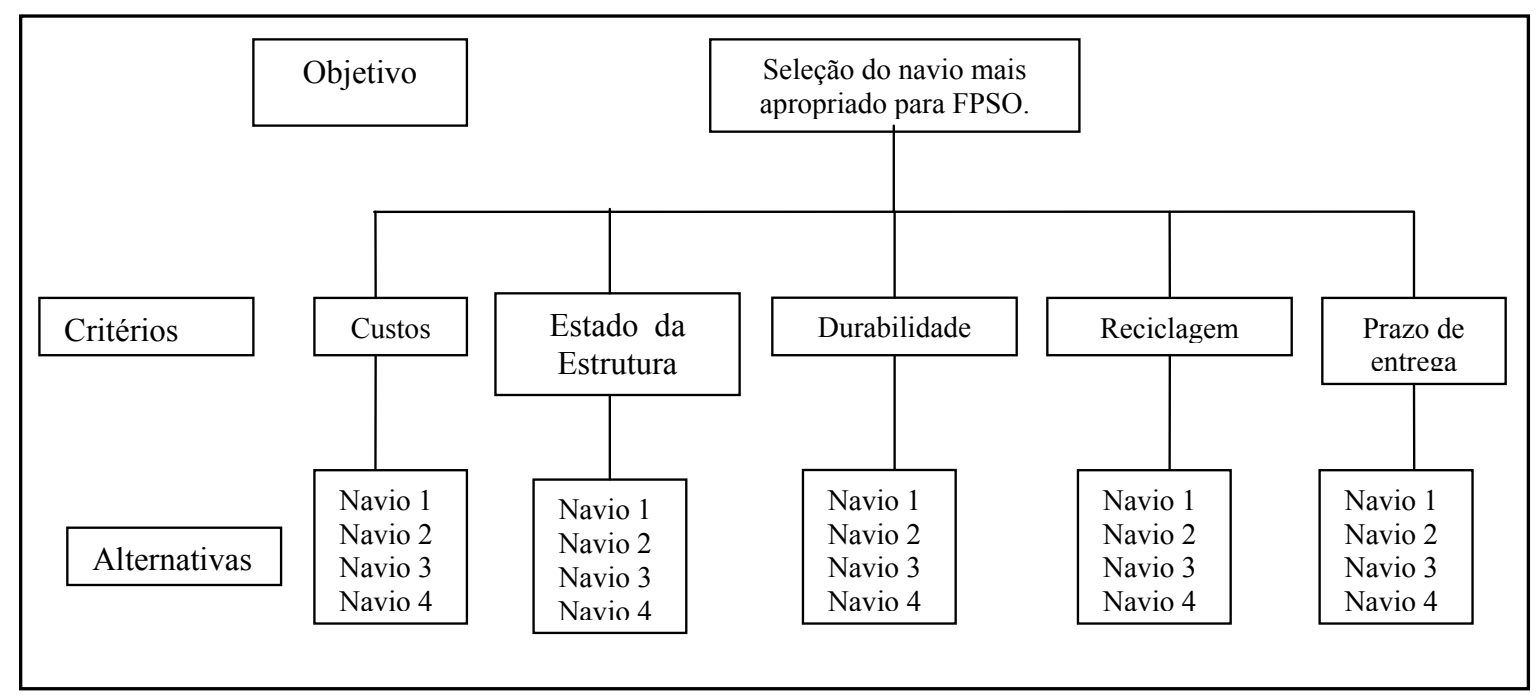

Figura 3.5: Estruturação do problema segundo AHP

As alternativas oferecidas nesta etapa são quatro, e reúnem os requisitos para serem utilizados como solução ao problema de escolha proposto.

Inicia-se a escolha montando as matrizes de critérios e desta forma poder definir o peso dos mesmos.

Matriz dos critérios

\begin{tabular}{|c|c|c|c|c|c|}
\hline CRITÉRIOS & Custo & $\begin{array}{c}\text { Estado da } \\
\text { estrutura }\end{array}$ & Durabilidade & Reciclagem & Prazos \\
\hline Custo & 1 & $1 / 4$ & $1 / 2$ & $1 / 2$ & $1 / 4$ \\
\hline $\begin{array}{c}\text { Estado da } \\
\text { estrutura }\end{array}$ & 4 & 1 & $1 / 2$ & $1 / 3$ & 5 \\
\hline Durabilidade & 2 & 2 & 1 & $1 / 4$ & 3 \\
\hline Reciclagem & 2 & 3 & 4 & 1 & 4 \\
\hline Prazos & 4 & $1 / 5$ & $1 / 3$ & $1 / 4$ & 1 \\
\hline
\end{tabular}

Colocando em forma decimal.

\begin{tabular}{|c|c|c|c|c|c|}
\hline CRITÉRIOS & Custo & $\begin{array}{c}\text { Estado da } \\
\text { estrutura }\end{array}$ & Durabilidade & Reciclagem & $\begin{array}{c}\text { Prazo de } \\
\text { entrega }\end{array}$ \\
\hline Custo & 1 & 0,25 & 0,5 & 0,5 & 0,25 \\
\hline $\begin{array}{c}\text { Estado da } \\
\text { estrutura }\end{array}$ & 4 & 1 & 0,5 & 0,3333333 & 5 \\
\hline Durabilidade & 2 & 2 & 1 & 0,25 & 3 \\
\hline Reciclagem & 2 & 3 & 4 & 1 & 4 \\
\hline Prazos & 4 & 0,2 & 0,33333 & 0,25 & 1 \\
\hline Total & 13 & 6,45 & 6,333333 & 2,3333333 & 13,250003 \\
\hline
\end{tabular}


Normaliza-se a matriz dividindo cada elemento pelo total da sua respectiva coluna:

\begin{tabular}{|c|c|c|c|c|c|c|}
\hline CRITÉRIOS & Custo & $\begin{array}{c}\text { Estado da } \\
\text { estrutura }\end{array}$ & Durabilidade & Reciclagem & $\begin{array}{c}\text { Prazo de } \\
\text { entrega }\end{array}$ & $\begin{array}{c}\text { Média } \\
\text { dos } \\
\text { critérios }\end{array}$ \\
\hline Custo & 0,07692 & 0,03876 & 0,07895 & 0,21429 & 0,01887 & $\mathbf{0 , 0 8 5 5}$ \\
\hline $\begin{array}{c}\text { Estado da } \\
\text { estrutura }\end{array}$ & 0,30769 & 0,15504 & 0,07895 & 0,14286 & 0,37736 & $\mathbf{0 , 2 1 2 3}$ \\
\hline Durabilidade & 0,15385 & 0,31008 & 0,1579 & 0,10714 & 0,22642 & $\mathbf{0 , 1 9 1 0}$ \\
\hline Reciclagem & 0,15385 & 0,46512 & 0,63158 & 0,42857 & 0,30189 & $\mathbf{0 , 3 9 6 2}$ \\
\hline Prazos & 0,30769 & 0,03101 & 0,05263 & 0,10714 & 0,07547 & $\mathbf{0 , 1 1 4 7}$ \\
\hline
\end{tabular}

Verificando a Consistência pelo método sugerido pelo professor Saaty explicado no item 1.3.2.

\begin{tabular}{|c|c|c|c|c|c|}
\hline CRITÉRIOS & Custo & $\begin{array}{c}\text { Estado da } \\
\text { estrutura }\end{array}$ & Durabilidade & Reciclagem & $\begin{array}{c}\text { Prazo de } \\
\text { entrega }\end{array}$ \\
\hline Custo & 1 & 0,25 & 0,5 & 0,5 & 0,25 \\
\hline $\begin{array}{c}\text { Estado da } \\
\text { estrutura }\end{array}$ & 4 & 1 & 0,5 & 0,333333 & 5 \\
\hline Durabilidade & 2 & 2 & 1 & 0,25 & 3 \\
\hline Reciclagem & 2 & 3 & 4 & 1 & 4 \\
\hline Prazos & 4 & 0,2 & 0,33333 & 0,25 & 1 \\
\hline
\end{tabular}

\begin{tabular}{|r|}
\hline 0,460986 \\
\hline 1,356156 \\
\hline 1,230364 \\
\hline 2,427908 \\
\hline 0,662234 \\
\hline Total: \\
\hline
\end{tabular}

Aplicando a fórmula do desvio sendo $\lambda$ máximo $=6,137649 ; \mathrm{e}, \mathrm{n}=5$

$$
\mathrm{IC}=(6,137649-5) / 4=0,2844122
$$

Comparando com o valor da escala proposta por Saaty (1980) verificamos que devido aos valores colocados na matriz de comparação de critérios o desvio medido foi maior que os $10 \%$ que Saaty indica como coerentes.

Voltando à matriz inicial e possível mudar alguns dos valores considerando que a primeira avaliação pode ser ajustada. 


\begin{tabular}{|c|c|c|c|c|c|}
\hline CRITÉRIOS & Custo & $\begin{array}{c}\text { Estado da } \\
\text { estrutura }\end{array}$ & Durabilidade & Reciclagem & $\begin{array}{c}\text { Prazo de } \\
\text { entrega }\end{array}$ \\
\hline Custo & 1 & 0,25 & 0,333333 & 0,166667 & 0,2 \\
\hline $\begin{array}{c}\text { Estado da } \\
\text { estrutura }\end{array}$ & 4 & 1 & 0,5 & 0,2 & 5 \\
\hline Durabilidade & 3 & 2 & 1 & 0,142857 & 3,00003 \\
\hline Reciclagem & 6 & 5 & 7 & 1 & 4 \\
\hline Prazos & 5 & 0,2 & 0,33333 & 0,25 & 1 \\
\hline
\end{tabular}

A matriz com os pesos dos critérios agora mudados é:

\begin{tabular}{|l|}
\hline $\mathbf{0 , 0 4 5 6 9 1}$ \\
\hline $\mathbf{0 , 1 7 5 1 7 4}$ \\
\hline $\mathbf{0 , 1 6 2 4 2 7}$ \\
\hline $\mathbf{0 , 5 0 8 5 0 1}$ \\
\hline $\mathbf{0 , 1 0 8 2 0 6}$ \\
\hline
\end{tabular}

Que multiplicada pela matriz anterior dará a seguinte matriz:

\begin{tabular}{|c|}
\hline 0,452 \\
\hline 1,149683 \\
\hline 1,055904 \\
\hline 2,20794 \\
\hline 0,507272 \\
\hline$\lambda \max .5,3728$ \\
\hline
\end{tabular}

Aplicando a fórmula empírica do desvio sendo $\lambda$ máximo 5,3728; e o número de critérios 5, o índice de coerência será:

$$
\mathrm{IC}=(5,3728-5) / 4=0,0932
$$

Conseguindo o parâmetro desejado.

Segunda etapa:

Nesta etapa se deve montar uma matriz de comparação por pares de cada alternativa, focadas em cada Critério.

\section{ESTADO DA ESTRUTURA (critério)}

\begin{tabular}{|l|c|c|c|c|}
\hline & Navio 1 & Navio 2 & Navio 3 & Navio 4 \\
\hline Navio 1 & 1 & 2 & 5 & 7 \\
\hline Navio 2 & $1 / 2$ & 1 & 3 & 5 \\
\hline Navio 3 & $1 / 5$ & $1 / 3$ & 1 & 3 \\
\hline Navio 4 & $1 / 7$ & $1 / 5$ & $1 / 3$ & 1 \\
\hline
\end{tabular}




\begin{tabular}{|l|c|c|c|c|}
\hline & Navio 1 & Navio 2 & Navio 3 & Navio 4 \\
\hline Navio 1 & 1 & 2 & 5 & 7 \\
\hline Navio 2 & 0,5 & 1 & 3 & 5 \\
\hline Navio 3 & 0,2 & 0,3333 & 1 & 3 \\
\hline Navio 4 & 0,14285 & 0,2 & 0,3333 & 1 \\
\hline
\end{tabular}

Normalizando:

\begin{tabular}{|l|r|r|r|r|c|}
\hline & \multicolumn{1}{|c|}{ Navio 1 } & Navio 2 & Navio 3 & Navio 4 & \multicolumn{1}{c|}{ Média } \\
\hline Navio 1 & 0,542635659 & 0,566037736 & 0,535714286 & 0,4375 & $\mathbf{0 , 5 2 0 4 7 1 9}$ \\
\hline Navio 2 & 0,271317829 & 0,283018868 & 0,321428571 & 0,3125 & $\mathbf{0 , 2 9 7 0 6 6 3}$ \\
\hline Navio 3 & 0,108527132 & 0,094339623 & 0,107142857 & 0,1875 & $\mathbf{0 , 1 2 4 3 7 7 4}$ \\
\hline Navio 4 & 0,07751938 & 0,056603774 & 0,035714286 & 0,0625 & $\mathbf{0 , 0 5 8 0 8 4 3}$ \\
\hline
\end{tabular}

Verificando o IC, desta matriz, se podem ajustar as avaliações, em forma interativa como foi executado com a matriz dos critérios.

Multiplica-se a matriz de comparação do critério Estado da Estrutura com a matriz da hierarquia obtida para este critério.

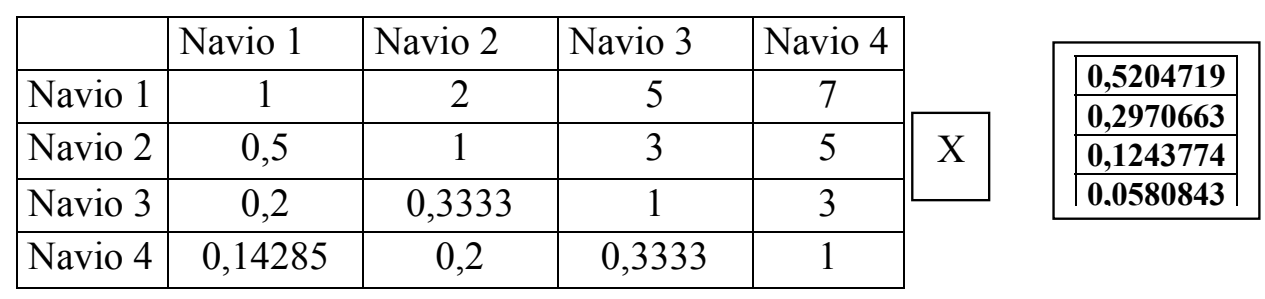

O resultado é:

\begin{tabular}{|r|}
\hline 2,143102 \\
\hline 1,220893 \\
\hline 0,501739 \\
\hline 0,233306 \\
\hline$\lambda \max .4,09904$ \\
\hline
\end{tabular}

Aplicando a fórmula empírica do desvio sendo $\lambda$ máximo $=4,09904$

$$
\mathrm{IC}=(4,09904-4) / 3=0,0330
$$

O que demonstra que a matriz de avaliação encontra-se dentro do parâmetro aceitável, neste caso não é necessário fazer nenhuma modificação, pois os pareceres são coerentes. 
DURABILIDADE

\begin{tabular}{|l|c|c|c|c|}
\hline & Navio 1 & Navio 2 & Navio 3 & Navio 4 \\
\hline Navio 1 & 1 & 6 & 7 & 9 \\
\hline Navio 2 & $1 / 6$ & 1 & 4 & 3 \\
\hline Navio 3 & $1 / 7$ & $1 / 4$ & 1 & 2 \\
\hline Navio 4 & $1 / 9$ & $1 / 3$ & $1 / 2$ & 1 \\
\hline
\end{tabular}

\begin{tabular}{|l|c|c|c|c|}
\hline & Navio 1 & Navio 2 & Navio 3 & Navio 4 \\
\hline Navio 1 & 1 & 6 & 7 & 9 \\
\hline Navio 2 & 0,16666667 & 1 & 4 & 3 \\
\hline Navio 3 & 0,14285714 & 0,25 & 1 & 2 \\
\hline Navio 4 & 0,11111111 & 0,33333333 & 0,5 & 1 \\
\hline Total & 1,420634921 & 7,833333333 & 10,5 & 15 \\
\hline
\end{tabular}

Normalizando as colunas.

\begin{tabular}{|l|r|r|r|r|c|}
\hline & \multicolumn{1}{|c|}{ Navio 1 } & Navio 2 & Navio 3 & Navio 4 & \multicolumn{1}{c|}{ Média } \\
\hline Navio 1 & 0,703911 & 0,765957 & 0,666667 & 0,6 & $\mathbf{0 , 6 8 4 1 3}$ \\
\hline Navio 2 & 0,117318 & 0,12766 & 0,190476 & 0,2 & $\mathbf{0 , 1 5 8 8 6}$ \\
\hline Navio 3 & 0,100559 & 0,06383 & 0,095238 & 0,133333 & $\mathbf{0 , 0 9 8 2 4}$ \\
\hline Navio 4 & 0,019553 & 0,042553 & 0,047619 & 0,066667 & $\mathbf{0 , 0 5 8 7 6}$ \\
\hline
\end{tabular}

Verificando o IC, desta matriz.

\begin{tabular}{|c|c|c|c|c|c|c|}
\hline & Navio 1 & Navio 2 & Navio 3 & Navio 4 & & Média \\
\hline Navio 1 & 1 & 6 & 7 & 9 & & 0,684134 \\
\hline Navio 2 & 0,16667 & 1 & 2 & 3 & \multirow{2}{*}{$X$} & 0,158864 \\
\hline Navio 3 & 0,14286 & 0,50 & 1 & 2 & & 0,09824 \\
\hline Navio 4 & 0,11111 & 0,33333 & 0 & 1 & & $\mathbf{0 , 0 5 8 7 6 3}$ \\
\hline Total & 1,42063 & 7,83333 & 10,5 & 15 & & \\
\hline
\end{tabular}

\begin{tabular}{|c|}
\hline 2,85386 \\
\hline 0,645654 \\
\hline 0,392931 \\
\hline 0,236852 \\
\hline$\lambda \max .4,129297$ \\
\hline
\end{tabular}


Aplicando a fórmula empírica do desvio sendo $\lambda$ máximo $=4,129297$

$$
\mathrm{IC}=(4,129297-4) / 3=0,04309
$$

Valor aceitável segundo Saaty.

\section{RECICLAGEM}

\begin{tabular}{|l|c|c|c|c|}
\hline & Navio 1 & Navio 2 & Navio 3 & Navio 4 \\
\hline Navio 1 & 1 & 5 & 7 & 9 \\
\hline Navio 2 & $1 / 5$ & 1 & 5 & 7 \\
\hline Navio 3 & $1 / 7$ & $1 / 5$ & 1 & 4 \\
\hline Navio 4 & $1 / 9$ & $1 / 7$ & $1 / 4$ & 1 \\
\hline
\end{tabular}

\begin{tabular}{|l|c|c|c|c|}
\hline & Navio 1 & Navio 2 & Navio 3 & Navio 4 \\
\hline Navio 1 & 1 & 5 & 7 & 9 \\
\hline Navio 2 & 0,2 & 1 & 5 & 7 \\
\hline Navio 3 & 0,14285714 & 0,2 & 1 & 4 \\
\hline Navio 4 & 0,11111111 & 0,14285714 & 0,25 & 1 \\
\hline Total & 1,453968254 & 6,342857143 & 13,25 & 21 \\
\hline
\end{tabular}

\begin{tabular}{|l|r|r|r|r|r|}
\hline & Navio 1 & \multicolumn{1}{|c|}{ Navio 2 } & Navio 3 & Navio 4 & \multicolumn{1}{c|}{ Média } \\
\hline Navio 1 & 0,68777 & 0,78829 & 0,52830 & 0,42857 & $\mathbf{0 , 6 0 8 2 3}$ \\
\hline Navio 2 & 0,13755 & 0,15766 & 0,37736 & 0,33333 & $\mathbf{0 , 2 5 1 4 8}$ \\
\hline Navio 3 & 0,09825 & 0,03153 & 0,07547 & 0,19048 & $\mathbf{0 , 0 9 8 9 3}$ \\
\hline Navio 4 & 0,07642 & 0,02252 & 0,01887 & 0,04762 & $\mathbf{0 , 0 4 1 3 6}$ \\
\hline
\end{tabular}

Verificando o IC, desta matriz.

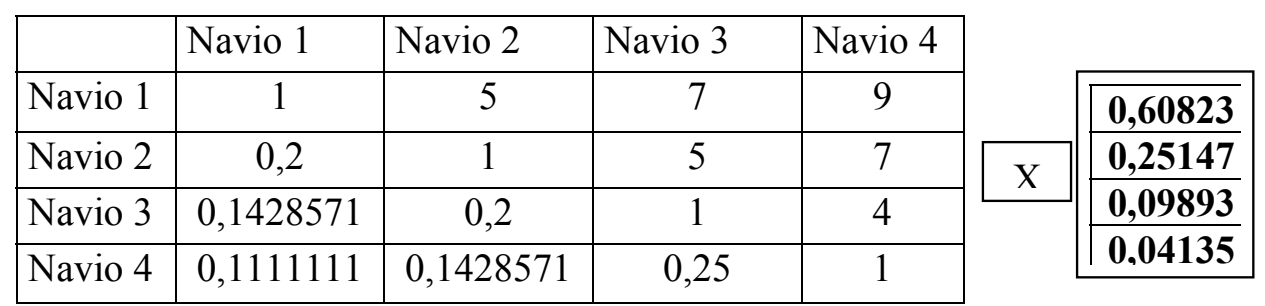

\begin{tabular}{|r|}
\hline 2,930359 \\
\hline 1,157288 \\
\hline 0,401547 \\
\hline 0,169597 \\
\hline$\lambda \max . \quad 4,658791$ \\
\hline
\end{tabular}


Aplicando a fórmula empírica do desvio sendo:

$$
\mathrm{IC}=(4,658791-4) / 3=0,219597
$$

Este resultado demonstra a falta de coerência nos julgamentos, para aproximá-los é necessário retornar à matriz origem do julgamento e fazer a mudança que resultará na interatividade e aproximação dos resultados.

\begin{tabular}{|c|c|c|c|c|}
\hline & Navio 1 & Navio 2 & Navio 3 & Navio 4 \\
\hline Navio 1 & 1 & 5 & 7 & 9 \\
\hline Navio 2 & 0,2 & 1 & 3 & 4 \\
\hline Navio 3 & 0,1428571 & 0,3333333 & 1 & 3 \\
\hline Navio 4 & 0,1111111 & 0,25 & $\begin{array}{c}0,3333333 \\
3\end{array}$ & 1 \\
\hline Total & 1,4539682 & 6,5833333 & 11,333333 & 17 \\
\hline
\end{tabular}

Foram mudados os valores da terceira e quarta coluna correspondentes à alternativa 2, e a quarta coluna correspondente à alternativa 3, obtendo-se a matriz das hierarquias:

\begin{tabular}{|r|}
\hline $\mathbf{0 , 6 4 8 5 8}$ \\
\hline $\mathbf{0 , 1 9 7 3 6 3}$ \\
\hline $\mathbf{0 , 1 0 3 3 9 8}$ \\
\hline $\mathbf{0 , 0 5 0 6 5 7}$ \\
\hline
\end{tabular}

Verificando o índice de coerência IC, multiplica-se a matriz origem com a matriz coluna, resultando a nova matriz:

\begin{tabular}{|r|}
\hline 2,8151 \\
\hline 0,839903 \\
\hline 0,413812 \\
\hline 0,206529 \\
\hline$\lambda$ máx 4,275344 \\
\hline
\end{tabular}

Aplicando a fórmula empírica do desvio sendo:

$$
\mathrm{IC}=(4,275344-4) / 3=0,091781
$$

Situando-se dentro dos valores coerentes. 
PRAZO DE ENTREGA

\begin{tabular}{|l|r|c|c|c|}
\hline & Navio 1 & Navio 2 & Navio 3 & Navio 4 \\
\hline Navio 1 & 1 & $1 / 3$ & $1 / 4$ & $1 / 5$ \\
\hline Navio 2 & 3 & 1 & $1 / 4$ & $1 / 3$ \\
\hline Navio 3 & 4 & 4 & 1 & $1 / 2$ \\
\hline Navio 4 & 5 & 3 & 2 & 1 \\
\hline
\end{tabular}

\begin{tabular}{|c|c|c|c|c|}
\hline & \begin{tabular}{|l|} 
Navio 1 \\
\end{tabular} & Navio 2 & Navio 3 & Navio 4 \\
\hline Navio 1 & 1 & 0,33333333 & 0,25 & 0,2 \\
\hline Navio 2 & 3 & 1 & 0,25 & 0,3333333 \\
\hline Navio 3 & 4 & 4 & 1 & 0,5 \\
\hline Navio 4 & 5 & 3 & 2 & 1 \\
\hline Total & 13 & 3,783333333 & 8,25 & 2,0333333 \\
\hline
\end{tabular}

\begin{tabular}{|l|r|r|r|r|r|}
\hline & \multicolumn{1}{|c|}{ Navio 1 } & Navio 2 & Navio 3 & Navio 4 & \multicolumn{1}{c|}{ Média } \\
\hline Navio 1 & 0,076923 & 0,088105 & 0,03030 & 0,09836 & $\mathbf{0 , 0 7 3 4 2}$ \\
\hline Navio 2 & 0,230769 & 0,066079 & 0,606060 & 0,16393 & $\mathbf{0 , 2 6 6 7 1}$ \\
\hline Navio 3 & 0,307692 & 0,052863 & 0,121212 & 0,24590 & $\mathbf{0 , 1 8 1 9 1}$ \\
\hline Navio 4 & 0,384615 & 0,792951 & 0,242424 & 0,49180 & $\mathbf{0 , 4 7 7 9 4}$ \\
\hline
\end{tabular}

Verificando o IC, desta matriz.

\begin{tabular}{|c|c|c|c|c|c|c|}
\hline & Navio 1 & Navio 2 & Navio 3 & Navio 4 & \multirow{5}{*}{$X$} & \\
\hline Navio 1 & 1 & 0,3333 & 0,25 & 0,2 & & 0,07342 \\
\hline Navio 2 & 3 & 1 & 0,25 & 0,33333 & & 0,26671 \\
\hline Navio 3 & 4 & 4 & 1 & 0,5 & & 0,18191 \\
\hline Navio 4 & 5 & 3 & 2 & 1 & & $\mathbf{0 , 4 7 7 9 4}$ \\
\hline Total & 13 & 3,7833 & 8,25 & 2,0333 & & \\
\hline
\end{tabular}

\begin{tabular}{|r|}
\hline 0.30338 \\
\hline 0.69177 \\
\hline 1.78142 \\
\hline 2.00903 \\
\hline$\lambda$ máx. 4.3156. \\
\hline
\end{tabular}

Aplicando a fórmula empírica do desvio sendo:

$$
\mathrm{IC}=(4,3156-4) / 3=0,1056
$$

Situando-se dentro dos valores coerentes. 
Aqui é montada a matriz final de decisão, sendo cada coluna um vetor de prioridade das Alternativas sob o ponto de vista de cada Critério utilizado.

No caso do Custo como critério, os valores de compra de cada navio podem ser considerados inversamente proporcionais na hierarquia já que para esta finalidade o de menor valor será a primeira opção o segundo menor valor como segunda opção e assim sucessivamente.

Custo do Navio

\begin{tabular}{|l|}
\hline Navio 1: US\$ 98milhões \\
\hline Navio 2: US\$ 85 milhões \\
\hline Navio 3: US\$ 77 milhões \\
\hline Navio 4; US\$ 66 milhões \\
\hline
\end{tabular}

Invertendo os valores, para obtenção dos critérios

\begin{tabular}{|c|}
\hline $1 / 98=0,01020$ \\
\hline $1 / 85=0,01176$ \\
\hline $1 / 77=0,01298$ \\
\hline $1 / 66=0,01515$ \\
\hline Total $: 0,5009$ \\
\hline
\end{tabular}

Normalizando os valores:

\begin{tabular}{|l|}
\hline $0,01020 / 0,05009=\mathbf{0 , 2 0 3 6}$ \\
\hline $0,01176 / 0,05009=\mathbf{0 , 2 3 4 8}$ \\
\hline $0,01298 / 0,05009=\mathbf{0 , 2 5 9 2}$ \\
\hline $0,01515 / 0,05009=\mathbf{0 , 3 0 2 4}$ \\
\hline
\end{tabular}

MATRIZ CONSOLIDADA DA HIERARQUIA DAS ALTERNATIVAS.

\begin{tabular}{|l|c|c|c|c|c|}
\hline & Custo & $\begin{array}{c}\text { Estado da } \\
\text { Estrutura }\end{array}$ & Durabilidade & Reciclagem & $\begin{array}{c}\text { Prazo de } \\
\text { Entrega }\end{array}$ \\
\hline Navio 1 & $\mathbf{0 , 2 0 3 6}$ & $\mathbf{0 , 5 2 0 4 7}$ & $\mathbf{0 , 6 8 4 1 3}$ & $\mathbf{0 , 6 0 8 2 3}$ & $\mathbf{0 , 0 7 3 4 2}$ \\
\hline Navio 2 & $\mathbf{0 , 2 3 4 8}$ & $\mathbf{0 , 2 9 7 0 6}$ & $\mathbf{0 , 1 5 8 8 6}$ & $\mathbf{0 , 2 5 1 4 7}$ & $\mathbf{0 , 2 6 6 7 1}$ \\
\hline Navio 3 & $\mathbf{0 , 2 5 9 2}$ & $\mathbf{0 , 1 2 4 3 7}$ & $\mathbf{0 , 0 9 8 2 3}$ & $\mathbf{0 , 0 9 8 9 3}$ & $\mathbf{0 , 1 8 1 9 1}$ \\
\hline Navio 4 & $\mathbf{0 , 3 0 2 4}$ & $\mathbf{0 , 0 5 8 0 8}$ & $\mathbf{0 , 0 4 4 0 9}$ & $\mathbf{0 , 0 4 1 3 5}$ & $\mathbf{0 , 4 7 7 9 4}$ \\
\hline
\end{tabular}


Finalmente se estabelece um resultado multiplicando a matriz das Alternativas (que externará a prioridade dos navios com relação a cada critério empregado), com a matriz que indica as prioridades dos Critérios obtido da matriz "I".

\begin{tabular}{|l|c|c|c|c|c|}
\hline & CUSTO & $\begin{array}{c}\text { ESTADO DA } \\
\text { ESTRUTURA }\end{array}$ & DURABILIDADE & RECICLAGEM & $\begin{array}{c}\text { PRAZO DE } \\
\text { ENTREGA }\end{array}$ \\
\hline Navio 1 & $\mathbf{0 , 2 0 3 6}$ & $\mathbf{0 , 5 2 0 4 7}$ & $\mathbf{0 , 6 8 4 1 3}$ & $\mathbf{0 , 6 0 8 2 3}$ & $\mathbf{0 , 0 7 3 4 2}$ \\
\hline Navio 2 & $\mathbf{0 , 2 3 4 8}$ & $\mathbf{0 , 2 9 7 0 6}$ & $\mathbf{0 , 1 5 8 8 6}$ & $\mathbf{0 , 2 5 1 4 7}$ & $\mathbf{0 , 2 6 6 7 1}$ \\
\hline Navio 3 & $\mathbf{0 , 2 5 9 2}$ & $\mathbf{0 , 1 2 4 3 7}$ & $\mathbf{0 , 0 9 8 2 3}$ & $\mathbf{0 , 0 9 8 9 3}$ & $\mathbf{0 , 1 8 1 9 1}$ \\
\hline Navio 4 & $\mathbf{0 , 3 0 2 4}$ & $\mathbf{0 , 0 5 8 0 8}$ & $\mathbf{0 , 0 4 4 0 9}$ & $\mathbf{0 , 0 4 1 3 5}$ & $\mathbf{0 , 4 7 7 9 4}$ \\
\hline
\end{tabular}

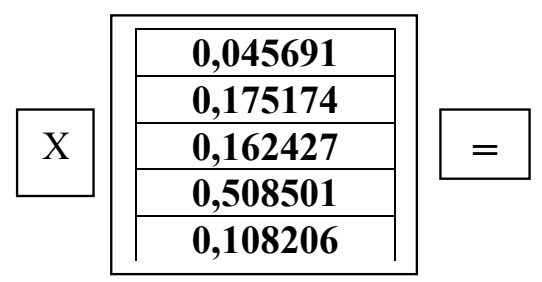

\begin{tabular}{|l|c|}
\hline \multicolumn{2}{|c|}{ Consolidação } \\
\hline Navio 1 Primeira opção & $\mathbf{0 , 5 2 8 8 3 \%}$ \\
\hline Navio 2 Segunda opção & $\mathbf{0 , 2 4 5 3 0 6 \%}$ \\
\hline Navio 3 Terceira opção & $\mathbf{0 , 1 2 1 5 5 4 \%}$ \\
\hline Navio 4 Quarta opção & $\mathbf{0 , 1 0 1 9 2 8 \%}$ \\
\hline
\end{tabular}




\section{Apresentação dos resultados}

Os resultados da primeira etapa do problema foram:

Valores obtidos pela árvore de decisão com tempo de produção de 15 anos:

$\mathrm{O}$ valor esperado da alternativa $1: \mathrm{VEA}_{1}=778,378 \mathrm{Mbp}$

$\mathrm{O}$ valor esperado da alternativa $2: \mathrm{VEA}_{2}=883,872 \mathrm{Mbp}$

$\mathrm{O}$ valor esperado da alternativa $3: \mathrm{VEA}_{3}=(65,448) \mathrm{Mbp}$ (valor negativo)

Verificando a sensibilidade do processo foram calculados os resultados mudando o dado de vida útil do campo no problema e permanecendo iguais os dados restantes.

Valores obtidos pela árvore de decisão com tempo de produção de 14 anos:

O valor esperado da alternativa $1: \mathrm{VEA}_{1}=708,912 \mathrm{Mbp}$

$\mathrm{O}$ valor esperado da alternativa $2: \mathrm{VEA}_{2}=806,76 \mathrm{Mbp}$

$\mathrm{O}$ valor esperado da alternativa $3: \mathrm{VEA}_{3}=0 \mathrm{Mbp}$ (valor nulo)

Valores obtidos pela árvore de decisão com tempo de produção de 17 anos:

$\mathrm{O}$ valor esperado da alternativa $1: \mathrm{VEA}_{1}=902,2 \mathrm{Mbp}$

O valor esperado da alternativa $2: \mathrm{VEA}_{2}=744,28 \mathrm{Mbp}$

O valor esperado da alternativa $3: \operatorname{VEA}_{3}=(196,696) \mathrm{Mbp}$ (valor negativo)

Valores obtidos pela árvore de decisão com tempo de produção de 20 anos:

$\mathrm{O}$ valor esperado da alternativa $1: \mathrm{VEA}_{1}=1102,52 \mathrm{Mbp}$

$\mathrm{O}$ valor esperado da alternativa $2: \mathrm{VEA}_{2}=883,872 \mathrm{Mbp}$

$\mathrm{O}$ valor esperado da alternativa $3: \mathrm{VEA}_{3}=(65,448) \mathrm{Mbp}$ (valor negativo) 
Os resultados da segunda etapa do problema foram:

Valores obtidos pela árvore de decisão considerando a utilidade e o investimento em cada alternativa, com perfil de extração de petróleo em instalações semelhantes:

Retorno do investimento da Alternativa 1: 226.991,2 milhões de US\$ Retorno do investimento da Alternativa 2: 286.991,2 milhões de US\$ Retorno do investimento da Alternativa 3: 216.991,2 milhões de US\$

Os resultados da terceira e última etapa do problema foram:

\begin{tabular}{|l|c|}
\hline \multicolumn{2}{|c|}{ Hierarquia das opções de solução do problema } \\
\hline Navio 1 Primeira opção & $\mathbf{0 , 5 2 8 8 3 \%}$ \\
\hline Navio 2 Segunda opção & $\mathbf{0 , 2 4 5 3 0 6 \%}$ \\
\hline Navio 3 Terceira opção & $\mathbf{0 , 1 2 1 5 5 4 \%}$ \\
\hline Navio 4 Quarta opção & $\mathbf{0 , 1 0 1 9 2 8 \%}$ \\
\hline
\end{tabular}




\section{Análise dos resultados}

$\mathrm{Na}$ primeira parte do problema foi definido como objetivo a ser atingido o prazo de entrada em funcionamento do FPSO, na segunda parte do problema foi definido qual navio seria o ideal para poder satisfazer essa exigência e a da capacidade instalada e vida útil, na terceira parte escolhemos o petroleiro mais indicado para poder ser reaproveitado seu casco.

Na primeira parte da aplicação do método da árvore de decisão os resultados indicaram que a embarcação com máximo valor esperado é aquele com a vida útil próxima ou igual à da jazida, sendo que a instalação feita especialmente para este fim tem dois elementos contrários a sua escolha, o prazo de entrega e a vida útil remanescente, que deve pesar direta ou indiretamente no custo.

O experimento da sensibilidade mostrou que passado o valor limite de 15 anos (coincidente com a vida útil da instalação construída com o navio tanque reaproveitado), quanto mais aumenta o prazo da vida útil do campo, a opção da instalação totalmente nova seria cada vez a mais indicada e quanto menos anos de vida útil tivesse o campo a opção da segunda alternativa é a mais indicada.

$\mathrm{Na}$ segunda parte do problema onde são considerados os retornos e os investimentos, foi tomado como elemento de comparação o valor esperado de cada alternativa, descontado respectivamente dos investimentos necessários a fazer para que cada uma das opções pudesse ser construída e funcionasse, assim para a alternativa de construção totalmente nova somente foi considerado o investimento total, enquanto que para as outras duas, com reaproveitamento de navios existentes, teve de ser somada a quantia necessária para deixar estas operacionais.

Observa-se que utilizando critérios de avaliação como o estado de conservação da estrutura de cada navio, se coloca parte do peso da decisão na sensibilidade do profissional que terá que fazer o julgamento.

Assim sendo caberá a este a imparcialidade do juízo, sendo que a ferramenta utilizada possui um índice que permite o controle do processo.

É importante a prática repetitiva do uso desta ferramenta para que os pareceres do profissional se tornem cada vez mais próximos aos valores coerentes. 
A opção de escolha foi definida pela hierarquia obtida a partir de análises feitas de valores determinísticos e de valores subjetivos obtidos dos pareceres, todos incorporados na matriz de decisão, outros critérios e outros navios podem ser avaliados na hora da decisão, modificando a preferência.

Este método permite definir o navio que será o mais apropriado para a utilização dentro dos critérios estabelecidos, atingindo assim o objetivo.

O navio 1 é a alternativa que apresenta maior hierarquia, seguido pelo navio2, ou navio3 e por último o navio 4.

Esta hierarquia indica que o mais coerente seria optar de pelo primeiro, embora todos preencham os requisitos do projeto original. 


\section{Conclusões e recomendações.}

$\mathrm{Na}$ hora da escolha é importante definir o número de possibilidades de critérios e de elementos concorrentes para a escolha, sem perder de vista o objetivo e os critérios adotados, avaliando por este método qual é a importância relativa de cada um.

É determinante poder definir inicialmente a importância que terá para o projeto o custo do mesmo e o prazo de execução, que são elementos econômicos que devem ser considerados.

No momento da aplicação das metodologias se deve ter a possibilidade de definir perfeitamente os objetivos.

A metodologia empregada permite o aperfeiçoamento do profissional com referência à avaliação que ele faz em cada estagio da última seleção, e corrigindo esta decisão fazendo que seja a escolha definitiva, do contrário poderia recair numa das outras alternativas.

Recomenda-se a utilização da metodologia fazendo que os projetistas se familiarizem com esta aperfeiçoando sua sensibilidade natural.

Em algumas oportunidades após o processo de auxílio à decisão ser implementado, ocorrem variações nas condições expostas e assim como é possível que surjam outros navios como alternativa, aquele que obteve a melhor hierarquia fica impossibilitado de ser adquirido ou disponibilizado para o projeto em questão, cabe então aos projetistas e armadores a decisão de executar novamente o processo. 


\section{BIBLIOGRAFIA.}

ARNOLD Marcelo, PhD. OSORIO Francisco M.A. Introducción a los Conceptos Básicos de la Teoría General de Sistemas, Cinta de Moebio N 3, abril 1998 Univ. Chile.

BEKMAN, Otto R. e COSTA NETO, Pedro L. de Oliveira, Análise estatística da decisão. Editora Edgard Blücher Ltda. 1980

CLEMEN, R.T. Making hard decisions. Duxbury, Press-Wadsworth.1991

DREWRY SHIPPING CONSULTANTS THE SHIPBUILDING MARKET - 19952010 FORMAN Ernest. DSc., SELLY Mary Ann, Decision By Objectives

FONSECA, Maurílio Magalhães Arte Naval. 5a. edição Serviço de Documentação Geral da Marinha - Rio de Janeiro 1989

HYMAN Barry, Fundamentals of Engineering Design.1998 Prentice-Hall Inc.

KEENEY,R.L.; RAIFFA, H. Decision with multiple objectives: preferences and value trade-offs, Wiley \& Sons 1976.

LEITE André J.P.; COOPETRÓLEO 2000 .Sistemas para produção de óleo e gás no mar e análise econômica de projetos.

MORITA Hideyuki, Revisão do Método de Análise Hierárquica - MAH (AHPAnalytic Hierarchy Process). Dissertação de Mestrado Engenharia, EPUSP, São Paulo 1998.

MOREIRA Daniel Augusto, Administração da Produção e Operações, 5.ed. Editora Pioneira São Paulo(2000) 
UKOOA FPSO DESIGN GUIDANCE NOTES FOR UKCS SERVICE, March 2002

PÖYHÖNEN Mari \& HÄMÄLÄINEN Raimo P., On the convergence of multiatribute weighting methods. 1997

RAIFFA, Howard, Teoria da Decisão, aulas introdutórias sobre escolhas em condições de incerteza.(Tradução de S. Girão) Editora Vozas. EDUSP. 1977

ROY B.,The outranking approach and the Foundation of ELECTRE Methods, Theory and Decision, 31 (1991), pp 49-73.

RIVA, Joaquim C.T., PNV-552 Projeto de navio I, apostila

SAATY, Thomas Lorie, The Analytic Hierarchy Process -planning priority setting, resource allocation. 1980 New York, Mc Graw Hill

SAATY, Thomas Lorie, Fundamentals of the Analytic Network Process. (ISHAP 1999, Kobe, Japan).

SAATY, Thomas Lorie, The Seven Pillars of the Analytic Hierarchy Process. ISAHP Proceedings. Kobe 1999

VINCKE, Philippe. Multicritéria Decision-Aid, Ec. Jhon Wiley \&Sons, 1992

Sites da internet consultados:

University of Pittsburg saaty@,katz.pitt.edu

Glosario Multicriterio, (Internet) http://unesco.org.uy.

http://212.78.70.142/index.cfm?PageID $=540$

http://www.europeanshippers.com/ 